\title{
Assessing National Employment Impacts of Investment in Residential and Commercial Sector Energy Efficiency: Review and Example Analysis
}

DM Anderson

OV Livingston
DB Belzer

MJ Scott

June 2014

Pacific Northwest NATIONAL LABORATORY

Proudly Operated by Battelle Since 1965 


\title{
DISCLAIMER
}

This report was prepared as an account of work sponsored by an agency of the United States Government. Neither the United States Government nor any agency thereof, nor Battelle Memorial Institute, nor any of their employees, makes any warranty, express or implied, or assumes any legal liability or responsibility for the accuracy, completeness, or usefulness of any information, apparatus, product, or process disclosed, or represents that its use would not infringe privately owned rights. Reference herein to any specific commercial product, process, or service by trade name, trademark, manufacturer, or otherwise does not necessarily constitute or imply its endorsement, recommendation, or favoring by the United States Government or any agency thereof, or Battelle Memorial Institute. The views and opinions of authors expressed herein do not necessarily state or reflect those of the United States Government or any agency thereof.

\author{
PACIFIC NORTHWEST NATIONAL LABORATORY \\ operated by \\ BATTELLE \\ for the \\ UNITED STATES DEPARTMENT OF ENERGY \\ under Contract DE-AC05-76RL01830
}

Printed in the United States of America
Available to DOE and DOE contractors from the Office of Scientific and Technical Information,
P.O. Box 62, Oak Ridge, TN 37831-0062;
ph: (865) 576-8401
fax: $(865)$ 576-5728
email: reports@adonis.osti.gov

\begin{abstract}
Available to the public from the National Technical Information Service, U.S. Department of Commerce, 5285 Port Royal Rd., Springfield, VA 22161 ph: (800) 553-6847 fax: $(703) 605-6900$ email: orders@ntis.fedworld.gov online ordering: http://www.ntis.gov/ordering.htm
\end{abstract}

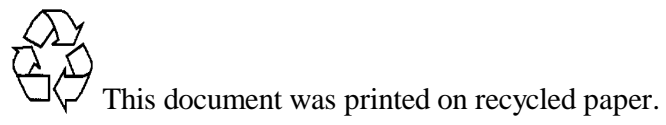




\title{
Assessing National Employment Impacts of Investment in Residential and Commercial Sector Energy Efficiency: Review and Example Analysis
}

\author{
DM Anderson \\ DB Belzer \\ OV Livingston \\ MJ Scott
}

June 2014

Prepared for

the U.S. Department of Energy

under Department of Energy Contract DE-AC05-76RL01830

with Battelle Memorial Institute

Pacific Northwest National Laboratory

Richland, Washington 99352 


\section{Executive Summary}

Energy efficiency is a key solution to concerns regarding future energy supply, energy security, and the harmful long-term effects of climate change. In addition to addressing these issues, actions motivated by governmental policies and programs, along with efforts by utilities and third parties, result in greater energy efficiency and also save consumers money. A continuing question is the degree to which energy efficiency measures spur economic growth and higher levels of employment. Research interest in this topic has recently risen in response to trends reflecting increased market adoption of energy efficiency measures, increased reliance on energy efficiency as a resource to offset new electricity generation, and the utilization of energy efficiency portfolio standards by states to spur wider adoption of energy efficiency and reduce future electricity demand.

One element of this research interest concerns the extent of employment supporting what is termed the "clean energy economy." Firms and workers that are supported by actions to improve energy efficiency are an important segment of this clean energy economy. It includes those occupations or portions of occupations that directly participate in the manufacturing, marketing, retailing, installation, and maintenance of technologies and practices that maintain or improve the quality of life, while saving energy in the process. Based on a detailed analysis of the 2007 Economic Census, the Department of Commerce in 2010 estimated that between 1.8 and 2.4 million jobs could be classified as "green jobs." A 2011 estimate by the Brookings Institution puts the number of jobs at nearly 2.7 million. The Brookings study estimates that over 450,000 of these jobs are related to building sector energy efficiency. Other segments of green jobs include environmental management, public mass transit, and renewable energy development.

In an effort to estimate national residential and commercial efficiency employment impacts, the current study presents three main results. The first is a summary of estimates of long-run, economy-wide job creation due to energy efficiency freeing up money that would otherwise have been spent on energy. The second is a summary of estimates of immediate, sector-specific job creation due to investments in energy efficiency. These results are most comparable to the typical results presented as the impacts of any targeted investment. The third is an original analysis of the employment impacts of both a 10 and 15 percent reduction in overall electricity consumption by 2030 , due to voluntary programs offered by electric utilities.

The study focuses principally on the economic effects arising from increased levels of energy efficiency in the buildings sector (both residential and commercial). The example analysis pertains solely to measures and practices that would affect the buildings sector, and does not include activities affecting the industrial or transportation sectors. Hence, the efficiency job estimates presented here are likely a lower bound on the true, economy-wide impacts of broad energy efficiency policies.

First, based on a detailed examination of literature related to the economic impacts of energy efficiency, energy efficiency results in positive economic impacts including overall levels of employment. Greater energy efficiency means households and businesses are able to maintain or increase the levels of service (e.g., comfortable indoor temperatures, illumination, and hot water) from their buildings or equipment while consuming less energy. Over the lifetime of energy efficiency measures, the money saved on energy becomes available to be spent on other goods and services. Typically, the number of jobs required to produce these other goods and services are greater per dollar of output than the number of 
jobs needed to produce the same dollar's worth of energy. Based on the results of a number of studies, spending money made available by reducing energy expenditures for these alternative goods and services generates a net gain of about 8 jobs per million dollars of consumer bill savings.

Second, and distinct from the effects of bill savings, the literature review shows that initial investments in energy efficiency generate about 11 jobs per million dollars of investment. These activities include the purchasing and installing of measures for retrofit or for new construction and also jobs in other sectors "induced" by this economic activity. This impact occurs in years when these investments occur. Results using this approach are comparable to typical industry-specific estimates of the job creation from spending targeted at specific sectors. A detailed examination of these initial investments over time is included in the body of the report.

These summary multiplier values result from this study's attempt to develop a general guidance estimate for national employment impacts of increased energy efficiency in the residential and commercial sectors. The study examined recent literature in detail. Other sectors such as industrial and transportation were excluded to keep the scope manageable, but efforts in those sectors also would save energy and affect employment. Studies undertaken by a variety of organizations were screened to determine if they included a transparent description of how energy efficiency can affect overall levels of employment. The primary objective was to elicit values of employment multipliers or ratios reflecting the number of additional jobs created per million dollars of energy efficiency investment or million dollars of energy savings. From those studies from which a multiplier could be derived, the authors applied professional judgment to assign a point estimate of the multiplier for use as a general guidance estimate (e.g., the value of 8 jobs per million dollars of energy savings mentioned above).

Third, the study includes an original example analysis. PNNL modeled the 2030 employment impacts of a national initiative to accelerate residential and commercial energy efficiency trends under both 15 percent and 10 percent electricity savings cases. In the 15 percent case, efficiency activities save about 15 percent of AEO Reference Case commercial and residential electricity consumption by 2030. It is assumed that the additional energy savings in both the residential and commercial sectors due to the scenario begin in 2015 at zero, then increase in an S-shaped market penetration curve, with the level of savings equaling about 7.0 percent of the AEO 2014 U.S. national residential and commercial electricity consumption saved by $2020,14.8$ percent by 2025 and 15 percent by 2030 . In the 10 percent case, the additional savings due to the scenario begin at zero in 2015, increase to 3.8 percent in 2020,9.8 percent by 2025 and, 10 percent of the AEO reference case value by 2030 .

The analysis of the 15 percent case indicates that by 2030 nearly 320,000 new jobs likely would result from energy efficiency. To achieve this level of new jobs in 2030 would require an annual average of more than 60,000 jobs in prior years directly supporting the manufacturing, installation, and maintenance of energy efficiency measures and practices. These are new energy efficiency jobs resulting initially from the investment associated with the construction of more energy-efficient new buildings or the retrofit of existing buildings and would be sustained for as long as the investment continues. Based on what is known about the current level of building-sector energy efficiency jobs, this would represent an increase of more than 13 percent from the current estimated level of over 450,000 such jobs. The more significant and longer-lasting effect comes from redirecting energy bill savings to the purchase of other goods and services in the general economy, with its attendant influence on increasing the total number of jobs. This example analysis utilized PNNL's ImSET model, a modeling framework that PNNL has used over the 
past two decades to assess the economic impacts of DOE's energy efficiency programs in the buildings sector. 


\section{Acknowledgements}

The authors are grateful to a committee of peer reviewers from a range of organizations for their contribution of helpful comments and insights. Several of the cited authors took time to answer clarifying questions about their published work, helping us characterize their findings accurately, and we thank them, as well. These comments and suggestions have improved the report with added clarity and specificity, and the authors take responsibility for any remaining issues or factual errors. Finally, we acknowledge DOE Office of Energy Policy and Systems Analysis and the DOE Office of Energy

Efficiency and Renewable Energy for sponsoring this work, and are grateful for the guidance of Carla Frisch and James Nachbaur in helping structure the report. 


\section{Acronyms and Abbreviations}

AEO

ARRA

Btu

DOE

EISA

EPA

HVAC

I-O

IMPLAN

ImSET

$\mathrm{LCC}$

$\mathrm{OMB}$

OPM

PNNL
Annual Energy Outlook

American Recovery and Reinvestment Act

British thermal units

Department of Energy

Energy Independence and Security Act

Environmental Protection Agency

heating, ventilating and air conditioning

input-output

IMpact analysis for PLANning Model

Impact of Sector Energy Technologies Model

life-cycle cost

Office of Management and Budget

Office of Personnel Management

Pacific Northwest National Laboratory 


\section{Contents}

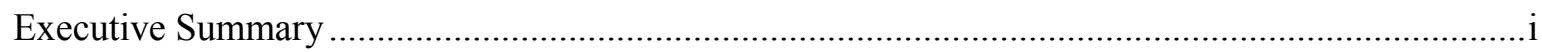

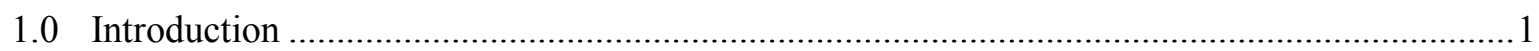

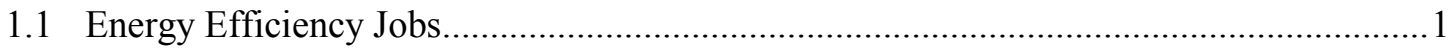

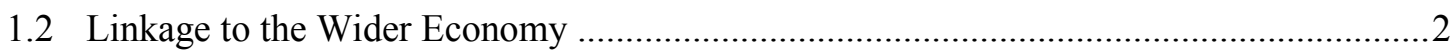

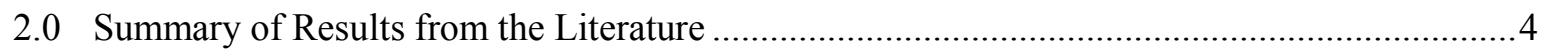

2.1 Net vs. Gross Impacts from Efficiency Investment …...............................................

2.2 Past Studies of Energy Efficiency Policies - General Observations..................................5

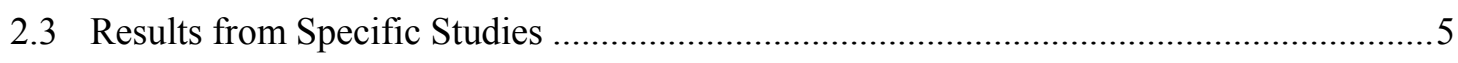

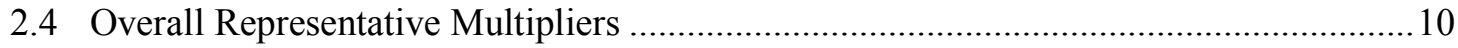

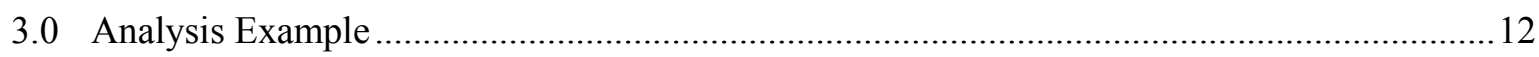

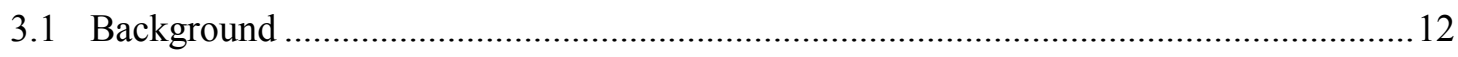

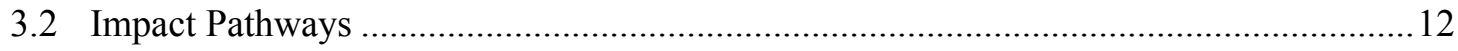

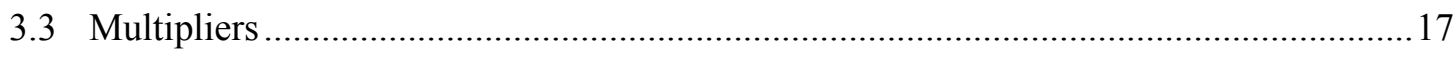

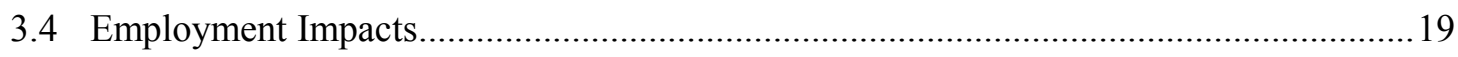

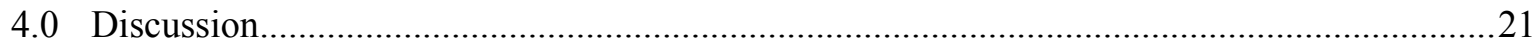

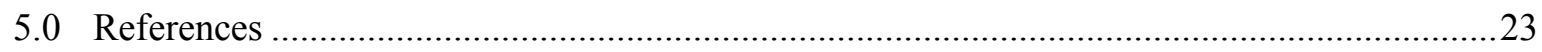

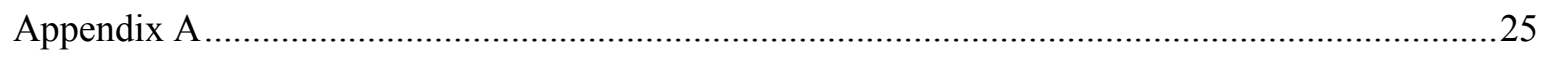

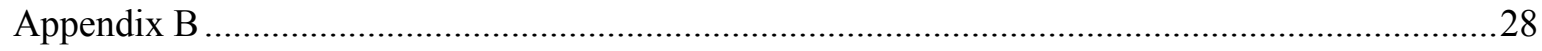

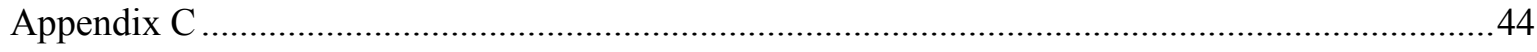




\section{Tables}

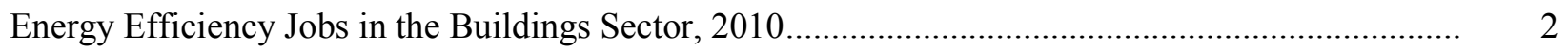

Tracing Energy Efficiency Employment Impacts......................................................................... 3

Summary of Employment Impact Multipliers from Key Studies ................................................

Representative Employment Multipliers for Building Energy Efficiency Initiatives (Jobs per Million 2011 \$ of Annual Consumer Bill savings).................................................................. 10

AEO Reference Case Residential and Commercial Electricity Consumption (delivered Energy)

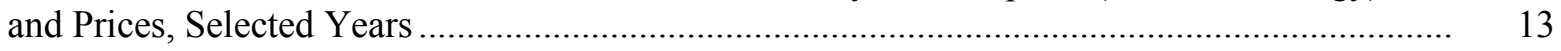

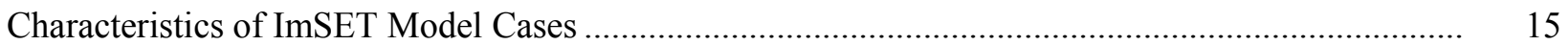

Economic Sectors Assumed to Receive Energy Efficiency Investments. ........................................ 17

Assumed Sources of Funds Invested in Building Energy Efficiency .............................................. 17

Summary ImSET Jobs Multiplier Statistics for the Period 2015-2030 in this Study ........................ 18

U.S. National Employment Impact of Residential and Commercial Building Energy Efficiency Programs, 50 percent Utility Financing Incorporated into Energy Bills, Under Various Market Conditions, Selected Years (Thousands of Net Jobs) 


\subsection{Introduction}

This report synthesizes the literature on prevailing approaches to the assessment of national employment effects resulting from investment in energy efficiency measures and practices in the residential and commercial sectors. Energy efficiency measures and practices refer to actions taken to improve the energy performance of a building, such as retrofitting less efficient equipment, installing better insulation, and improving maintenance practices, among many additional options. This research focuses on recent relevant studies that have examined the employment effects that would occur given higher levels of expenditure on energy efficiency measures. It offers a quantitative example analysis illustrating how employment impacts can be estimated using an approach that balances technical rigor with analytical effort. Finally, it offers discussion of relevant and important considerations that must be factored into the interpretation of job impact studies. While there are numerous approaches chronicled in the literature, in order to keep the scope manageable, only the most frequently used approach is examined in detail.

The focus is only on building-sector energy efficiency, such as measures and practices directed to residential and commercial customers of electric utilities. Additional literature covering transportation energy efficiency or industrial energy efficiency is not considered within the limited scope of this study. As a result, the findings discuss only covered measures and practices aimed at buildings, and therefore, are understated in the context of all potential economic impacts from energy efficiency activities.

\subsection{Energy Efficiency Jobs}

Energy efficiency jobs include occupations or portions of occupations that directly participate in the manufacturing, marketing, retailing, installation, and maintenance of technologies and practices that maintain or improve the quality of life while saving energy in the process. No standardized employment accounting has been adopted by government statistical agencies that provides annual estimates of jobs by industry sector classified as energy efficiency jobs or clean energy jobs.

Two notable recent attempts to classify occupations estimated to be green jobs suggest that between 1.8 and 2.7 million jobs could be considered "green." A 2010 analysis by the Economic and Statistics Administration (Commerce Department 2010) utilized the 2007 economic census to estimate the extent of employment linked to "green" industry. It suggests a range between 1.8 million and 2.4 million jobs, equivalent to 1.5 to 2.0 percent of total private sector employment in 2007. Muro et al. (2011) utilize a bottom-up approach to segment employment by "clean-energy" component. They estimate nearly 2.7 million jobs in 2010 could be attributed to "clean" energy industries.

Both studies point out the challenges of segmenting aggregate industry employment statistics into subsectors or entirely new industries or occupations attributable to energy efficiency. However, they establish a reference point from which comparisons can be made. For example, Muro et al. (2011) derive classifications for sub-industries that primarily focus on buildings sector energy efficiency, which amount to over 450,000 jobs in 2010 . Table 1.1 presents the industries likely to be directly affected by energy efficiency policies and programs in the buildings sector. 
Table 1.1. Energy Efficiency Jobs in the Buildings Sector, 2010

\begin{tabular}{|c|c|c|c|c|}
\hline Industry Segment & $\begin{array}{c}\text { Employment } \\
2010 \\
\text { (Jobs) }\end{array}$ & $\begin{array}{l}\text { Share of Jobs } \\
\text { Held By } \\
\text { Workers with } \\
\text { at Least a } \\
\text { High School } \\
\text { Diploma } \\
2010(\%)\end{array}$ & $\begin{array}{c}\text { Share of Jobs } \\
\text { that are Green } \\
\text { Collar } \\
2010(\%)\end{array}$ & $\begin{array}{c}\text { Average } \\
\text { Annual } \\
\text { Income } \\
2009\end{array}$ \\
\hline Appliances & 36,608 & 54.0 & 77.8 & $\$ 37,980$ \\
\hline Battery Technologies & 16,129 & 44.9 & 64.0 & $\$ 43,011$ \\
\hline Energy-saving Building Materials & 161,896 & 58.7 & 81.6 & $\$ 36,786$ \\
\hline Energy-saving Consumer Products & 19,210 & 49.2 & 71.4 & $\$ 40,725$ \\
\hline Green Architecture and Construction Services & 56,190 & 26.0 & 32.9 & $\$ 56,487$ \\
\hline HVAC and Building Control Systems & 73,600 & 45.0 & 65.2 & $\$ 42,806$ \\
\hline Lighting & 14,298 & 49.6 & 71.4 & $\$ 39,469$ \\
\hline Professional Energy Services & 49,863 & 20.5 & 26.2 & $\$ 56,063$ \\
\hline Smart Grid & 15,987 & 33.4 & 48.2 & $\$ 48,758$ \\
\hline Water Efficient Products & 13,066 & 50.2 & 72.9 & $\$ 39,479$ \\
\hline Total & 456,847 & 45.6 & 63.8 & $\$ 43,344$ \\
\hline
\end{tabular}

\subsection{Linkage to the Wider Economy}

Economic linkages bind the industries of the economy together. Any given industry has upstream suppliers of goods and services used in the production of output and has downstream customers for the output to be used as inputs to other industries or as final goods and services. These linkages can be understood and simulated using modeling approaches discussed in more detail in the next section.

This is best illustrated in the energy efficiency context by a simple example. In the case of the homeowner desiring to lower energy bills by installing LED lamps in place of incandescent lamps, he/she buys the lamps from a retailer. That retailer bought the lamps from a wholesaler or the manufacturer directly. The manufacturer purchased the products needed to mass produce the lamps, including labor, parts, machinery, tools, etc. Each of these inputs to the lamp production also must purchase production inputs until we can trace production back to the initial raw material extraction activities such as mineral mining and the production of electricity and natural gas.

Modeling individual economic activities engages this linked structure such that the specific effects of any economic activity can be traced and estimated. Table 1.2 illustrates this for employment in the context of energy efficiency investments. Whether funded by government (e.g., by taxes), by utilities (e.g., by ratepayers) or by third parties, investing in energy efficiency has direct, indirect, and induced effects in the economy. Direct employment effects result from the immediate expenditures for installing or retrofitting measures or practices, such as the labor needed for purchasing more efficient appliances, making incremental efforts to upgrade a building to higher energy code levels, installing higher efficiency windows or lighting, etc. Indirect employment effects result from the engagement of the supply chain for these various products and services as they employ labor to replenish inventories or provide support 
services for the directly supplying industries. Induced employment effects are the jobs supported by the spending of income generated from the direct and indirect activities that deliver the initial energy efficiency investments.

For energy efficiency investments, employment impacts happen in three ways. The initial investment is used to purchase goods and services to implement measures and practices as described above and shown in the first row of Table 1.2. As energy efficiency investments are made, consumers and businesses save energy, and expenditures on energy are reduced. These impacts persist in the economy for as long as the efficiency measures continue to save money spent on energy. These saved expenditures, commonly termed bill savings, are redirected to purchases previously not made by consumers and businesses, in lieu of their expenses on energy (second row of the table). The third row of the table describes the effects attendant to the financing of the investment, either in the period in which the investment is made or over a longer timeframe. The diversion of funds that would have been spent elsewhere in the economy may lead to offsetting changes in employment in the general economy.

Table 1.2. Tracing Energy Efficiency Employment Impacts

\begin{tabular}{l|l|l|l}
\hline Economic Effect & \multicolumn{1}{c|}{ Direct } & \multicolumn{1}{c}{ Indirect } & \multicolumn{1}{c}{ Induced } \\
\hline $\begin{array}{l}\text { Initial Investment in } \\
\text { Energy Efficiency }\end{array}$ & $\begin{array}{l}\text { "Energy Efficiency" jobs added } \\
\text { as efficiency measures are } \\
\text { implemented }\end{array}$ & $\begin{array}{l}\text { Supply chain jobs } \\
\text { added to support the } \\
\text { investment }\end{array}$ & $\begin{array}{l}\text { New jobs added as a } \\
\text { result of spending from } \\
\text { new incomes }\end{array}$ \\
\hline $\begin{array}{l}\text { Redirection of bill } \\
\text { savings }\end{array}$ & $\begin{array}{l}\text { Jobs added in the general } \\
\text { economy from the spending of } \\
\text { energy bill savings }\end{array}$ & $\begin{array}{l}\text { Supply chain jobs } \\
\text { added }\end{array}$ & $\begin{array}{l}\text { New jobs added as a } \\
\text { result of spending from } \\
\text { direct and indirect } \\
\text { impacts }\end{array}$ \\
\hline $\begin{array}{l}\text { Financing the initial } \\
\text { and continued } \\
\text { investment }\end{array}$ & $\begin{array}{l}\text { Jobs offset in the general } \\
\text { economy }\end{array}$ & Supply chain jobs offset & $\begin{array}{l}\text { Jobs offset by the } \\
\text { offsetting income impacts }\end{array}$ \\
\hline
\end{tabular}

The sections that follow provide extensive review of the literature covering these effects and the predominant modeling approach used to estimate employment impacts from energy efficiency. An example analysis is also provided in Section 3 to illustrate the application of an established methodology for estimating employment impacts in this context. 


\subsection{Summary of Results from the Literature}

This study undertook an extensive review of the recent literature related to the economic and employment impacts of energy efficiency policies and programs. The review covered both national and regional (including state and local) studies, with emphasis on national studies published in the past decade.

This section examines national studies and the extent to which those studies employ methods that yield multipliers that can be used to estimate employment impacts of efficiency investments primarily in the buildings sector. Almost exclusively, these methods rely on input-output (I-O) models and data to consider the differential impacts across industry sectors that such policies are likely to produce.

While the I-O methodology is widely used to perform employment impact studies, it is not the only accepted approach. Appendix A briefly introduces a range of alternative approaches to estimating employment impacts. Practitioners of the I-O approach recognize, as with any modeling approach, assumptions are required to facilitate the approach. The economic assumptions of the I-O methodology are well known and extensively documented in the literature and briefly discussed in Appendix A, along with the alternative methodologies available. The I-O methodology is the most widely reported for economic impact studies because of its low cost, flexibility, and transparency in approach, despite its implied economic assumptions.

\subsection{Net vs. Gross Impacts from Efficiency Investment}

A number of recent reports have emphasized the distinction between net and gross jobs associated with efficiency investment (Scott et al. 2008, Scott et al. 2009, Bell 2012a, 2012b, and 2012c, EPA 2011). ${ }^{1}$ The issue of whether the energy efficiency investment comes at the expense of other investment or consumption spending in the economy, and thus leads to an offsetting impact on jobs, is addressed in depth in Scott et al. (2009), a PNNL report issued to document its ImSET (I-O based) model used to analyze the economic impacts of U.S. Department of Energy (DOE) energy efficiency programs. This issue is also addressed more thoroughly in Section 3 of the present report.

Net versus gross impacts typically are not explored in other energy jobs studies. For example, in the case of regional studies (e.g. state-level or lower) it is entirely possible that the offsetting impacts from geographic relocation of labor or from redirection of consumer spending from energy to consumer goods and services can be assumed to affect other regions not in the scope of study. In fact, the impacts seen in a regional impact study are bounded by the geographic limits. Thus, analysis of new energy efficiency investment in a particular state or region is usually not concerned with any offsetting impacts in a different state or region.

In the case of national level assessment, these offsetting impacts must be considered. The nation becomes the geographic boundary, and increased energy efficiency investments imply that the new expenditures will be offset by reduced expenditures elsewhere within that same geographic bound.

\footnotetext{
${ }^{1}$ One should note that this distinction between net and gross job impacts is unrelated to energy efficiency program evaluation where a differential net and gross impact is evidence of "free ridership," a situation where some consumers who participate in efficiency programs do so even without any incentives offered by a utility or government entity, and "spillover," where consumers outside the targeted audience participate in efficiency programs.
} 


\subsection{Past Studies of Energy Efficiency Policies - General Observations}

This study reviewed key literature associated with energy efficiency policies and programs, with particular attention focusing on how employment impacts were estimated in these studies. While most of these studies utilized an I-O modeling approach to conduct an analysis, there is considerable variation in how this approach has been applied. Appendix A provides a brief overview of approaches that have been used to estimate employment impacts.

An overarching goal of the current effort is to determine whether some common factors can be extracted from these studies to provide a short-hand method of assessing employment impacts from future energy efficiency policies and programs at both the national and state levels. To be specific, these common factors are multipliers that can convert anticipated levels of efficiency investment and resulting energy savings to first-order estimates of employment impacts (i.e., a rule-of-thumb approach).

Given the background, the review of past studies focused on three elements:

- The level of employment associated with the redirection of energy bill savings (jobs per dollar of savings).

- The level of employment associated with the efficiency investment (jobs per dollar of efficiency investment).

- Consideration of the opportunity cost of the investment reflected by the number of offsetting jobs - thus influencing whether jobs per dollars of investment is gross or net.

Eight national studies were determined to provide appropriate employment multipliers for use in developing approximate estimates of the impacts of future proposed energy efficiency initiatives. ${ }^{2}$ As mentioned earlier, there has been considerable variation in how the I-O modeling approach has been applied. In some studies, only the employment impact from the efficiency investment appears to have been considered. In others, only the effect from the redirection of bill savings has been estimated. While the majority considers both effects, only in a few cases are the effects clearly delineated in the report (such that separate multipliers can be calculated). Finally, it appears that just a few of the studies have considered the opportunity cost of the efficiency investment.

\subsection{Results from Specific Studies}

Table 2.1 summarizes the employment multipliers associated with the key studies that were examined for this work. ${ }^{3}$ The first three columns provide the 1) study name from its citation in the annotated bibliography available in Appendix C, 2) the scope and time frame of the study, and 3) the method or tool used.

\footnotetext{
${ }^{2}$ Seven of the studies were selected from those presented in Appendix B. The selected studies were those where the energy efficiency investment was primarily related to the building sector, and where the job impacts from a specific efficiency scenario were developed. The eighth is the original work reflected in this current study.

${ }^{3}$ Table 2.1 is extracted from a more detailed table that is discussed in Appendix B to this report. The table in Appendix B contains all of the national studies from which multipliers could be derived, as well as more specific information from each study. Additional discussions of the studies shown here are provided in Appendix C.
} 
The next two columns present the relevant multipliers that are either shown directly in the report (shown in bold type in the table) or which could be derived from the absolute values of investment, energy savings, and employment. ${ }^{4}$ Column (4) presents the jobs multiplier with respect to consumer energy bill savings (savings redirection), and column (5) shows the multiplier relative to initial investment.

The next column (6) denotes whether the study considered if (and how) the efficiency investment was financed. In essence, the question posed here is whether any opportunity cost in terms of offsetting activity elsewhere in the economy was recognized, either contemporaneous with the investment or later as repayments were made.

The first two entries in Table 2.1 relate to two relatively recent studies conducted by the Political Economy Research Institute (PERI) at the University of Massachusetts, Amherst. The first (Burr et al. 2012) examined the employment impact from a national program to develop energy ratings for multifamily and commercial buildings. This program was envisioned to prompt improvements in building operations and upgrades to capital equipment. As shown in column (5) the multiplier associated with building operation was nearly 16 jobs per million dollars of investment, with somewhat lower multipliers (13.4 jobs per million dollars of investment, and 12.9 jobs per million dollars of investment) associated with capital upgrades. All of the multipliers in the report included indirect and induced effects as well as the direct effect. With regard to multipliers associated with the energy bill savings (column 4), the report shows two very similar values: 9.9 jobs per million dollars of bill savings in multi-family buildings, and 9.7 jobs per million dollars of bill savings in commercial buildings. All of multipliers in the study were derived directly from the IMPLAN data for 2009 (and thus are shown in bold in the table). ${ }^{5}$

The second report uses a similar methodology to represent a comprehensive national initiative to retrofit commercial buildings (DOE's "Better Buildings" initiative). The multiplier for installation of equipment (13.6 jobs per million dollars of investment) is similar to those in Burr et al. (2012). Factoring in the greater labor intensity for "facilities services" (i.e., maintenance and better operating procedures), the overall multiplier implied by the study was 14.3 jobs per million dollars of investment. The study did not examine the employment impacts associated with the long-run energy bill savings from the retrofit actions.

\footnotetext{
${ }^{4}$ A brief discussion of how an implied multiplier was derived from the relevant studies is provided in Appendix B.

${ }^{5}$ To be clear, the study itself calculated these multipliers from more basic data from IMPLAN, via appropriate weighting of specific industry sectors to reflect the efficiency investments. These calculated multipliers were then shown directly in the report. The multipliers are not "implied" in the sense that they might have resulted from a more extensive economic modeling approach.
} 
Table 2.1. Summary of Employment Impact Multipliers from Key Studies

(1)

(2)

(3)

(4)

(5)

(6)

Employment Multipliers

Jobs per

million dollars Jobs (or job- Investment

of annual years) per financing

energy bill million dollars of (opportunity

savings

(Types of EE measures)

General Method or

Tool

cost)?

Notes

Building energy ratings

Building operations,

environmental

improvements

Capital upgrades - multi-

family

No

Capital upgrades -

commercial

$12.94 \quad$ No

Net jobs from redirected bill

savings - multifamilty

Net jobs from redirected bill

savings - commercial

9.88

9.70

Garrett- Commercial building

2) Peltier 2011 retrofits, "Better buildings" IMPLAN (2009)

Investment, manufacturing/

installation

13.6

17.4

Overall retrofit

14.3

No

No

No Weighted average

Multi-year scenario ending

Rhodium in 2030, all end-use

3) Group 2013 sectors IMPLAN

IMPLAN only, all end-use

sectors, investment

13.7

Young et al. "Shaheen-Portman Energy IMPLAN, through

4) 2013

Bill" Analysis, to 2030

DEEPER Model

Yes

Opportunity

cost

considered, but Personal

Approximate multiplier related to energy bill savings

9

details not communication with available. See Jim Barrett, ACEEE, Appendix B. 4/29/14 
Table 2.1 (continued))

(1)

Study Scope
Study $\quad$ (Types of EE measures)

(3)

(4)

(5)

(6)

(7)

Employment Multipliers

$\begin{array}{lll}\text { Jobs per } & \text { Jobs (or job- Investment }\end{array}$

of annual years) per financing

energy bill million dollars of (opportunity

cost)?

\begin{tabular}{|c|c|c|c|c|c|c|}
\hline 5) & $\begin{array}{l}\text { Rockefeller } \\
\text { Foundation } \\
2011\end{array}$ & $\begin{array}{l}\text { Long-term, } 10 \text {-year } \\
\text { program of building retrofits }\end{array}$ & $\begin{array}{l}\text { Multipliers from } \\
\text { Pollin et al. } 2009\end{array}$ & & & $\begin{array}{l}\text { Investment multipliers, } \\
\text { direct and indirect only }\end{array}$ \\
\hline & & Total Residential & & 11.8 & No & \\
\hline & & Total Commercial & & 12.8 & No & \\
\hline & & Total Institutional & & 11.7 & No & \\
\hline
\end{tabular}

\begin{tabular}{llllll} 
Gold et al. & equipment stds. 2010- & & & \\
\hline $\mathbf{2 0 1 1}$ & 2030 & DEEPER, I-O & & N/A & Text from report \\
& Report text & 10 & N/A & Implied \\
& Existing standard - 2010 & 9.9 & N/A & Implied
\end{tabular}

Evaluation of Better

Research into Buildings Neighborhood

7) Action 2013 Program IMPLAN

$\begin{array}{lll}\text { Total dollars spent over 4th } & & \text { Gross investment } \\ \text { qtr. } 2010 \text { thru 2nd qtr } 2012 & 12.2 & \text { multiplier estimated }\end{array}$

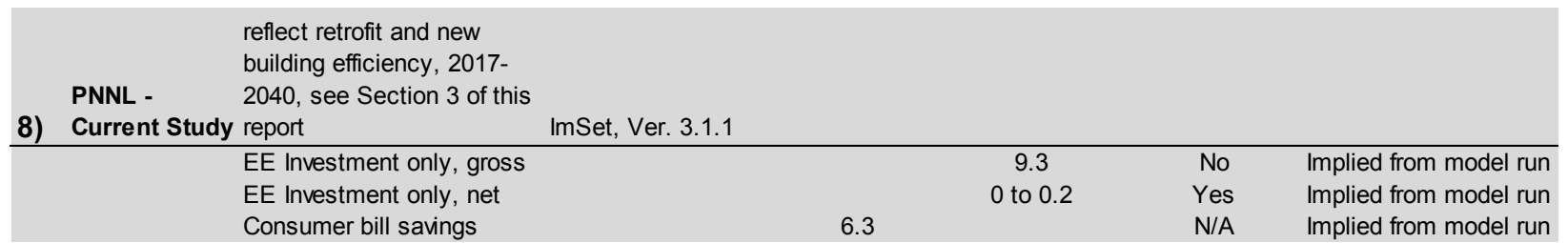

The third study was performed by the Rhodium Group (2013) and explored the consequences of a national energy efficiency initiative to double the nation's "energy productivity" by 2030 . The information in the study did not permit separate multipliers to be developed for individual end-use sectors. The (implied) overall multiplier with regard to efficiency investment across all sectorsbuildings, industry, and transportation —was 13.9 jobs per million dollars of investment.

Report number 4 in Table 2.1 (Young et al. 2013) was a recently published report from the American Council for an Energy Efficient Economy (ACEEE) that analyzed the proposed energy legislation from Senators Jeanne Shaheen (D) and Rob Portman (R) ("Shaheen-Portman"). This bill primarily would spur more energy-efficient building codes, as well as promote a number of other actions to increase energy efficiency in buildings and industrial sectors. As discussed in Appendix B, the multiplier associated with the redirection of energy cost savings in this work is approximately 9 jobs per million dollars of bill savings. The report did not provide sufficient details for this literature review to accurately compute a multiplier for the investment impact (further discussion is provided in Appendix B). The study 
considered direct, indirect, and induced effects from energy efficiency investments and resulting energy bill savings.

The Rockefeller Foundation (2012) considered the employment impacts of a major national initiative, lasting about 10 years, to retrofit a significant fraction of the nation's residential, commercial, and industrial buildings. The employment multipliers were taken from an earlier study (Pollin et al. 2009), which in turn was based on data from IMPLAN. The multiplier for commercial buildings is slightly lower than that shown in the PERI studies ( 1 and 2 above). In part, the multiplier is lower because the Rockefeller Foundation did not include the induced spending portion of the IMPLAN-derived multiplier.

The Gold et al. (2006) study focused on the employment impacts that could be attributed to the national appliance and equipment energy efficiency standards. As stated in the study, the employment impact was "primarily" the result of consumer bill savings engendered by the standards. The report, sponsored by ACEEE, used their DEEPER model, which was based upon an aggregation of I-O data from IMPLAN. Discussion in the report cites a "savings redirection" multiplier of 10 jobs per million dollars of bill savings, and the results from applying the DEEPER model to the savings from "existing" (in 2011) energy efficiency standards indicated a multiplier of 9.9 jobs per million dollars of bill savings. When the model was applied to analysis of "prospective" standards, the (implied) multiplier for 2020 was 7.2 jobs per million dollars of bill savings. The DEEPER model includes direct, indirect, and induced effects as part of its overall approach.

The seventh study in the table completed in November 2013 evaluated the Better Buildings Neighborhood Program (BBNP), a program that was initially funded through the American Recovery and Reinvestment Act (ARRA). The program was exclusively concerned with energy retrofits of residential and commercial buildings. The evaluation considered the time period extending from the last quarter of 2010 through the second quarter of 2012. The study used IMPLAN to estimate the number of jobs associated with the investment and energy savings from the program (including direct, indirect, and induced effects as in the other IMPLAN-based studies discussed above). The study accounted for both components of impact on employment - investment and consumer cost savings — but did not provide an explicit breakdown in the report. Given the relatively small energy cost savings achieved over this short period of time, an approximation to number of jobs associated with this cost savings was calculated, using an assumed multiplier of 10 jobs per million dollars of annual bill savings (as suggested by studies 1, 4, and 6 in Table 2.1). After adjusting the total number of jobs for this component, the implied jobs multiplier associated with the investment component of the program was calculated to be just over 12 jobs per million dollars of investment.

The last entry in Table 2.1 pertains to simulation modeling undertaken by PNNL with its ImSET model as the example analysis in Section 3 of this report. This input-output based model is described briefly in Section 3.1 and was more extensively documented in Scott et al. (2009). From a model run examining a comprehensive energy efficiency scenario through 2040 (primarily affecting residential and commercial buildings) the multiplier associated with redirection of energy bill savings was derived. The current set of simulations indicates a value of 6.3 jobs per million dollars of annual bill savings. This value is somewhat lower than the multipliers based on IMPLAN modeling, primarily because the induced economic effects are treated in a somewhat different fashion in ImSET. The ImSET multipliers here are also expressed in 2011 dollars, a factor that would also tend to make the multiplier just slightly smaller (see footnote 7 below). 
The ImSET model also provides an estimate of the implied employment multiplier with respect to investment - a derived value of 9.3 jobs per million dollars of investment. The PNNL work is among the few groups to have explicitly considered the opportunity cost of the investment in terms of displaced economic activity in other sectors (some of which occurs in the years in which the investment was made). The investment opportunity cost is typically not included in job studies of other energy sectors. When this element is included in the simulation, the aggregate employment multiplier is negligible for initial investments in efficiency. Depending on assumptions made about utility and other administrator financing, the net multipliers associated with the efficiency investment ranged between zero and 0.2 jobs per million dollars of investment.

\subsection{Overall Representative Multipliers}

Many values of employment multipliers were discussed above. The balance of the evidence suggests ranges for values that should be used. Table 2.2 presents employment multipliers associated with additional employment that stems from consumer energy bill savings that can be used to represent a comprehensive set of national energy efficiency activities primarily affecting buildings. ${ }^{6}$ In the judgment of the authors, these ranges are generally plausible based on the results above, adjusted to 2011 dollars. $^{7}$ If, however, a point estimate of the multiplier is desired, a reasonable value may be taken to be 8 jobs/million dollars of bill savings, close to the average of the low and high values obtained across the various studies shown in Table 2.1. Thus, a policy or measure that saved $\$ x$ million on energy bills would generate from $7 x$ to $9 x$ jobs.

Table 2.2. Representative Employment Multipliers for Building Energy Efficiency Initiatives (Jobs per Million 2011\$ of Annual Consumer Bill savings)

\begin{tabular}{lc}
\hline & Influence from Consumer Bill Savings \\
\cline { 2 - 2 } & Multiplier \\
\hline Range & 7 to 9 \\
Point estimate & 8 \\
\hline
\end{tabular}

Any type of investment, considered by itself, is going to have a positive effect on jobs. For energy efficiency investment the gross multipliers in column (5) of Table 2.1 reflect an estimate of the number of national jobs (per million dollars of investment) that might be expected in the short run from an energy efficiency investment that is focused on the building sector. Based on the results across the studies shown in the table, a value of about 11 jobs per million dollars is judged to be a reasonable generalized estimate of this gross multiplier. ${ }^{8}$ However, as explained in Section 2.1, reporting gross impacts would be

\footnotetext{
${ }^{6}$ The values in Table 2.2 reflect some degree of analyst judgment, as the small number of studies and differences in methodology and underlying data do not lend themselves to statistical measures of average results. It also should be understood that the judgment was influenced slightly toward showing conservative values for use in future studies.

${ }^{7}$ Several of the earlier studies shown in Table 2.1 use a base year prior to 2011, so that the values in column (4) of Table 1 would be adjusted downward to be 2011 dollars. The relative modest changes in the overall price level in recent years make such adjustments small. The Gold et al. (study no. 6) presented its results in terms of $2007 \$$; thus, the reported multipliers in the table would be adjusted down by about 6 percent to conform to a 2011 dollar basis. The first two studies in the table based on the IMPLAN 2009 data presumably report the multipliers in terms of 2009 . The corresponding adjustment to 2011 \$ would be just over a 3 percent decline. The more recent work by ACEEE (e.g., Y oung et al.) is in terms of $2011 \$$. Finally, the simulation results for the current study, shown as study number 8 in Table 2.1 and reported in the next section, are shown in terms of $2011 \$$. Given the adjustments to the three earlier studies brings the values of those reported multipliers to be generally in range midway between 9 and 10 .

${ }^{8}$ The value of 11 is in terms of investment in 2011 dollars; thus, it also reflects the small adjustments described in the previous footnote. A reasonable range for this multiplier might include values from 9 to 13 jobs per million (2011) dollars of investment.
} 
misleading without acknowledgement of the effects on employment of reduced expenditures elsewhere. Thus, a net multiplier reflects a longer and broader view of the effects throughout the economy. If the sources of funds to finance the efficiency investment lead to lower spending on other goods and services (i.e., an opportunity cost), then employment reductions (i.e., offsets) associated with these spending reductions are likely. The net effect reflects simple recognition that the overall actual effect of an efficiency investment involves a difference between the jobs created and jobs offset. The net effect has not been reported typically for studies considering jobs created by capital investment in other sectors.

If the opportunity cost of the investment, in terms of foregone economic activity in other sectors of the economy, is assumed to occur in the same year of the efficiency investment, then the net multiplier would apply directly. For a situation in which this opportunity cost is reflected in long-term financing of the investment from sources outside the economy in question (regional or national), the interpretation is slightly more complicated. In this case, the net aspect of the multiplier must be seen in the context of a period of years, where the net impact is measured in terms of total jobs over this entire period. In the years in which the actual investment is made, the impact on jobs would be positive. In subsequent years, when repayment of the loans or bonds that originally financed the investment are paid back, ${ }^{9}$ the impact on jobs would be negative. Given overall slack in the labor market one may view employment increases in the short run as a desirable outcome, even if potentially offset by reductions in the long run.

If long-run impacts are considered the most appropriate metric, the long-run impact of efficiency initiatives comes mainly through its influence on the redirection of consumer energy bill savings toward less energy-intensive (and higher labor-intensive) goods and services. As a first approximation, the net long-term number of job-years created from energy investment is likely to be very small; thus, the point estimate is judged to be effectively zero. In this case, because the net effects on employment of the efficiency investment may be small or temporary, the multipliers associated with those investments were not included in Table 2.2.

\footnotetext{
${ }^{9}$ It should be recognized that for this impact to occur, at least some of the repayments are made to financing sources outside the economy in question. Thus, for example, utility bonds are generally sold to persons and institutions outside the utility service area. Thus, when money is collected, via rates, to pay back the bonds, purchasing power is lowered for the ratepayers in the utility service area, and thus would have a negative effect on jobs in the service area.
} 


\subsection{Analysis Example}

To illustrate how the multiplier process works to increase the number of jobs in the U.S. economy, PNNL economists used the ImSET model described in Scott et al. (2009) to calculate the effects of a high energy efficiency scenario.

\subsection{Background}

The ImSET model was designed by PNNL to provide an approachable and low-cost software tool to analyze key macroeconomic consequences of improvements in the energy efficiency of the U.S. residential and commercial building stock, building equipment, industry and transportation. It has been used both to assess scenarios of adopting specific building energy technologies and the economic impacts of DOE's entire energy efficiency program, including non-building components. The model is based on the U.S. benchmark I-O table published by the U.S Department of Commerce, Bureau of Economic Analysis (BEA 2014). The current version, ImSET 3.1.1, is based on the 2002 table and is being updated to the 2007 benchmark table at this time. ${ }^{10}$ ImSET has been validated by comparing impacts from ImSET to the impacts estimated by other macroeconomic models, especially other I-O models. When run for comparable scenarios, ImSET has produced similar results as these other models (see Roop et al. 2005 and Scott et al. 2009). The jobs multipliers estimated in this study are summarized in Table 3.5 in Section 3.3. The actual impacts are shown in Section 3.4. These multipliers are close to multipliers produced by the IMPLAN (IMPLAN, Inc. 2013) and DEEPER (ACEEE 2012) models, as shown in Section 2 of this report.

\subsection{Impact Pathways}

ImSET recognizes several ways by which adoption of energy-efficient technology can affect macroeconomic activity (e.g., gross output, wage income, employment), of which changes in employment are most frequently of interest.

- Energy savings. The transformation of the nation's energy-using infrastructure and equipment can have a real and lasting impact on the national economy, since the same standard of living and business productivity can be maintained at a lower operating cost, freeing up financial and physical resources that can be redirected (spent or invested elsewhere). Although this reduces purchases of energy (natural, gas, oil, coal, and electricity), which may cost some jobs in the energy industry and closely related sectors, non-energy expenditures are typically much more labor intensive than energy expenditures. The lasting savings created by energy efficiency are the chief source of net long-term job increases.

- Investment effects. Investments are necessary to build or retrofit and equip more efficient buildings, improve industrial process productivity, and purchase and deploy more efficient vehicles and supporting infrastructure. These activities do create jobs, but most impact assessments of energy projects and other investments emphasize the short-term jobs created in construction and industries that produce the installed capital. Rarely recognized is the fact that, in the absence of the investment, consumers, businesses, and governments would have used the resources invested in

${ }^{10} \mathrm{BEA}$ also releases annual tables outside of the benchmark years, but these tables are less detailed and are still based on the benchmark year tables. 
building, purchasing, and deployment activities for different purposes, such as personal consumption, savings, other capital investments, or government services. Since investment activities are typically more capital-intensive than the economy as a whole, the net short-term effect on jobs from diverting resources into efficiency investment activities is smaller than typically shown.

- Long-term financing effects. Unlike the investment effects, the impact of financing these investments, depending on the financing mechanism, can have a much longer horizon. Energy efficiency investments may be funded in a number of different ways, some of which add to energy bills and some of which do not. This analysis assumes that half of the initial cost of efficiency investment is borne by customers and the other half is borne by the electric utilities, who are allowed to add the cost to their rate base. ${ }^{11}$ The utility's cost would be recovered as an annual program charge spread over all energy delivered to all of the utility's consumers, not just those benefitting from the improvement. Net energy bill savings are only slightly affected.

\section{Specific Scenario Inputs}

The energy reference case for this set of scenarios is the Energy Information Administration (EIA) AEO 2014 Reference Case for electricity demand in residential and commercial buildings. The Reference Case includes various energy-efficiency trends and policies - energy savings in this study are additional to those included in the reference case. The analysis considers future voluntary efficiency improvements in electricity consumption in residential and commercial buildings relative to this reference case, funded in whole or in part by utility financing. Table 3.1 shows the Reference Case consumption of electricity and its delivered price in selected years.

Table 3.1. AEO Reference Case Residential and Commercial Electricity Consumption (delivered Energy) and Prices, Selected Years

\begin{tabular}{|c|c|c|c|c|}
\hline & \multicolumn{3}{|c|}{ Year } & \\
\hline & 2015 & 2020 & 2025 & 2030 \\
\hline \multicolumn{5}{|c|}{ Annual Electricity Consumption (Quadrillion Btu) } \\
\hline Residential & 4.74 & 4.84 & 5.00 & 5.21 \\
\hline Commercial & 4.51 & 4.69 & 4.94 & 5.18 \\
\hline Total & 9.25 & 9.43 & 9.94 & 10.39 \\
\hline \multicolumn{5}{|c|}{ Average Electricity Price (2012 Dollars per MMBtu) } \\
\hline Residential & 34.94 & 36.15 & 36.14 & 36.98 \\
\hline Commercial & 29.99 & 30.80 & 30.55 & 31.26 \\
\hline
\end{tabular}

\footnotetext{
${ }^{11}$ It is not within the scope of this study whether a 50 percent program administrative cost (or any other level, which may or may not include a capital cost subsidy to customers) would be necessary to achieve the market penetration of energy efficient technologies and practices assumed in savings scenarios. The study simply assumes that a substantial program cost would be associated with large voluntary market penetration of efficiency and that 50 percent is initially born by the utilities. The question for this study was whether subsequent customer charges required to pay back the utilities' initial program cost would make a significant difference in employment impacts. As modeled in this study, they do not. The short-term opportunity cost to the economy of the initial investment uses the same economic resources. The payments from the customers back to the utilities to pay for program costs have only small net effects on employment.
} 
The study evaluates two scenarios of building energy efficiency savings:

- 15 percent savings by 2030 . In this scenario, the programs save about 15 percent $^{12}$ of AEO Reference Case commercial and residential electricity consumption by 2030. It is assumed that additional energy savings in both the residential and commercial sectors due to the scenario begin in 2015 at zero, and then increase in an S-shaped market penetration curve, which mimics the usual pattern of cumulative market penetration of new technologies (originally Bass 1969; see also Bass 2004). Adoption initially is slow, then rapidly accelerates during mass adoption, and then slows as market saturation is reached. The level of savings equal about 7.0 percent of the AEO 2014 U.S. national residential and commercial electricity consumption saved by $2020,14.8$ percent by 2025 , and 15 percent by $2030 .{ }^{13}$

- 10 percent savings by 2030. In this scenario, additional savings due to the scenario begin at zero in 2015 , increase to 3.8 percent in 2020, 9.8 percent by 2025, and 10 percent of the AEO reference case value by 2030 .

In this example we use an estimate of $\$ 50$ per MWh of annual energy savings, in 2011 dollars. This is a reasonable value given that recent literature identifies program administrator costs that have been roughly $\$ 20$ per MWh of annual energy savings, and notes that administrator costs have been roughly half of the total combined costs experienced by administrators and program participants. ${ }^{14,15}$ To account for program participant costs, we have doubled the administrator costs to produce a $\$ 40$ total cost per MWh and then added $\$ 10$ per MWh to produce a conservatively high cost of saved energy. ${ }^{16}$

The study assumes that 50 percent of the investment costs for energy efficiency would be financed by an electric utility or third party administrator, and that these costs would be recovered by a service charge per kWh on electricity, levied on all customers. This charge reduces the overall net consumer bill savings. We acknowledge that, in addition to utilities, energy service companies (ESCOs) often administer efficiency programs, but for simplicity, they are not included in the scenario. Two real (without inflation) discount rates are assumed: 7 percent and 3 percent, as is typical for government policy evaluation. ${ }^{17}$

\footnotetext{
12 Billingsley et al. (2014) show administrator cost of saved energy at 2.1 (2012\$) per kWh for commercial and industrial efficiency savings and 1.8 cents per $\mathrm{kWh}$ for residential savings. Full resource costs varied but were roughly 50 percent of the total. Taking the 1.8 and doubling it and rounding down gives 3 cents as the lower bound in this study. Downs and Cui (2014) show that at an average of 2.8 cents per kWh, electric utility energy efficiency programs in various states are about one-half to one-third the cost of alternative new electricity resource options. The upper bound value of 5 cents in this study would be between one-half and one third of new units costing 10 to 15 cents per $\mathrm{kWh}$.

${ }^{13}$ The savings in buildings are implemented in ImSET by reducing residential electricity spending in final demand and proportionately reducing electricity spending for economic sectors housed in commercial buildings with the input-output transactions table, thereby reducing the energy intensity of the commercial sector. Commercial sector savings are allocated to value added (profits, indirect business taxes, and payrolls). Residential savings are allocated proportionately to industry final demand in the proportions contained in consumer final demand. Commercial savings are first allocated proportionately to the components of final demand, and then allocated to the final demand spending patterns of business, government, and consumers. Simultaneously, the input-output model is reconfigured at each time step to account for the lower use of electricity per unit of output in business when the model is run to calculate impacts.

${ }^{14}$ Molina, Maggie, 2014. The Best Value for America's Energy Dollar: A National Review of the Cost of Utility Energy Efficiency Programs. Washington, DC: American Council for an Energy-Efficient Economy. http://www.aceee.org/research-report/u1402.

${ }^{15}$ Billingsley, Megan A., Ian M. Hoffman, Elizabeth Stuart, Steven R. Schiller, Charles A. Goldman, Kristina LaCommare, 2014. The Program Administrator Cost of Saved Energy for Utility Customer-Funded Energy Efficiency Programs. Ernest Orlando Lawrence Berkeley National Laboratory. http://emp.lbl.gov/sites/all/files/lbnl-6595e.pdf.

${ }^{16} \mathrm{We}$ also examined the impacts of $\$ 30$ and $\$ 80$ annualized cost per MWh, but the employment results are primarily driven by energy savings, both because the investments had an opportunity cost elsewhere in the economy in the short term, and because ratepayers' savings benefits in the long term were reduced by the utilities' service charge to recover their component of the investment cost as noted in the next paragraph. The investment costs had little influence on the jobs estimates.

${ }^{17}$ Office of Management and Budget, 1992. Circular No. A-94 (Revised): Guidelines and Discount Rates for Benefit-Cost Analysis of Federal Programs. http://www.whitehouse.gov/omb/circulars_a094/. Three percent is generally characterized as a "social discount rate" and 7 percent is generally characterized as "private discount rate."
} 
The analysis also accounts for the assumed lifetime of these investments and the requirement to replace investments at the end of their lifetime in order to maintain the savings.

- Measure life is the length of time that an energy efficiency measure is expected to be functional and generating savings. Measure life is sometimes referred to as expected or effective useful life and is a function of equipment life and measure persistence.

- Equipment life is the number of years that a measure is installed and operating at the assumed efficiency.

- Measure persistence refers to the duration of an energy-consuming measure, taking into account business turnover, early retirement of installed equipment, and other reasons that measures might be removed from a building or discontinued. ${ }^{18}$

At the portfolio level, the median savings lifetime is 12 years, with an interquartile range of plus or minus 3 years. ${ }^{19,20}$ We use a conservative value of 10 years for this modeling.

At a discount rate of 7 percent and a 10-year period to recover the investment (assumed equal to the lifetime of the investment), the present value per dollar of a $\$ 1$ annualized cost for a MWh of delivered electricity savings in the year the investment occurs is $\$ 7.02$, and when converted to dollars per delivered MMBtu, is $\$ 2.06$. That $\$ 2.06$ per $\$ 1$ of annualized cost is then multiplied by the $\$ 50 / \mathrm{MWh}$ annualized cost for the improvement. At $\$ 50 / \mathrm{MWh}$, the present value of the investment is $\$ 102.92 / \mathrm{MMBtu}^{21}$

The study considers the following scenarios, which together bracket the main uncertainties in energy bill savings, investment cost, and discount rates. All assume a 10-year life of investment. The scenarios include 15 percent and 10 percent electricity savings; high, medium, and low investment costs, and high and low discount rates. Table 3.2 lists the specific cases modeled.

Table 3.2. Characteristics of ImSET Model Cases

\begin{tabular}{cccc}
$\begin{array}{c}\text { Model } \\
\text { Scenario }\end{array}$ & Description & Annualized Investment Cost & $\begin{array}{c}\text { Discount } \\
\text { Rate }\end{array}$ \\
\hline 1 & 15 percent electricity savings & No Investment Assumption & NA \\
2 & 10 percent electricity savings & No Investment Assumption & NA \\
3 & 15 percent electricity savings & $\$ 50 / \mathrm{MWh}$ & $7 \%$ \\
4 & 10 percent electricity savings & $\$ 50 / \mathrm{MWh}$ & $7 \%$ \\
5 & 15 percent electricity savings & $\$ 50 / \mathrm{MWh}$ & $3 \%$ \\
6 & 10 percent electricity savings & $\$ 50 / \mathrm{MWh}$ & $3 \%$ \\
\hline
\end{tabular}

\footnotetext{
${ }^{18}$ SEE Action Evaluation, Measurement and Verification Working Group. "Energy Efficiency Program Impact Evaluation Guide” 2012. DOE/EE-0829 Accessible at http://www1.eere.energy.gov/seeaction/pdfs/emv_ee_program impact guide.pdf.

${ }^{19}$ Hoffman, Ian, Megan Billingsley, Steven Schiller, Charles A. Goldman. Forthcoming. Energy efficiency portfolio and program lifetimes. Berkeley: Lawrence Berkeley National Laboratory.

${ }^{20}$ Northwest Power and Conservation Council, 2013. Sixth Power Plan- Mid-Term Assessment Report. http://www.nwcouncil.org/media/6391355/2013-01.pdf.

${ }^{21}$ It is difficult to translate a long-term jobs/dollar of savings estimate from a scenario analysis into a jobs per dollar of investment estimate because a) the level of savings in any year depends on the level of all previous investments, b) because in any one year, the stock of previous investments will also produce future savings, and c) to maintain the savings into the future will also require replacement investments. Thus, there is never really a final year except in the very artificial case where a one-time investment occurs, and the savings are measured over the entire lifetime of the one-time investment. That does not apply in this study, where savings are being compared to a dynamic reference case.
} 
The impact of efficiency investments and energy savings on employment is affected by two other factors. The first factor is the overall labor intensity of the investment, which depends on what sectors of the economy are involved, what other sectors are involved in their supply chains, and how many jobs are supported by a dollar of activity in each sector. Because a variety of economic sectors produce goods and services that would be needed directly for an investment in building energy efficiency, the analysis allocates each dollar of investment to a group of sectors that would provide more efficient heating, cooling, and lighting equipment, windows, and construction services. These sectors, in turn would buy needed goods and services from other sectors. Table 3.3 shows the economic sectors assumed to receive the investment expenditures. This distribution is based on the impact of building energy codes evaluated in Scott et al. 2009. The table also shows the total jobs multiplier (direct, indirect, and induced) for one million 2011 dollars invested in the sector. The sectors listed in the table receive part of the additional cost premium required to construct and equip (or remodel and re-equip) a more efficient building rather than a conventional one. Other sectors (for example, wholesalers and retailers or transportation companies) are still involved but would receive only their usual markup payment rather than a premium. ${ }^{22}$ This pattern is not necessarily the actual future pattern of energy efficiency investment spending but it is broadly consistent with investments that might be needed to improve a wide array of residential and commercial buildings and does contain a variety of high labor intensity and low labor intensity sectors.

The second factor affecting the net impact of the efficiency investment is the pattern of economic activity that would have to be given up so that the investment could occur. The analysis assumes a closed economy with a balanced overall budget so that spending of a dollar on improved efficiency during a year implies that a dollar of other consumption and investment would be foregone. Even if the invested funds were borrowed, there would be an alternative use for the funds. This analysis assumed that the invested funds are proportionately drawn from the rest of the economy. Table 3.4 shows the assumed proportions from the U.S. national domestic income accounts, which are slightly different from year to year, but broadly consistent with recent U.S. economic history. Consumers account for a little over two-thirds of the domestic economy, with private investment accounting for about 15 percent and all levels of government for about 17 percent.

\footnotetext{
${ }^{22}$ This approach assumes that factors like wholesale, retail, and transportation markups are cost-based and that premium equipment and building components are not disproportionately costly to ship, store, sell, and service compared with baseline equipment and components. Additional dollars are earned, but only in proportion to the usual markups. Additional services connected to installation are assumed to be captured by the indirect impacts of the construction sector premiums.
} 
Table 3.3. Economic Sectors Assumed to Receive Energy Efficiency Investments.

\begin{tabular}{lrr}
\hline \multicolumn{1}{c}{ Sector } & $\begin{array}{c}\text { Percentage of } \\
\text { Investment } \\
\text { Cost }\end{array}$ & $\begin{array}{r}\text { Investment Multiplier: } \\
\text { Gross Jobs per Million } \\
\text { 2011\$ }\end{array}$ \\
\hline Commercial Building Construction & 7.5 & 8.09 \\
Residential New Construction & 10.0 & 12.87 \\
Commercial Remodeling Construction & 7.5 & 4.96 \\
Residential Remodeling & 5.0 & 10.45 \\
Flat Glass Manufacturing & 10.0 & 6.82 \\
Glass and Glass Products Manufacturing & 10.0 & 9.66 \\
Air Conditioning, Refrigeration, and Forced- & 22.5 & 9.87 \\
Air Heating Manufacturing & 7.5 & 11.39 \\
Air Purification Equipment Manufacturing & 10.0 & 9.33 \\
Electronic Components Manufacturing & 5.0 & 7.64 \\
Electric Light Bulb and Part Manufacturing & 5.0 & 9.23 \\
Light Fixture Manufacturing & 100.0 & 9.29 \\
\hline Total & \multicolumn{2}{c}{} \\
\hline Source: Scott et al (2009), p. 3.11, and unpublished ImSET model sector data on gross jobs multipliers \\
\hline
\end{tabular}

Table 3.4. Assumed Sources of Funds Invested in Building Energy Efficiency

\begin{tabular}{lr}
\hline Economic Activity & $\begin{array}{c}\text { Percentage } \\
\text { of Final } \\
\text { Spending }\end{array}$ \\
\hline Personal Consumption Expenditures & 66.9 \\
Private Investment & 14.8 \\
Federal Government Consumption, Defense & 3.9 \\
Federal Investment in Defense & 0.6 \\
Federal Government Consumption, Non-Defense & 1.9 \\
Federal Government Investment, Non-Defense & 0.3 \\
State and Local Government Consumption, Education & 4.8 \\
State and Local Government Investment Education & 0.6 \\
State and Local Government Consumption, Other & 4.5 \\
State and Local Government Investment, Other & 1.7 \\
\hline Total & 100.0 \\
\hline
\end{tabular}

\subsection{Multipliers}

As discussed in Section 2, many economic impact studies of energy programs discuss employment multipliers, which are basically summary statistics showing the total number of jobs or job-years that would be expected from the energy efficiency activities being evaluated, usually calculated as the number of jobs or job-years per million dollars of investment. While employment impacts were actually calculated by running the ImSET model for a group of specific scenarios rather than simply multiplying these factors by investments or savings, it can be useful to compare the ImSET multiplier summary statistics with those used in other studies or other models. As described in the first section of this study, employment impacts can include direct, indirect, and induced impacts. A Type I multiplier includes direct and indirect impacts (i.e., additional employment in directly affected businesses, and additional employment in businesses that supply the directly affected businesses and other supply chain businesses). A Type II multiplier additionally includes induced impacts from the spending of the additional wages earned by households as a result of the additional activity in the economy. In making this comparison, it 
is useful to know that ImSET produces a "Type I+ multiplier." It accounts for all of the employment impacts on directly affected and supplier industries, as well as the impacts of consumer savings when spent in the general economy; however, additional personal income earned by households as a result of the additional direct and indirect business activity is not automatically assumed to be spent as it is in some other models, so the "induced" effect is lower in ImSET than in models with a full induced effect. ${ }^{23}$

The employment impacts for the ImSET model for the scenarios described in the previous sections are summarized in Table 3.5. The savings multiplier in Table 3.5 allows for recovery of the financing of efficiency investments, which in turn offsets consumer savings (costs are repaid). However, the offset is so small that it has virtually no effect on the employment associated with energy bill savings. On the investment side, a $\$ 1$ million investment in efficiency by itself creates about 9.29 jobs in construction and equipment manufacturing and the related supply chain. This 9.29 estimate is the most comparable to those in other studies that emphasize the jobs created by investments in energy supply and other major capital projects, and compares with the discussion in Section 2.4 describing that these multipliers generally range between 9 and 13. As discussed in that section, some of those job gains may be offset in other sectors that would have reduced expenditures, but that would also be true in other studies that do not recognize an offset. $^{24}$ This analysis also shows a net long-term 6.26 jobs from each $\$ 1$ million in energy bill savings (net of any jobs offset as a result of lower utility sales). This number is comparable to the values from the literature reported in Table 2.2.

Table 3.5. Summary ImSET Jobs Multiplier Statistics for the Period 2015-2030 in this Study

\begin{tabular}{|c|c|}
\hline Multiplier & Average Value, 2015-2030 \\
\hline Short term Gross Jobs per \$1 million Efficiency Investment & $9.29^{\mathrm{a}}$ \\
\hline Long term Net Jobs per $\$ 1$ million Electricity Savings & 6.26 \\
\hline Direct Gross Jobs per $\$ 1$ million Efficiency Investment & 3.99 \\
\hline
\end{tabular}

These two multipliers are summary statistics that characterize separate effects that are comparable to similar effects estimated in other models. The first effect (9.29) is a multiplier associated only with the short-term \$1 million investment in efficiency, but does not count the opportunity cost of that investment, nor the impact of the resulting subsequent energy savings that occur as a result of the investment. It is comparable to the jobs impact of an energy investment (such as building a power plant), but not accounting for any impact of alternative uses of the invested funds. The second multiplier (6.26) summarizes the effect of $\$ 1$ million in savings, but does not count the costs and impacts of the previous and ongoing investments required to create and sustain that level of savings. Because of the mismatch between the timing and pathways of investments and savings, neither multiplier is contained in or a subset of the other. The only way to "sum up" the multiplier effects is to introduce consistent scenarios of

\footnotetext{
23 In input-output model jargon, ImSET's total requirements matrix is not closed with respect to the household sector, so it does not produce a full induced effect.

${ }^{24}$ Accounting for all of the potential offsets from forgone investment and consumption, the net impact of the efficiency investment is about 0.17 jobs/ million dollars of investment. The net impacts for energy supply and other investments would be similar if they were recognized in other studies. They are not recognized in part because many studies are local and assume no local offset; e.g., from a national perspective an investment in Ohio may be paid for by a lower investment in California or New York, but that need not be recognized in Ohio.
} 
investment and savings into the ImSET model and run the model. This is done in Section 3.4 for a number of investment/savings scenarios.

The third multiplier (3.99) shown in Table 3.6 is the short term direct gross jobs created in industries that receive the efficiency investments. The direct jobs created by the energy efficiency investment can be classified as energy efficiency jobs. This multiplier was calculated as a weighted average of the direct employment per million dollars of investment in energy efficiency for the industries directly affected by the investment, and is a subset of the short-term gross investment multiplier. ${ }^{25}$ Based on the 15 percent Scenario by 2030 with $\$ 50 / \mathrm{MWh}(2011 \$$ ) (7\% discount rate), an annual average of 60,000 direct jobs would be created. These are the jobs that would implement the measures and practices in which the investment occurs or manufacture the related equipment. The actual number in any year fluctuates with the turnover of appliance and equipment stocks. This estimate implies a direct employment multiplier of 3.99 jobs per million dollars of investment (2011\$).

\subsection{Employment Impacts}

Table 3.6 shows the potential impact of the energy efficiency scenarios for selected years. This is a snapshot of additional jobs in the U.S. economy relative to whatever employment would have been without the building energy efficiency program, and includes both savings and investment effects. The calculations assume that 50 percent of the investment cost for efficiency improvements is financed by electric utilities that book the costs in their rate base and recover it through electricity bills. ${ }^{26}$ Some ratepayers benefit from the financing; others see only the minor electricity bill increase. Since the bill increase is so small (less than one percent), it is unlikely to affect electricity consumption, so that effect has been assumed to be zero for this analysis. The effects of the discount rate are very small, since the savings benefits in a particular year depend only on the price of electricity and the amount of electricity consumed in that year, and the annualized cost of the energy efficiency has already been specified. In this context a higher discount rate increases the overnight cost in the year that the investment occurs ${ }^{27}$ and the amount of the financing repayment in each year. These factors largely offset each other. The investment itself has a relatively small net impact on employment. The projected impacts mainly come from two sources: 1) the improvement in the efficiency of the economy shown as energy bill savings, savings that are spent on other sectors and 2) the differences in the labor intensities of the economic sectors affected. The employment impacts of the modeled activities are positive and modest in size relative to the size of the economy.

\footnotetext{
${ }^{25}$ The proportions of the investment across industries are the same as shown in Table 3.3. However, Table 3.3 shows the full ImSET investment multiplier for each sector, whereas the direct impacts are confined to the jobs impact within each sectors shown in Table 3.3 and exclude the indirect and induced effects.

${ }^{26}$ As noted earlier, the investment costs also could be borne by a third party who would share the cost savings with the customer, or the utility might be able to bear the investment costs within its current rate base, in which case no extra financing charge would be necessary. Alternatively, the utility could bear 100 percent of the cost, and recover all of it though the rate base. The study has assumed a middle case, with 50 percent financing, Since the study assumes scenarios of adoption that are independent of the level of financing, the effects on employment from alternative financing schemes are confined to differences in the spending patterns of households and utilities during the payback period and are very small. As noted earlier in the text, net investment job creation recognizes the domestic U.S. opportunity cost of invested funds, and is not influenced by how the investment is actually financed, so long as the funds are supplied by the domestic economy.

${ }^{27}$ The investments were specified as annualized costs per MWh of delivered electricity for a 10-year life, without reference to a discount rate, which implies that the annualized cost is the same at 3 percent and 7 percent. However, the same annualized cost of a one-time investment implies different present values for that one time investment at different discount rates. These different present values, annualized at 3 percent and 7 percent, respectively, over 10 years would produce the same annualized value.
} 
Table 3.6. U.S. National Employment Impact of Residential and Commercial Building Energy Efficiency Programs, 50 percent Utility Financing Incorporated into Energy Bills, Under Various Market Conditions, Selected Years (Thousands of Net Jobs)

\begin{tabular}{|c|c|c|c|c|}
\hline \multirow{2}{*}{$\begin{array}{c}\text { Scenario: } \\
\text { Level of Investment, } \\
\text { Discount Rate, and } \\
\text { Savings }\end{array}$} & \multicolumn{4}{|c|}{ Year } \\
\hline & 2015 & 2020 & 2025 & 2030 \\
\hline \multicolumn{5}{|l|}{$\begin{array}{l}\text { Savings only (No } \\
\text { Investment) }\end{array}$} \\
\hline $\begin{array}{l}15 \text { Percent Electricity } \\
\text { Savings by } 2030\end{array}$ & 0 & 138 & 301 & 327 \\
\hline $\begin{array}{l}10 \text { Percent Electricity } \\
\text { Savings by } 2030\end{array}$ & 0 & 74 & 199 & 218 \\
\hline \multicolumn{5}{|c|}{ With Investment of $\$ 50 / \mathrm{MWh}, 7$ Percent Discount Rate } \\
\hline $\begin{array}{l}15 \text { Percent Electricity } \\
\text { Savings by } 2030\end{array}$ & 0 & 130 & 300 & 319 \\
\hline $\begin{array}{l}10 \text { Percent Electricity } \\
\text { Savings by } 2030\end{array}$ & 0 & 69 & 198 & 213 \\
\hline \multicolumn{5}{|c|}{ With Investment of \$50/MWh, 3 Percent Discount Rate } \\
\hline $\begin{array}{l}15 \text { Percent Electricity } \\
\text { Savings by } 2030\end{array}$ & 0 & 131 & 300 & 320 \\
\hline $\begin{array}{l}10 \text { Percent Electricity } \\
\text { Savings by } 2030\end{array}$ & 0 & 70 & 198 & 213 \\
\hline
\end{tabular}




\subsection{Discussion}

This study is not fully comprehensive or exhaustive. However, it covers the landscape of the topic and provides important insights and quantitative examples. It briefly introduces the various approaches available to examine the question of employment effects generally and for energy efficiency investment expenditures specifically. It focuses on the predominant approach cited in the literature, and provides detailed examination of that approach. It offers an example analysis of the relevant question of the magnitude and characteristics of employment impacts associated with voluntary increased adoption of energy efficiency in the residential and commercial building sectors, driven initially by utility and thirdparty investment and sustained by the redirection of energy bill savings to other expenditures.

One objective of the study overall is to determine, based on careful review of the literature, whether employment impacts generated by energy efficiency activities and related investment and bill savings could be summarized with general guidelines. Review of the literature revealed that the gross impact of the initial energy efficiency investment generally ranges between 9 and 13 jobs per million dollars of investment, and would be 11 jobs per million dollars of investment if a point estimate is desired. These jobs include both those directly related to the energy efficiency investment itself, as well as the supporting jobs in the general economy. However, few studies accounted for the expected movement of jobs between industries or geographies or the implications of accounting for the financing cost of the energy efficiency investment. These aspects of policies and investments that spur energy efficiency have offsetting impacts over time, compared to the initial impacts of the actions taken to implement efficiency measures. Thus, given these offsetting impacts, the redirection of consumer and business energy bill savings is the primary engine for sustained employment impacts resulting from greater energy efficiency. As general guidance, in the judgment of the authors, this impact ranges between 7 and 9 jobs per million dollars of bill savings and would be 8 jobs per million dollars of bill savings if a point estimate is desired.

The example analysis in Section 3 highlights the gross impact of the initial investment on employment. For the scenarios examined in Section 3, investment varies year to year over the 2015-2030 period to account for appliance and equipment stock turnover effects. The example analysis finds that, on average, about 60,000 energy efficiency jobs (gross direct jobs) could be generated or supported annually by policies or investments that spur a 15 percent reduction in building-sector electricity consumption by 2030. This amounts to 4 energy efficiency jobs annually per million dollars of annual investment (2011\$). Based on the information provided in Table 1.1, 60,000 energy efficiency jobs would represent an increase of more than 13 percent above 2011 estimates of all building-sector energy efficiency employment. Further, the energy bill savings that would accrue to consumers and businesses in 2030 in this scenario is $\$ 50$ billion ( $2011 \$$ ). The example analysis finds these savings would support nearly 320,000 new jobs (net direct, indirect, and induced) jobs economy-wide in 2030. Alternatively, using the multiplier of 8 jobs per million dollars of energy savings (the average impact from the literature, shown in Table 2.2) the estimate is slightly greater than 400,000 jobs in 2030.

Based on the findings of Section 2 and the analysis in Section 3, positive, though modest, employment effects can be expected in the out years, relative to current national employment. For comparison purposes, the estimated impacts are not substantially different than recent month-to-month increments to national employment. As expected, the principal activities generating these impacts are the redirection of residential and commercial customer energy savings and higher labor intensities in the economic sectors receiving the redirected energy bill savings. The study does not consider other 
applicable economic impacts such improved economic productivity, increased industrial output, or increased income to labor and households. 


\subsection{References}

American Council for an Energy-Efficiency Economy (ACEEE). 2012. "How Does Energy Efficiency Create Jobs." ACEEE Fact Sheet, American Council for an Energy-Efficiency Economy, Washington D.C.

Bass FM, 1969. A new product growth model for consumer durables. Management Science 15(5): 2 1522.

Bass FM, 2004. Comments on "A new product growth for model consumer durables." Management Science 50 (12 Supplemental): 1833-1840.

BEA (Bureau of Economic Analysis). 2014. Benchmark Input-Output Data: 2002 Data. Accessed on 5-22014 at http://www.bea.gov/industry/io benchmark.htm.

ACEEE. 2012. "A Brief Methodology of the DEEPER Modeling System." Fact Sheet available at: http://aceee.org/files/pdf/fact-sheet/DEEPER_Methodology.pdf

Bell CJ, 2012a. "Energy Efficiency Job Creation: Real World Experiences." American Council for an Energy-Efficient Economy, Washington D.C. White paper, October 15, 2012.

Bell CJ, 2012b. "How Does Energy Efficiency Create Jobs." American Council for an Energy-Efficient Economy. ACEEE blog posting. Available at http://aceee.org/print/blog/2011/11/how-does-energyefficiency-create-job.

Bell CJ, 2012c. "Understanding the True Benefits of Both Energy Efficiency and Job Creation." Community Development Investment Review Vol. 10, Issue 1. Federal Reserve Bank of San Francisco.

Billingsley MA, IM Hoffman, E Stuart, SR Schiller, CA Goldman, K LaCommare, 2014. The Program Administrator Cost of Saved Energy for Utility Customer-Funded Energy Efficiency Programs. LBNL$6595 \mathrm{E}$, prepared for the U.S. Department of Energy by Lawrence Berkeley National Laboratory. http://emp.lbl.gov/sites/all/files/lbnl-6595e.pdf.

Burr A, C Majersik, S Stellberg, H Garrett-Peltier. 2012. Analysis of Job Creation and Energy Cost Savings from Building Energy Rating and Disclosure Policy. Institute for Market Transformation, Washington, D.C.

Downs A, C Cui, 2014. Energy Efficiency Resource Standards: A New Progress Report on State Experience. Report U1403. American Council for an Energy-Efficient Economy, Washington, D.C.

Environmental Protection Agency (EPA). 2011. Assessing the Multiple Benefits of Clean Energy: A Resource for States. EPA-430-R-11-014. Environmental Protection Agency, Washington D.C. September.

Gold R, S Nadel, JA Laitner, and A deLaski, 2011. Appliance and Equipment Efficiency Standards: A Money Maker and Job Creator. American Council for an Energy-Efficient Economy, Washington, D.C. January 2011. 
IMPLAN Version 3.0. Hudson, WI: MIG, Inc. https://implan.com/

Muro M, J Rockwell, and D Saha. 2011. Sizing the Green Economy: A National and Regional Green Jobs Assessment. The Brooking Institution, Metropolitan Policy Program in collaboration with Battelle Technology Partnership Practice, Washington, D.C. July 13, 2011.

Pollin R, J Heintz, and H Garret-Peltier, 2009. The Economic Benefits of Investing in Clean Energy. Department of Economics and Political Economy Research Institute, University of MassachusettsAmherst, and Center for American Progress, Amherst, Massachusetts. June 2009.

Prindle WR, AM Shipley, and RN Elliott. 2006. Energy Efficiency's Role in a Carbon Cap-and-Trade System: Modeling Results from the Regional Greenhouse Initiative. Report No. E064, American Council for an Energy-Efficient Economy, Washington, D.C. May 1, 2006.

Rhodium Group. 2013. American Energy Productivity: The Economic, Environmental and Security Benefits of Unlocking Energy Efficiency. Prepared for The Alliance to Save Energy, Washington, D.C. February 2013.

The Rockefeller Foundation. 2012. The United States Building Energy Efficiency Retrofits: Market Sizing and Financing Models. The Rockefeller Foundation and DB Climate Change Advisors (Deutsche Bank Group), New York, New York. March 2012.

Roop JM, MJ Scott, and RW Schultz, 2005. ImSET: Impact of Sector Energy Technologies. PNNL-15273. Pacific Northwest National Laboratory, Richland, Washington.

Scott MJ, JM Roop, RW Schultz, DM Anderson, KA Cort, 2008. "The impact of DOE building technology energy efficiency programs on U.S. employment, income, and investment." Energy Economics, 30 (5): 2283-2301.

Scott MJ, OV Livingston, JM Roop, RW Schultz, and PJ Balducci, 2009. Impact of Sector Energy Technologies Model Description and User's Guide. PNNL-18412, Pacific Northwest National Laboratory, Richland, Washington.

Wei M, S Patadia, and DM Kammen. 2009. "Putting Renewables and Energy Efficiency to Work: How Many Jobs can the Clean Energy Economy Generate in the United States." Energy Policy 38(2010):918931.

Young R, Sara Hayes, Steven Nadel, Garrett Herndon, and Jim Barrett, 2013. Economic Impacts of the Energy Provisions in the Energy Savings and Industrial Competitiveness Act of 2013 and Selected Amendments. ACEEE White Paper, American Council on Energy-Efficient Economy, Washington, D.C. September 2013. 


\title{
Appendix A
}

\section{Background on Employment Multipliers and Energy Efficiency}

To place this study in context, it is important to understand the continuum of approaches available for estimating employment effects and assessing alternative employment multiplier metrics. These approaches do not only pertain to energy efficiency impact analysis, but are applicable to most research questions involving employment impacts. This appendix briefly discusses these approaches in rough order of increasing technical rigor in the view of the authors and lists some known examples, but defers to the reader to investigate these in more depth. Thus, it is not the intent to offer suggested citations for each potential modeling approach. Readers are directed to further research any specific approach if interested in additional detail.

\section{A.1 Multiplier-Based Models}

\author{
Examples: Job and Economic Development Impact Model (JEDI), Rocky Mountain Institute (RMI) \\ Community Energy Opportunity Finder, Renewable Energy Policy Project (REPP) Labor Calculator
}

These models are based on multiplier values that are drawn from more rigorous analyses. Multipliers indicate how a change in one industry will trickle through the economy by causing changes in other industries. These multiplier-based models are fairly simple tools that are suitable for rough approximations of the impacts. Their application is warranted for high-level screening or developing rough estimates to prioritize activities. Multiplier-based models provide a first-cut estimate of the direction and magnitude of the impacts.

The disadvantage of using simple or generalized multipliers stems from how they are defined (jobs vs. job-years vs. full-time equivalent job (FTE), jobs per million dollars expended, etc.), whether they consider direct impacts alone or indirect and induced impacts, whether the multiplier accounts for net effects (jobs created in one sector may be offset in another), or whether the level of sector aggregation masks specific effects. Thus, effort is required to place multiplier values on equal footings across studies for comparison purposes. The main advantage of the multiplier approach is its relative ease of use and ability to provide results in short timeframes or under resource constraints, recognizing that the benefits of quick answers to policy questions often require a compromise in the reliability of those answers.

\section{A.2 Input-Output Models (I-O)}

\section{Examples: IMPLAN, RIMS II, ImSET}

I-O models provide a convenient and technically simplified view of all of the financial transactions within the economy. For the U.S., the Bureau of Economic Analysis produces this snapshot of the financial flows in the economy every 5 years, lagged by about 5 years. The snapshot results in a large table mapping the output of each individual producing industry to the purchases made by each consuming industry, household, and government. The majority of analytical work in the area of energy efficiency employment impact assessment has relied upon variants of the I-O modeling framework, citing the advantages in cost and flexibility as the reasons. 
While often favored for a variety of reasons such as cost and simplicity, and although limited by some implied assumptions, when presented with small marginal direct impacts, the I-O approach provides a reasonable characterization of the full economic impact. Full economic impact includes direct, indirect and induced effects. For national assessments of employment impacts related to energy efficiency expenditures, the direct effects would typically be small in the context of the national economy (and therefore not structure-altering). Therefore, the resulting indirect and induced impact estimates are expected to be reasonably robust for short-term analyses, but would lose robustness as results are projected further in time.

As with any modeling framework, using the I-O logic requires acceptance of some restrictive implied assumptions. Using a snapshot table of financial transactions requires the assumption that the purchasing relationships are frozen at that point in time and thus, all relationships between industries are linear with constant and instant returns to scale. Thus, impacts scale linearly, which becomes less and less plausible for increasing levels of direct impact. The I-O model response is instantaneous, when in reality the percolation of impacts through the economy takes time, and thus effort is required to effectively stage impacts through time. Because no prices or explicit behavioral adjustment mechanisms are found in I-O models, no internal market features are present, such as increasing prices for sector output or for factors of production that automatically overstate the size of impacts. Also, the U.S. transactions table is produced every 5 years and is lagged by 5 years, thus analysts must acknowledge that impact assessment for any national question would be estimated based on the technical relationships between industries in place at least 5 years prior under ideal circumstances - but often longer. The degree to which the economy changes in the intervening years is lost without additional special analytical attention.

The literature acknowledges the trade-offs involved in the use of the I-O approach. However, in the judgment of the authors, most national level studies of energy efficiency using this approach examine questions that would not necessarily be expected to alter the underlying structure of the economy. In other words, while the scale of investments studied may be significant in the context of all energyefficiency investment, in the context of the wider economy, they would not be large enough to affect structural changes. As long as the expected research questions do not introduce structural changes, the approach is reasonable and generally accepted.

\section{A.3 Computable General Equilibrium Models (CGE)}

Examples: Energy and Resources (BEAR) model, E-DRAM, Council of Economic Advisors models, EPRI

The CGE framework is more suitable for analyzing impacts that can result in price or productivity changes. The CGE model determines relative prices, outputs, and income distributions in markets through reconciling supply and demand for goods and services. Three basic assumptions represent the core of the CGE logic: rational preferences based on availability of full information to all market agents, utility maximization by consumers, and profit maximization by producers. These basic assumptions, while allowing characterization of larger-scale impacts on the economy, are also the main source of criticism as to how CGE model arrives at the solutions. The "all markets clear" approach implies that the model starts at equilibrium (baseline), and then baseline values of the variables are changed to represent the policy impact. Through supply, demand, and most importantly, price adjustment and investment adjustments, a new equilibrium emerges - one unique solution representing a post-shock snapshot of the economy at its new balance point. This mechanism of arriving at the solution enables CGE to account for 
many of the I-O modeling framework's limitations (including substitution effects, supply constraints for labor and capital, which in turn endogenously raises the prices and dampens economic effect).

\section{A.4 Econometric Models}

Example: RAND, Ramey (UCSD)

Econometric models of employment are often thought to provide more realistic solutions than classical static or dynamic CGE models, or the I-O framework. Statistical research first develops a set of functional relationships that describe impacts of various factors on employment. These functional relationships are tested on data. Successfully specified models are grounded in real world data specific to the analyzed phenomena. Therefore the solutions are driven by 1) historical data, and 2) the selected functional form for describing the relationships of interest. While these two aspects represent advantages of the econometric approach, they are also subject to criticism. First, if the functional relationship is mischaracterized by a researcher, then even the best possible dataset will produce unreliable solutions. Second, being a data-driven method, availability of relevant data is often a challenge that forces researchers to use alternative frameworks (CGE or I-O, which primarily rely on established data-driven snapshots of the economy at equilibrium). Another distinction is that econometric models can track policy effects over time. They can be used effectively either for short-term or long-term analysis.

\section{A.5 Hybrid Frameworks}

\section{Example: REMI's Policy Insight}

Hybrid models most frequently rely on econometric and I-O models linked into one analytical framework. Typically these models are more complex than simply combining I-O or econometric approaches as they require a common integrating framework and take more resources to develop and parameterize. They are often organized as system flow models where labor and capital, output, population and other aspects are included as separate submodels that are linked to each other. This integration of multiple submodels, each tuned to characterize a specific aspect of the economic activity, allows dynamic analysis to project what changes in the economy as a result of a shock, as well as the timing of the changes. While these models allow complex detailed simulations, they are by far the most resource-intensive to develop, validate and maintain. 


\section{Appendix B}

\section{Quantitative Assessment of Employment Multipliers in Selected Studies}

The primary rationale for undertaking energy efficiency policies should ultimately be based on the improvement in overall productivity in the economy and to the extent that environmental externalities are mitigated, rather than on wage income increased or net jobs created. That said, given the levels of overall unemployment experienced in the U.S. since 2008, policymakers concerned with energy efficiency are especially interested in assessing whether new energy efficiency initiatives would also have positive impacts on the level of overall employment. It is perhaps in that vein that an effort to understand the methods and results of past studies should best be considered.

\section{B.1 Modeling Approaches and Issues Faced in Comparing Models}

The articles and reports produced by Pacific Northwest National Laboratory (PNNL), (e.g., Scott et al. 2008, and Scott et al. 2009), a related series of short papers and documents by ACEEE (Bell 2012a, Bell 2012b, Bell 2012c, ACEEE 2012), and a resource guide prepared for states by the Environmental Protection Agency (EPA 2011) provide very succinct discussions of the methodology generally used to estimate employment impacts from typical energy efficiency (EE) policies. ${ }^{28}$ Almost exclusively, these methods rely on input-output models and data to consider the differential impacts across industry sectors that such policies are likely to produce.

In general, the typical methodology using such models has considered two ways in which energy efficiency is likely to affect the overall level of employment in the economy. The first is the employment generated by the efficiency investment itself. The input-output approach can provide an estimate of the both the jobs directly associated with the investment activity plus the associated ("indirect") jobs that support the sector from which the investment is made. Moreover, the use of input-output methods also can capture additional jobs that are created from the increase in income that ensues in the wake of the initial investment ("induced" jobs).

The second way in which energy efficiency is presumed to generate greater employment is through the redirection of money saved on energy toward other goods and services in the economy. The employment increase comes from the differential labor use per dollar of output between energy and non-energy sectors of the economy. Energy sectors - that include electric and gas utilities selling directly to end users - have distinctly lower labor requirements (both in terms of direct and "indirect" jobs) per dollar of sales as compared to an average of non-energy industries. Thus, there is a straightforward impact that tends to favor more employment as the savings in energy bills are redirected as spending on other goods and services in the economy.

It is important to note that the relative magnitudes of the two separate effects on employment will change depending on the time horizon of an energy efficiency policy. The investment aspect of the efficiency investment affects employment only in the period in which the investment is made. The "redirection"

\footnotetext{
28 "Policies" here includes both tax and other policy actions, as well as efficiency programs run by governments and utilities.
} 
effect of energy bill savings is a function of the investment in both the current and previous time periods, assuming that energy efficiency measures from those investments have a life-span of multiple years.

Casey Bell, the principal author of the recent ACEEE materials cited above, makes the important point that in analyzing job impacts of an efficiency investment one must consider "gross" versus "net" jobs. Notably, in her white paper (2012a) she clearly discusses the opportunity cost of the funds used to support the efficiency investment (in her example, "the city's funds [that] otherwise would have been spent in a 'business-as-usual' spending pattern"). The real issue is the extent to which the energy efficiency investment comes at the expense of other investment or consumption spending in the economy and thus leads to an offsetting impact on jobs. This topic has also been considered in depth in the reports Pacific Northwest National Laboratory has issued to document its ImSET (input-output based) model used to analyze the economic impacts of DOE energy efficiency programs (Scott et al. 2008 and Scott et al. 2009).

Note that there are other employment impacts in addition to net job creation from the energy efficiency investment itself. The energy sectors are typically more capital-intensive relative to non-energy sectors, as measured by the share of income that accrues to capital as compared to labor. Thus, the redirection savings from lower energy bills may result in more wage income overall, but that will be a function of the average annual pay on the jobs replacing jobs in the higher paying energy-providing sectors. After all, greater labor-intensity reflects that for certain activities (a) there is a limit to how much capital can be used (say in a restaurant or a hotel), and (b) that labor is the cheaper input to production compared to another unit of capital. In contrast, the energy-generating sectors are more capital-intensive; they employ fewer units of labor per $\$ 1$ million of output, but those workers are rewarded for their higher labor productivity with higher annual pay. Increased aggregate wage income may stimulate the economy, at least in short run, but may come at the cost of a slightly higher proportion of lower-paying jobs overall.

As a major element of this study, PNNL was engaged to review the relevant literature associated with energy efficiency policies and programs, paying particular attention to how employment impacts were estimated in these studies. While most of these studies have used an input-output modeling approach to conduct an analysis, there is considerable variation in how this approach has been applied.

\section{Key Multipliers}

An overarching goal of the work is to determine whether there are some simple multiplicative factors that can be extracted from these studies that can provide a short-hand method of assessing employment impacts from future energy efficiency policies and programs at both the national and state levels. To be specific, these factors are economic "multipliers" that can convert anticipated levels of efficiency investment and resulting energy savings to first-order estimates of employment impacts.

Given the background, the review of past studies has focused on three elements:

- The level of employment associated with the efficiency investment (jobs created per dollar of energy efficiency investment).

- The level of employment associated with the redirection of energy bill savings (jobs created per dollar of energy bill savings). 
- Consideration of the "opportunity cost" of the investment, as emphasized by PNNL and Bell thus influencing whether the number of jobs created per/dollar investment is "gross" or "net."

Another very high-level multiplier may relate to jobs generated per physical unit of energy (e.g., Trillion Btu) saved from the program. It should be noted that this multiplier is subject to a variety of influences such as the amount of investment required to save a unit of energy in any given location or time frame, as well as the prevailing prices of energy. Nevertheless, lacking specifics with regard to investment or consumer bill savings in the published studies, this metric may serve a useful purpose.

Ten national studies were identified as ones where suitable "employment multipliers" could be extracted. As mentioned in Section 2 of the report, there has been considerable variation in how the input-output modeling approach has been applied. In some studies, only the employment impact from the efficiency investment appears to have been considered. In others, only the effect from the redirection of bill savings has been estimated. While the majority consider both effects, only in a few cases are the effects clearly delineated in the report such that separate multipliers can be calculated. Finally, it appears that none of the studies have considered the opportunity cost of the efficiency investment.

\section{Data and Models}

The majority of studies considered below use data from the Impact Analysis for Planning (IMPLAN) data base maintained by the IMPLAN Inc. ${ }^{29}$ The underlying data behind IMPLAN are derived from the comprehensive input-output tables published by the Bureau of Economic Analysis (BEA) in the U.S. Department of Commerce. IMPLAN Inc. provides an annually adjusted updated version of the U.S. input-output tables and also provides regionalization of the U.S. structure down to the county and zip code levels, based on a proprietary regional purchase coefficient modeling methodology.

ACEEE has been responsible for a greater number of national-level studies of energy efficiency initiatives than any other single organization. In their recent studies, they have employed an internally developed model, its $\underline{D} y n a m i c \underline{E}$ ergy $\underline{\text { Efficiency }} \underline{\text { Policy }} \underline{\text { Evaluation }} \underline{\text { Routine }}$ (DEEPER) ${ }^{30}$ modeling system. ACEEE summarizes DEEPER as "a dynamic input-output (I-O) model of the U.S. economy that leverages information about how different institutions - households, industries, businesses, and governments - trade goods and services with one another to estimate the impact that a given policy or investment will have on the larger economy." Although ACEEE has embedded a 15-sector input-output structure within DEEPER, it acknowledges IMPLAN as the source of the underlying data.

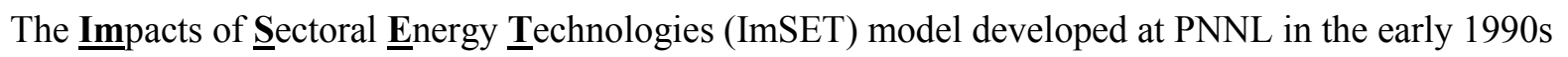
takes its input-output information directly from the official BEA input-output tables. The input-output table is aggregated to 177 sectors, as compared to the 360 sectors in the most recent (2007) input-output table available from BEA.

One study to be discussed below relies in part on the Energy Information Administration's (EIA's) National Energy Modeling System (NEMS). NEMS is a large-scale model of the U.S. energy sector,

\footnotetext{
${ }^{29} \mathrm{http}: / / \mathrm{implan} \cdot \mathrm{com} /$

${ }^{30} \underline{\mathrm{http} / / / \text { aceee.org/files/pdf/fact-sheet/DEEPER_Methodology.pdf }}$
} 
with detailed submodels for energy supply and end-use energy demand. NEMS also includes an econometrically-based macroeconomic model of the U.S. that contains statistical relationships for overall labor supply and demand.

\section{B.2 Specific Results for National-Level Studies}

Table B.1 was constructed to help explain how employment multipliers associated with the various published studies were derived. The purpose of each of the columns is summarized as follows:

Information about the studies. The first three columns provide the 1) study name (from its citation in the annotated bibliography), 2) the scope and time frame of the study, and 3) the method or tool used.

Multipliers used to derive results. The next set of columns (4) through (6) presents the multipliers that can be either taken from the study as published or can be derived from numbers presented in the study. In the former case, the authors present the relevant multipliers from which the employment estimates were made (based on their own or external input-output modeling work). In all cases where the multipliers were shown directly in the study, they have been shown in bold in the table. Where they have been derived from the aggregate numbers, they are shown in normal font.

Methods. Columns (7) through (10) convey the extent to which the study corresponded to the recommended approach outlined by Casey Bell or PNNL. Column (7) addresses how the investment was financed; i.e. whether any opportunity cost in terms of reduced activity elsewhere in the economy was considered. Columns (8) through (10) display the type of employment impact considered in the report: 1) investment only, 2) redirection of consumer savings only, or 3) both.

Key aggregate results. The next set of four columns show the relevant magnitudes of key metrics associated with the efficiency analysis. The columns in order show: 1) employment impact [jobs or jobyears], 2) investment (millions of dollars), 3) energy savings (TBtu), and 4) energy cost savings (millions of dollars). The right-most two columns in the table display notes and specific tables or page numbers in the report from which values were taken.

Before turning to a discussion of the specific studies, some brief discussion of the distinction between jobs and job-years is warranted. One job-year is defined as full-time employment for one person for the duration of one year. Some of the studies of multi-year investment programs present employment impacts in terms of job-years rather than jobs in specific year. This is especially the case when investment is undertaken over a number of years. Each year's investment can be assumed to generate a specific number of jobs and those jobs can be added up over the duration of the programs. Typically, the employment impact associated with the redirection of consumer energy savings is presented in terms of the number of jobs for a given year. It is important to note that these (additional) jobs will persist after all investments have been made, at least to the extent that energy continues to be saved from the past investment activity. The important point is there is no quantitative difference in employment multipliers, either expressed as the total number of job-years divided by the total investment over an unspecified time period, or expressed as the number of jobs generated in a single year by spending in that same year. In other words, across the studies examined, "jobs" and "job-years" are typically used interchangeably, Because the employment multipliers are more commonly expressed in terms of jobs per million dollars, 
it should always be viewed as jobs lasting for a period of one year; that is the metric displayed in columns (4) through (6). Column (11) shows either "jobs" or "job-years", depending on the choice of that metric used in the particular study.

\section{Specific Studies}

Garrett-Peltier 2011. The first study shown in Table B.1 is that authored by Heidi Garrett-Peltier for the Political Economy Research Institute (PERI) at the University of Massachusetts, Amherst. The study was directed toward analyzing the impacts from DOE's Better Building Initiative and was focused on retrofits of commercial buildings.

The report presented tables of multipliers for specific types of retrofit activities, including both retrofits and actions to improve building operation. The multipliers shown in bold (13.6 and 17.3) reflect these activities, respectively. Table 8 in her report presents the employment impact from the tax incentive portion of the Better Buildings Initiative. The values in columns (10) and (11) provide the number of jobyears $(57,106)$ and total investment $\left(\$ 4,000\right.$ million) for the program. ${ }^{31}$ The implied multiplier is shown in column (4) as 14.3. This value is consistent with weighted average of the cited multipliers for retrofit investment and building operations, with most of weight associated with retrofit investment. As such the report provides a clear linkage between the IMPLAN multipliers and the estimate of total impacts from the investment.

The situation is nearly the same for the redirection effect, but with some uncertainty. The report shows an annual savings of $\$ 1,450$ million as shown in column (14) in this table here. This savings is assumed to generate 20,183 jobs, or as indicated in the table, 20,183 job-years. The implied multiplier of 13.9 , however, is exactly the same multiplier as directly cited in the Garrett-Peltier report for the job impact associated with the spending of a million dollars by real estate establishment spending. Thus, it appears most likely the 20,183 figure applies to jobs in the terminal year of the program (with the savings of $\$ 1,450$ million), and that any loss of jobs in the energy sector has not been considered. Somewhat less likely is a case where an offsetting job loss in the energy sector has been considered, and that the calculated multiplier of 13.9 does, in fact, apply to job-years rather than jobs. Given that all multipliers from IMPLAN were carefully documented in the report, the omission of multipliers for the energy sector suggests the former interpretation is correct.

In spite of this difficulty with the employment impact associated with the redirection of savings, the report is clear about how the IMPLAN-based multipliers were derived, and more importantly, makes a clear distinction between jobs (actually job-years) associated with the investment and the jobs (or jobyears) associated with redirection of spending.

Burr et al. 2012. Similar in basic form to the 2011 Garrett-Peltier study was a later PERI study that examined the impact of a national policy to develop energy ratings for multi-family and commercial building. This is the (Burr et al. 2012) study, listed as study number 5 in Table B.1 In this study, only the

\footnotetext{
${ }^{31}$ Column numbers pertaining to Table B.1 are shown above the column text headings.
} 
input multipliers are listed. Note the similarity in the multipliers for "capital upgrades" (12.9) and the very similar value for "building retrofit investment" (13.6) in the Garrett-Peltier study.

The Burr et al. study also considered the impact from the redirection of energy savings stemming from the improved energy efficiency stimulated by the ratings system. In this case, some of the cost savings for multi-family buildings is assumed to accrue to the residents of the buildings (and thus affect household consumption) rather the pattern of spending by building owners. This assumption has the effect of slightly influencing the final employment multiplier for this building subsector. The text in the report clearly states that there is an offsetting loss of jobs in the energy sector from the redirected savings, which appears as the "net" multipliers (9.88 and 9.70) shown in column (6) of Table B.1.

Rockefeller Foundation 2011. This study examined a large-scale national effort to retrofit residential and commercial buildings. No specific time was provided in the report, but the report indicated the level of investment needed to generate large energy savings. The multipliers for retrofit investment activities for detailed buildings sectors are shown in bold in column (4) of Table B.1. As point of comparison, the (in this case, calculated) multiplier for commercial retrofits (12.8) is very similar to that in the two prior reports.

The report does not consider any employment impact from the bill savings for either residential or commercial building owners. While the report discusses issues related to financing of building retrofit investments, there is no recognition of opportunity costs in terms of the real economic variables such as reduced consumption or investment elsewhere in the economy.

Gold et al. 2011. In contrast to the Rockefeller (2012) report, the Gold et al. (2011) study from ACEEE appears to consider only the employment impacts associated with redirected savings. This study seeks to estimate the employment impacts associated with the federal appliance and equipment energy efficiency standards program. No aggregate investment with regard to the increased costs of more efficient appliances was provided in the report. The report suggests that the "employment outcomes are driven primarily by the changes in the demand for energy services as a result of appliance standards energy savings" (emphasis added).

The report presents estimates of the employment impacts from an aggregation of existing efficiency standards, as well as the impacts from prospective standards. As shown in the first row related to this study in the table, the value of energy savings from existing standards in 2010 was \$38 billion with estimated employment impact of 380,000 jobs. Consequently, the implied (or assumed by Gold et al., see below) multiplier is 9.9, as shown in column (6) in the table. Using the same procedure for the report's estimated employment impacts for both existing and prospective standards in 2020 and 2030, the implied multipliers fall to 6.0 and 5.6 in those years, respectively. The reduction may be due to methodology in the report that reduces the impact of existing standards over time, under the assumption that higher efficiency levels eventually become part of the baseline. To quote from the study, "After the end of the first measure life (i.e., the useful life of the product) we assume savings attributable to the standard decays at $5 \%$ each year. In other words, $5 \%$ of the new, more efficient appliances purchased in each year are attributed to increases in efficiency that would part of the business-as-usual scenario, not the baseline." Another factor that results in the lower values for these multipliers in the later year is that more money is being used to repay the loans that originally financed the some of the energy efficiency investments. Any 
effect due to the study's method of reducing the effect of standards over time would be expected to be smaller for analysis of prospective standards, especially for the impacts shown for 2020. (That is, the useful lives of equipment for prospective standards would likely all extend to sometime later than 2020). Unfortunately, the report does not break out the bill savings only for the prospective standards for 2020 or 2030. As an approximation, the estimated bill savings were developed under the assumption that the average energy prices for energy saved under the prospective standards would be the same as the average price of energy saved by the existing standards. Thus, the bill savings (in col. 14, shown in red) for prospective standards were estimated by prorating the reported bill savings for existing-plus-prospective standards by the reported energy savings in column (13). Using these values to calculate the "redirection savings" multipliers in column (6) yields values of 7.2 and 6.3 .

The reported values in the report do provide a means to calculate the multipliers with respect to amount of energy saved (jobs per TBtu, primary). These values are shown in column (5) of the table. For the first three rows pertaining to this study, the pattern of multipliers is generally consistent between those based on energy consumption savings (col. 5) and energy expenditure savings (col. 6).

An important note is that the authors explicitly point to an approximate value of 10 for the multiplier associated with a reduction in energy expenditures. A summary figure in the report shows the number of jobs per million dollars of revenue to various sectors of the economy, supporting the author's statement that "the impact of a million dollars of consumer energy bill savings implies a net gain of roughly 10 jobs (or about 17 jobs in a more typical set of consumer purchases compared to 7 jobs supported by electric and gas utilities)." This value appears to be the one used to estimate the 2010 employment impact from "existing" appliance and equipment standards. The report does not provide sufficient discussion that allows one to understand exactly why the implied multipliers are lower for 2020 and 2030.

Wei et al. 2009. The study by Max Wei et al. (2009), published in the Energy Journal, sought to estimate the employment impact from a comprehensive "clean-energy" strategy for the U.S. The model synthesizes data from 15 job studies covering renewable energy (RE), energy efficiency (EE), carbon capture and storage (CCS) and nuclear power. The report provides only a single value for a jobs multiplier related to energy efficiency, a value derived from an average of two prior studies. As indicated in the article, the derived value was 0.38 job-years per GWh of electricity savings. The study is represented in Table B.1as study 5. The multiplier was converted to jobs per TBtu of primary energy (assuming a conversion of $10,240 \mathrm{Btu} / \mathrm{kWh}$ ). According to the report, the multiplier reflects $90 \%$ respending of savings and 10\% investment, (see note in column (15) of the table). The use of a metric of job-years rather than jobs in a given year is somewhat confusing in that "respending" effects are typically presented in terms of impacts for a single year. The value of 37.1 (job-years/TBtu) is considerably lower than the values implied in the Gold et al. discussed above [as seen from column (5) in the table].

The next three studies to be discussed all deal with comprehensive energy efficiency policies and programs to reduce U.S. energy consumption over the long term. Unfortunately, all of these studies emphasize bottom-line results in terms of overall savings and employment impacts and provide little discussion of the detailed methodologies. The reports do not clearly separate out the employment impacts from investment versus the redirection of consumer energy bill savings. Moreover, two of the reports include efficiency policies affecting the transportation sector and provide no means of allocating economy-wide impacts between buildings, industry, and transportation. 
Rhodium Group 2013. The first of these studies is that performed by the Rhodium Group for the Alliance to Save Energy in 2013. This study was designed to explore the implications of a doubling of "energy productivity" by 2030 for the U.S. (As a practical matter, this doubling was defined in terms of energy consumption per dollar of GDP, and not a doubling of energy efficiency as defined by the majority of energy analysts.).

The Rhodium Group used their own version of the NEMS (2012) along with a 2011 version of IMPLAN to develop their estimates of employment and income. The report indicates that IMPLAN was used to consider the job impacts associated with the redirection of consumer bill savings. However, the change in employment resulting from the NEMS macroeconomic model was also considered. At this point, it is expedient to simply excerpt the relevant discussion from the report that deals with employment:

We combine the IMPLAN model of the US economy and the IHS Global Insight Macroeconomic Model integrated in NEMS to assess the net impact of this mix of factors on overall US employment. Investing \$166 billion in energy-efficient buildings, industrial equipment, vehicles and transportation systems produces 2.28 million jobs (Table 3 ). The construction and manufacturing sectors see significant gains, and when workers in those industries spend their paychecks the service, wholesale and retail trade sectors get a boost. As households and businesses spend the $\$ 372$ billion in projected energy savings (net of investment costs), another 5.1 million jobs are created, primarily in the service, wholesale and retail trade sectors.

Offsetting these gains are employment declines resulting from a reduction in revenue to the energy industry. Mining employment (which includes coal, oil and natural gas) falls by 240,000 and wholesale and retail trade employment falls by 2.1 million, primarily due to less demand for labor at gasoline stations. Finally, using the IHS Global Insight model we estimate that broader macroeconomic effects would reduce the employment gains of efficiency investment and energy savings by an additional 991,000 jobs. That leaves a net increase in US employment in 2030 of 1.3 million as a result of doubling American energy productivity.

The first line in Table B.1 associated with this report (Study 6) attempts to impute a multiplier associated only for the buildings sector. From Table 1 in the Rhodium Group report, total energy expenditure savings (from both energy efficiency and lower energy prices is $\$ 494$ billion in 2030, of which $\$ 167$ billion is attributable to buildings. In this first row, the total employment impact incorporating the negative "broader macroeconomic effects" is 1.268 ("1.3") million jobs. Allocating on the basis of expenditure savings, this translates the jobs from the buildings energy efficiency initiatives as 429,000 as shown in column (11) of the table. Thus, the employment multiplier for the "redirection" of energy savings calculated to be 2.6 jobs/\$million.

The report also suggests that a portion of the 2030 employment impact is attributable to investment activity. If one assigns the same (total) employment increase as coming solely from the investment channel, then the $\$ 72$ billion of investment in buildings converts to an investment multiplier of 6.0 (jobs/ $\$ 1$ million) as shown in column (4) of the table. The report indicates that investment figures shown are "annualized using sector-specific interest rates and financing terms." Thus, the investment impact is not comparable to the other studies considered here, as those studies provide the actual investment 
occurring in a single year or over a period of years. However, as the first paragraph in the above excerpt from the report suggests, there is deemed to be an explicit impact on jobs in 2030 from investment-as somewhat vaguely defined.

A more appropriate comparison of the results from the Rhodium Group study should remove the influence of the macroeconomic module in NEMS (with its economy-wide reduction of nearly one million jobs in 2030). The second row in the Table B.1 pertaining to this study excludes this effect and then recomputes the multipliers estimated for the buildings sector. As expected the multipliers all increase to levels closer to those shown in some the studies considered earlier.

The third line in the table presents the economy-wide investment multiplier implied by the IMPLAN aggregate employment impact of 2.268 million jobs in 2030 and the total "investment" across all sectors of $\$ 166$ billion. This results in an investment multiplier of 13.7 shown in column (4) of the table. It is uncertain whether this is an investment multiplier comparable to other studies, as the $\$ 166$ billion represents an annualized value across the entire policy period, rather than the investment in 2030 per se. (One could estimate the 2030 investment if information were provided on the general path of investment over the time frame of the study.)

Finally, it is interesting to examine the overall employment impacts for the spending redirection effect when a transportation policy is included in the analysis. Based upon the IMPLAN multiplier, the study appears to conclude that there are net job losses economy-wide. Note the phrase in the second paragraph of the report excerpt that there were significant offsetting job losses in the retail sector "primarily due to less demand for labor at gasoline stations."

Laitner et al. 2012. The next study to be discussed is the recent ACEEE study by Laitner et al (2012). This study (number 7 in Table B.1) goes out the farthest into the future of any of the studies considered here (2050). While the study uses the ACEEE DEEPER model (input-output based, with IMPLAN data), it does not explicitly break out the separate pathways of employment impact that were emphasized in immediately preceding reports and papers produced by Bell (and others) at ACEEE. Moreover, the study also includes a transportation analysis. While the report produces detailed energy savings by sector and for two efficiency scenarios, there is no presentation of the economic or employment impacts attributable to the individual sectors.

In the second line associated with this study, total energy bill savings of $\$ 723$ billion is shown, as derived from Appendix Figure B-2 in the report. Using the reported impact of an additional1.3 million jobs in 2050, an implied savings redirection multiplier of 1.8 is calculated. This value is considerably smaller than those previously considered. It is likely that the job increases that are typically associated with building-related energy efficiency programs are offset when electricity production is spurred by a program in another sector.

The report states that some of the job impacts in 2050 are due to the ongoing investment activity. For instance, the comment is made that "the very large improvements that might be possible for the year 2050 will be the result of decisions, behaviors, and investments that will have to be made beginning next year and continuing right on through 2050." Given this statement, an alternative multiplier (i.e., for investment) was based upon the assumption that all of the increased employment in 2050 was due to investment in that year. The problem is that there is no presentation of a year-by-year path of investment. 
The study reports that "more than half of the program effort and investment activity occurs in the last 10 years of the time horizon." Here it is assumed that the 2050 investment would be twice that of the average annual investment for the 39-year time period (again, for the "Advanced scenario.") Using the reported total investment of $\$ 2.4$ Trillion, this assumption results in a 2050 investment of about $\$ 123$ billion. Converted to an employment multiplier for investment, this results in a value of 10.6 (jobs/\$million) as shown in column (4) of the table.

As indicated clearly in the report, the macroeconomic (employment) impacts were developed using ACEEE's DEEPER model. Unfortunately for the purpose of the present study, the report as it stands does not provide a detailed discussion of how the elements of that model were used to represent the separate ways energy efficiency would influence jobs in 2050.

Research into Action 2013. This report presents the results of a preliminary energy savings and economic impact analysis of the Better Buildings Neighborhood Program (BBNP). The BBNP is an energy efficiency program administered by the U.S. Department of Energy's Office of Energy Efficiency and Renewable Energy. Much of the initial funding beginning in 2010 was through the American Recovery and Reinvestment Act (ARRA). The BBNP program is directed entirely toward building retrofits, both residential and commercial. Over the evaluation period considered in this report (fourth quarter 2010 through second quarter 2012), about $80 \%$ of the total retrofit cost was related to residential buildings.

Similar to Koson et al. (2013), the discussion of the economic impacts does not contain detailed information on exactly how IMPLAN was used. Specifically, it is also not clear the extent to which any impact of the redirected energy cost savings factor into the reported employment impact. The report, however, does permit one to develop an approximate estimate of the overall multiplier associated with the investment aspect of the program. The report indicates that total spending over the evaluation period was $\$ 525.5$ million and that consumer bill savings over that same period was $\$ 27.8$ million. Under the assumption that 10 jobs (in the context of this report, person-years) are generated per million dollars of bill savings, it is possible to subtract an approximate number of person-years from this effect $(=10 \times 27.8$ $=278$ ) and consider all other person-years $(6,681-278=6,403)$. Dividing this adjusted number by $\$ 525.5$ million suggests a (gross) jobs multiplier of 12.2 that is related to the efficiency investment. ${ }^{32}$

Young et al. 2013. The final study to be considered in this targeted analysis of recent national-level efficiency studies is the 2013 ACEEE report that examined the proposed Shaheen-Portman energy bill [introduced by Senators Jeanne Shaheen (D-NH), and Rob Portman (R-OH)]. For the purpose of the present study, this report is particularly appropriate as it addresses energy efficiency policies affecting the buildings sectors (and to a lesser extent, the industrial sector). More than two-thirds of the net economic savings are attributable to enhanced building energy codes. The analysis here considers the set of initiatives entitled "Group A."

Based upon separately calculated implied multipliers, it is clear that the ACEEE analysis appears to involve both ways in which energy efficiency influences employment. The report, however, does not contain sufficient detailed results to disentangle these separate effects. Solely as an exercise, some

\footnotetext{
${ }^{32}$ It should be noted that some amount of the $\$ 525.5$ million was for "program spending on things such as contractor training or marketing loan offerings," according to Matt Koson, a principal contributor of the 2013 report. (Personal communication via e-mail message on May 14, 2014.) As result, the multiplier derived in the manner shown above may be slightly understated compared to some other studies.
} 
assumed multipliers were used to see how close one could approximate the ACEEE employment impact estimate for 2020. As shown in the first row associated with this study (number 9), the (gross) investment multiplier was set to a value of 13 and the savings redirection multiplier was set to 10 (both in red bold type). Using these multipliers with the estimated investment and consumer energy bill savings values yields an estimate of about 64,000 jobs as shown (in red italics) in column (11). This figure is consistent with the actual estimate shown in the report of 70,000 jobs, and thus provides a modest level of confidence that these values approximate those effectively used in this ACEEE study.

The same set of calculations was performed for the 2030 numbers presented in the report. In this case, the assumed multipliers yielded a much higher figure (320,000 jobs) than that shown by ACEEE $(172,000$ jobs). Obviously, this simplified characterization of the ACEEE approach is not appropriate for extended time horizons.

Subsequent discussion with ACEEE indicated that a number of separate effects were modeled (in DEEPER) and underlie the aggregate results presented in the report. The energy efficiency investments are developed for each of the major elements of the Shaheen-Portman bill. There are differential impacts on jobs depending upon the degree to which the investments are financed over a period of years, or are assumed to displace current consumption. In later years, these investments must be repaid and so the resulting negative influence on employments grows over time. The energy efficiency investments are not constant over time (as was assumed in the very simple test of the assumed multipliers considered above). Accordingly, these aspects of the ACEEE methodology help to explain why the estimated employment impact from simple use of two multipliers substantially overestimates the actual ACEEE results.

The conclusion after the discussion with ACEEE staff was that it would very difficult to extract a simple multiplier to represent the investment impacts on jobs from the legislation. However, it appears that a reasonable approximation to a multiplier associated with the redirection of consumer savings would be about 9 , based upon the data underlying their DEEPER model. ${ }^{33}$

Garrett-Peltier 2010. The last two studies, strictly speaking, are not employment impact studies of any particular program or policy, but they provide some relevant information with regard to such studies. The first of these studies (number 10) shown in Table B.1 is the Ph.D. dissertation written by Heidi GarrettPeltier in 2010 (Garrett-Peltier 2010). Garrett-Peltier tested several variants of how to best represent an energy-efficiency investment within an input-output model framework. Her work is also valuable as it included some survey results to try to best characterize the jobs associated with various categories of energy efficiency investments. In a category she labeled as "Green Building" (including new building design and energy retrofits), the resulting investment multipliers ranged roughly between 9 and 10 (jobs per million dollars), depending on the way the category was handled within the input-output framework. The multipliers are smaller than those in the first two studies in Table B.1, principally because they do not include any induced effects on employment. Some further discussion of Garrett-Peltier's dissertation is included in Appendix C.

Goldman et al. 2010. The final entry in Table B.1 references a report jointly authored by researchers at the Lawrence Berkeley National Laboratory and staff at the consulting firm Research into Action. A

\footnotetext{
${ }^{33}$ Personal communication with Jim Barrett of ACEEE on April 29, 2014.
} 
principal aim of the study was to measure the size of the current U.S. workforce involved in providing energy efficiency services. The study focused on the workforce related to building energy efficiency, those "personnel "needed to design, implement, manage and evaluate energy efficiency programs and to design, construct, install efficient building systems"

The study employed an extensive set of interviews ( $\sim 300)$ with "program administrators, education and training providers, regulatory staff and a variety of EESS [energy efficiency services sector] employers, trade associations, and unions; communications with over 50 sector experts; as well as an extensive literature review." Based upon this process, the study was able to develop estimates of the number of EESS (full-time) jobs that would be generated per million dollars of efficiency investment. Based on the data for 2008, an average of 6.3 jobs is created per million dollars of investment, but there is a significant range underlying this average. For energy services companies (ESCOs) the survey results suggested about 2.5 jobs per million dollars of investment, while for weatherization and insulation activity 8.9 jobs are generated. These values do not include indirect or induced jobs from such investment. (The overall magnitude of the energy efficiency services sector in 2008, as defined in this study, is discussed in a longer summary of this report in Section C.5). 
Table B.1. Employment Multipliers Derived from Selected Studies

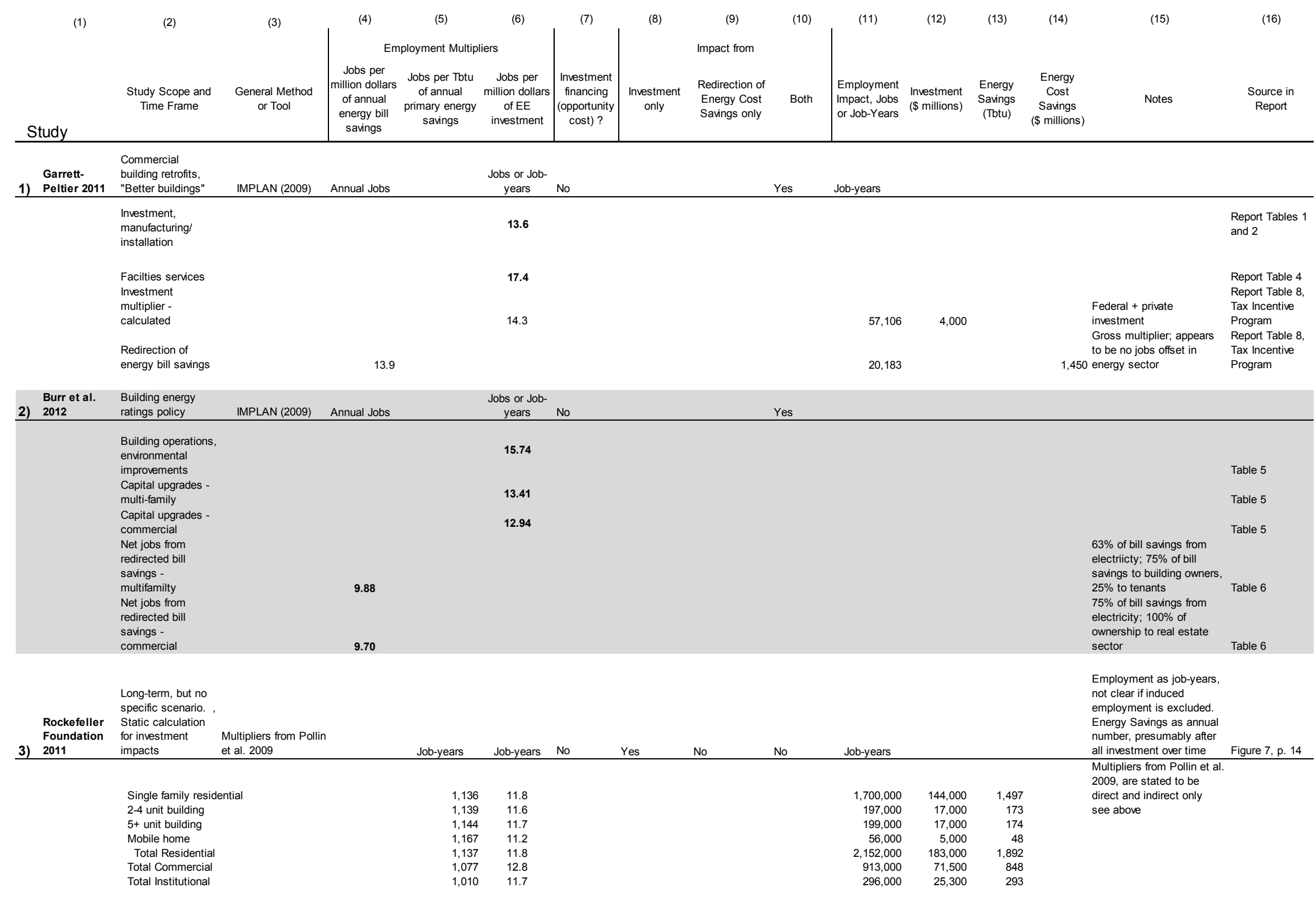


Table B.1. Employment Multipliers Derived from Selected Studies (cont'd)

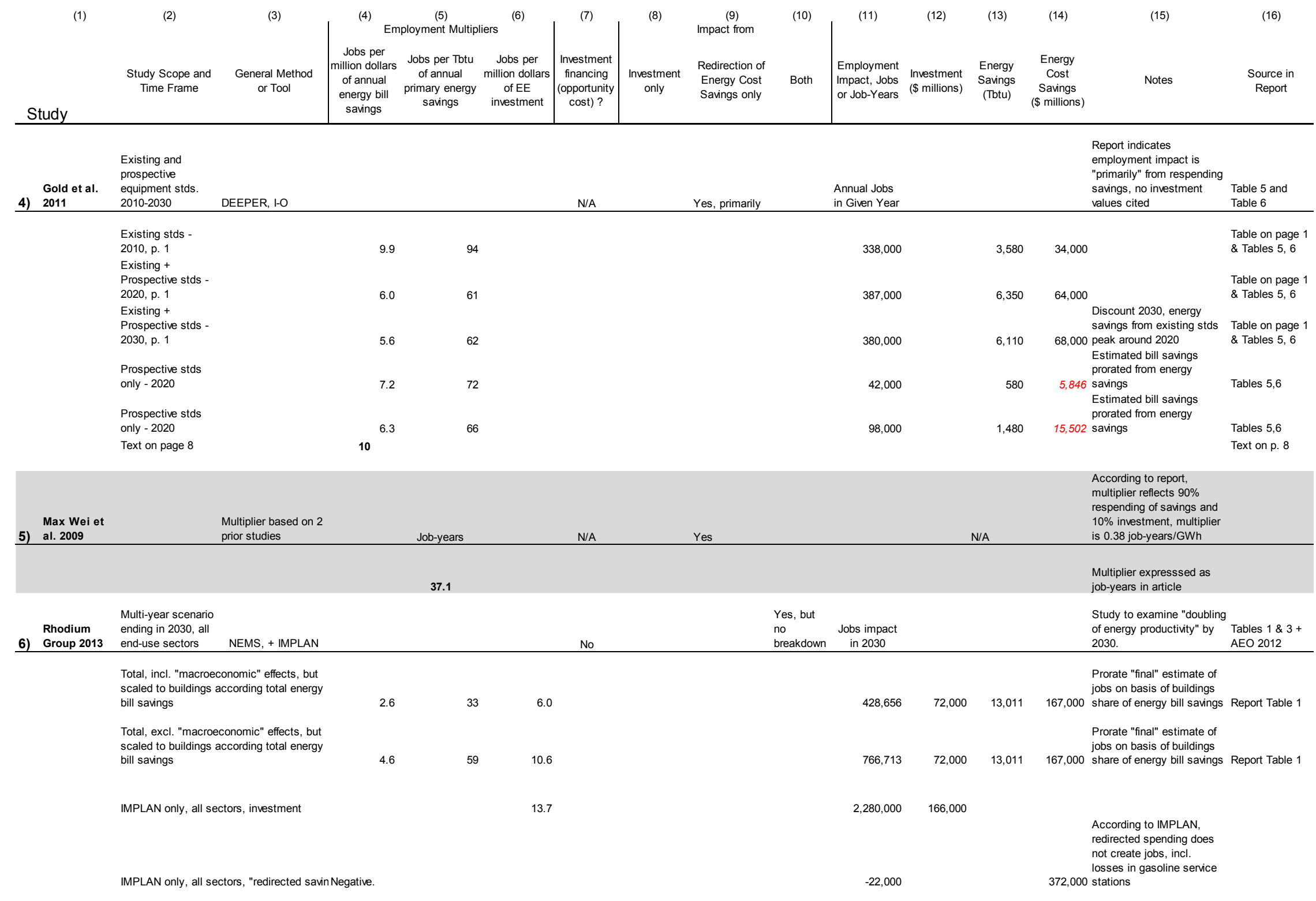


Table B.1. Employment Multipliers Derived from Selected Studies (cont'd)

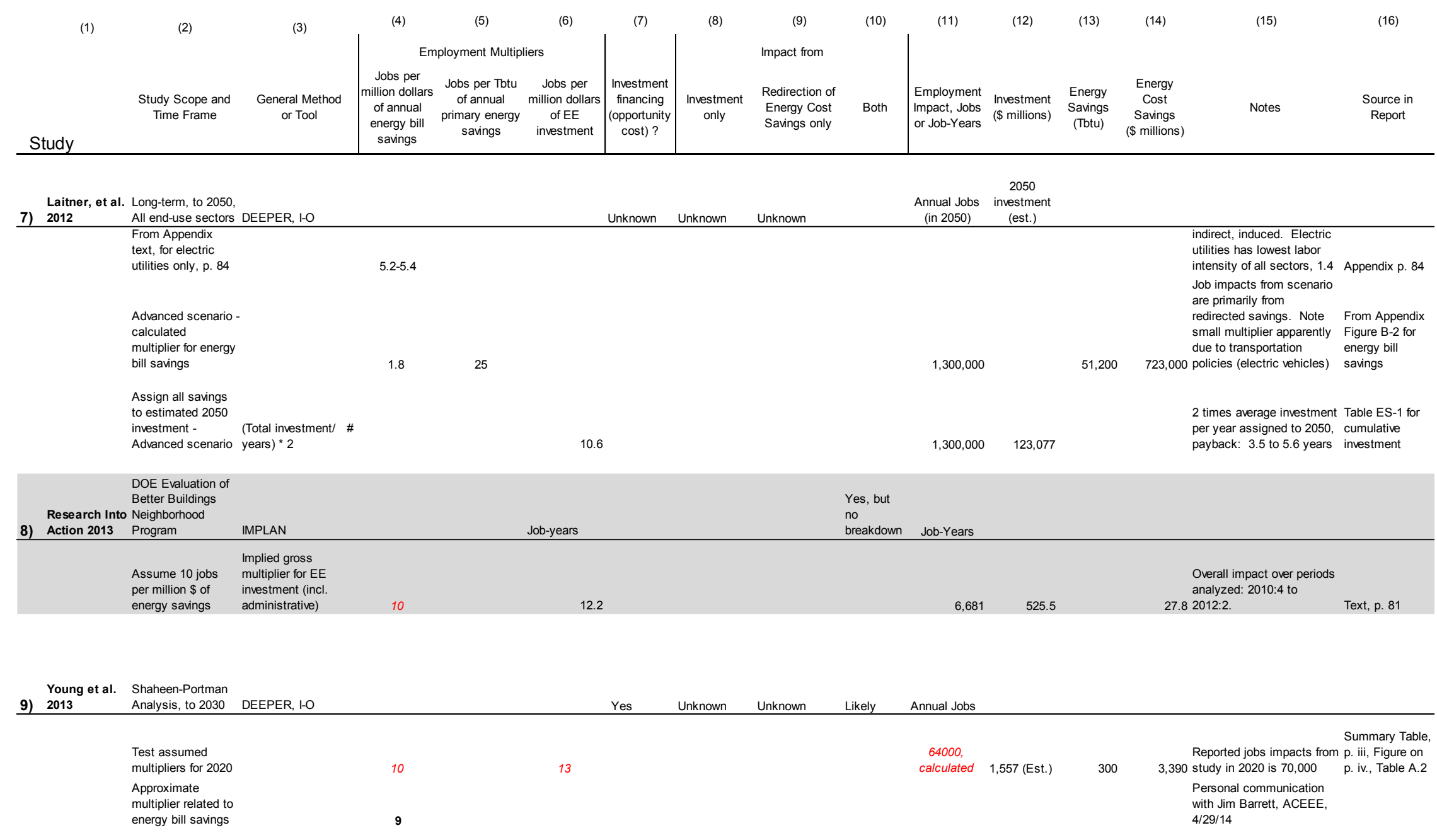


Table B.1. Employment Multipliers Derived from Selected Studies (cont'd)

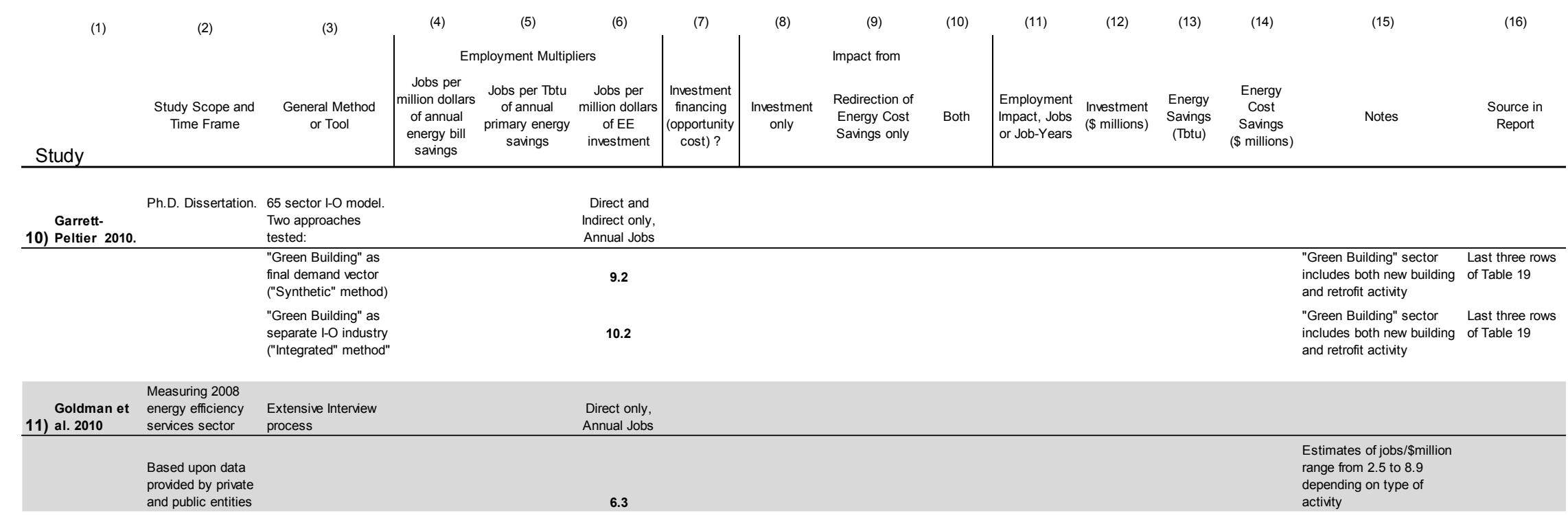




\section{Appendix C}

\section{Summary Literature Review}

This appendix presents a review of more than 50 studies that have addressed in some manner the impact on employment from energy efficiency policies and programs. For each study, an effort has been made to provide a brief description of the study's purpose, scope, and analytical methods. The focus in the review is to examine the methods and results of those aspects of the study that are concerned with employment impacts, and more specifically, to the issue of whether any type of "jobs multiplier" can be determined. It should be recognized that many of the studies are primarily concerned with estimating the energy savings from policies and programs; those elements of the studies are generally ignored in this review.

The studies have been organized into five broad categories as follows:

- National-Level Impact Studies (Section C.1)

- National Studies of State-Level Impacts (Section C.2)

- Regional and State-Specific Impact Studies (Section C.3)

- Studies Related to American Recovery and Reinvestment Act (ARRA) (Section C.4)

- Miscellaneous Studies (Section C.5)

With only a few exceptions, all of the studies have been published since 2000. Thus, they represent recent methods and data that have been used to estimate employment impacts. Within each major category, the studies are presented in order of most recent to oldest.

The list of studies was developed primarily from web searches that involved key words such as "energy efficiency," "employment impacts," "job impacts," "buildings and equipment," - with an effort to include only those studies that combined several of these aspects. The search also looked for entries that included names of specific models (e.g., IMPLAN). A focus was also directed toward energy efficiency studies that involved primarily the building sector, and to a lesser extent (if at all) the industrial sector. Some studies were omitted because they were concerned primarily with fuel standards or, more broadly, transportation. There is no presumption that the studies included here are exhaustive of this current literature. However, it is believed that they clearly represent the principal types of studies - with the most up-to-date methods and data — that have been performed over the past decade. ${ }^{34}$

\footnotetext{
${ }^{34}$ An annotated review that included some slightly older, state-level, studies (1995-2005) was made by John Laitner while he was on the staff of the Office of Atmospheric Studies in the Environmental Protection Agency. That review can be accessed at: http://fourfact.com/images/uploads/SKP State_2005.pdf.
} 


\section{C.1 National-Level Impact Studies}

Within the category of national models, a distinction is made between those that are generally based on econometric analysis at the macroeconomic level and those that employ detailed sectors, typically using input-output data and methods. It is recognized, however, that sometimes a model will blend elements of both approaches.

\section{C.1.1 Econometric/Macroeconomic Models}

Appleby J. 2013. "Canada's Integrated Energy and Macro Economic Modeling of Energy Efficiency Gains", Presented at the IEA Workshop on Capturing the Multiple Benefits of Energy Efficiency, January 25, 2013. Paris, France.

This presentation was made to an IEA Workshop held in January 2013. John Appleby, of Natural Resources Canada (NRC), presented the results of simulations made to explore the macroeconomic impacts of energy efficiency policies. The simulations involved two hybrid modeling approaches: 1) Environment North East [Canada] using the REMI Model, and 2) Integrated Energy 2020/Informetrica Model. The Informetrica macroeconomic model of Canada is no longer supported, so the brief summary below focuses on the results from the REMI model (still actively developed by a U.S. firm). As shown in the presentation materials, the basic approach is conventional in that major aspects of an energy efficiency policy are included: 1) reduced local sales of energy, 2) "Investment tied to new technologies," 3) energy savings to participants, and 4) ratepayer effects. The presentation indicates that net annual energy cost savings ("avoided costs less efficiency costs) were $5 \%$ for electricity and $4 \%$ for natural gas under what was termed a "Mid Scenario" energy efficiency policy (where efficiency investments were made over the first fifteen years of the simulation). Over the full simulation period, 20122040, the cumulative increase in GDP for four northeast Canadian provinces was simulated to be $\$ 45$ billion, and the increase in job-years was 330,000. In terms of program and energy efficiency investment impacts, the employment "multipliers" were 57 job-years per million dollars of program spending, and 29 job-years per million dollar of program-plus-participant spending. Of the overall job gains, the direct energy efficiency investment contributed about $15 \%$ and the "direct and indirect effect in services account[ed] for about $84 \%$ of employment [impacts]." http://www.iea.org/media/workshops/2013/roundtableonmacroecoemploymentimpactsofee/16 Jo hnAPPLEBY.pdf

Barker T. 2013. "Macroeconomic impacts of energy-efficiency policies." Presented at the IEA Workshop on Capturing the Multiple Benefits of Energy Efficiency, January 25, 2013. Paris, France.

This presentation was made to the International Energy Agency in 2013. The bottom line was that energy-efficiency policies lead to economic growth as measured by gross domestic product (GDP) and consequently to an increase in employment. The presentation references what were termed "New economics models" that apparently combine econometric and computable general equilibrium (CGE) concepts within a dynamic model of the economy. Results from the United Kingdom were shown in the presentation, based upon the MDM-E3 Multisectoral Dynamic Model, including energy-environment-economy (E3) interactions. 
http://www.iea.org/media/workshops/2013/roundtableonmacroecoemploymentimpactsofee/4_Ter ryBarker.pdf

\section{C.1.2 National Models with Sectoral Disaggregation (Input-Output) Hayes S, G Herndon, JP Barrett, J Mauer, M Molina, M Neubauer, D Trombley, and L Ungar.}

2014. "Change Is in the Air: How States Can Harness Energy Efficiency to Strengthen the Economy and Reduce Pollution." Report E1401. American Council for an Energy-Efficient Economy. Washington, D.C. April 2014.

This most current ACEEE study "evaluates the implications of using end-use efficiency to reduce greenhouse gas emissions from the power sector." The study was motivated by President Obama's decision to direct the Environmental Protection Agency (EPA) to regulate greenhouse gases from existing power plants, under the provisions of Section 111(d) of the Clean Air Act.

ACEEE examined the impacts of a strategy by which states could implement Section 111(d), and achieve a $25 \%$ reduction in national electricity use by the year 2030 compared to 2012 . The strategy developed by ACEEE considered four major policy options available to a state:

- Implement an energy efficiency target

- Enact national model building codes

- Construct combined heat and power systems

- Adopt efficiency standards and products

In terms of national impacts, the ACEEE study indicates that these actions would, by 2030, reduce carbon emissions by $26 \%$ (compared to 2012), save over 925 MWh of electricity, and obviate the need for 500 (500 MW) power plants. Economic impacts would include an increase in the GDP of $\$ 17$ billion and produce a net gain of 611,000 jobs. Consumers would save about $\$ 95$ billion on their annual electricity bills.

In addition to these national impacts, ACEEE also examined the impacts of its proposed initiatives for each state, and for each of the above policy options. Percentage electricity savings in 2030 ranged between 19\% and 39\% across states. ACEEE also included an estimate of the net jobs gained in each state.

As in recent studies, ACEEE used its Dynamic Energy Efficiency Policy Routine, or DEEPER model. As characterized by ACEEE, DEEPER "is a 15-sector quasi-dynamic input-output (I-O) model of the U.S. economy that draws upon social accounting matrices from the Minnesota IMPLAN group, energy data from the U.S. Energy Information Administration's Annual Energy Outlook, and employment and labor data from the Bureau of Labor Statistics."

DEEPER accounts for both major pathways of the influence of energy efficiency on employment, namely: 1) the jobs associated with the investment itself (and any offsetting changes to finance that investment), and 2) the jobs associated with the redirection of energy cost (bill) savings from energy to non-energy goods and services. In its application of DEEPER, ACEEE also considers temporal effects on jobs when long-term financing is undertaken, noting that (net) jobs are 
created during those periods in which efficiency investments are significant, but later recognizing potential losses in jobs as repayments are made.

Because all of these modeling elements underlie the ACEEE estimates of future job impacts, multipliers that capture only a single effect can only be derived through special simulations of DEEPER, and the report offers no detail to even approximate such multipliers. However, one can surmise that the major impact on jobs in 2030 stems from the redirection of consumer bill savings. On the basis of other recent studies using IMPLAN, a conservative estimate of this multiplier is 9 jobs per million dollars of consumer cost savings. Taking the report's estimate of $\$ 95$ billion in cost savings in 2030 and multiplying by 9 , yields a net employment impact of 855,000. The lower ACEEE estimate of 611,000 is consistent with offsets to this higher value resulting from repayment of earlier efficiency-related loans, and ACEEE's assumed long-term increases in labor productivity (that would reduce the number of jobs for any given level of spending in real dollars).

Research into Action. 2013. Preliminary Energy Savings Impact Evaluation: Better Buildings Neighborhood Program. Prepared for U.S. Department of Energy, Office of Energy Efficiency and Renewable Energy. November 2013.

(A summary of this comprehensive report is included in the first entry in Section C.4)

Young R, S Hayes, S Nadel, G Herndon, and JP Barrett. 2013. Economic Impacts of the Energy Provisions in the Energy Savings and Industrial Competitiveness Act of 2013 and Selected Amendments. ACEEE White Paper, American Council on Energy-Efficient Economy, Washington, D.C. September 2013.

This report estimated energy savings, provision by provision, in a proposed bill with bipartisan support, "Energy Savings and Competitiveness Act of 2013" (S. 1392), with assumptions based on data from the Annual Energy Outlook 2013 (EIA 2013). (This bill is perhaps more generally known as the Shaheen-Portman bill reflecting the two senators who are its primary sponsors.) Cost and energy savings calculations were then run through ACEEE's DEEPER input-output economic-modeling system to estimate economy-wide impacts including the net increase in jobs and impact on Gross Domestic Product (GDP). The DEEPER model is briefly described in Appendix E of the report.

For the purpose of the current study for DOE, this report is particularly appropriate as it addresses energy efficiency policies affecting the buildings sectors (and to a lesser extent, the industrial sector). More than two-thirds of the net economic savings are attributable to enhanced building energy codes.

The report apparently considers both the investment and redirection (of energy bill savings) pathways through which increased energy efficiency would promote greater employment. The report itself does not provide sufficient information to break out the relevant contributions of both effects. If one gross assumes an investment multiplier of 13 and a "bill savings redirection" multiplier of 10 , then a calculated job increase of 64,000 in 2020 is reasonably close to the 70,000 
figure shown in the report (for a set of measures including "Group A" provisions of the bill). See the additional discussion of this report in Appendix B.

Lecca P, P McGregor, JK Swales, and K Turner. 2013. "The Added Value from General Equilibrium Analyses from Increased Efficiency of Household Energy Use." Department of Economics, University of Strathclyde, Glasgow, Scotland.

From the paper's abstract: The aim of the paper is to identify the added value from using general equilibrium techniques to consider the economy-wide impacts of increased efficiency in household energy use. We take as an illustrative case study the effect of a 5\% improvement in household energy efficiency on the UK economy. This impact is measured through simulations that use models that have increasing degrees of endogeneity but are calibrated on a common data set. That is to say, we calculate rebound effects for models that progress from the most basic partial equilibrium approach to a fully specified general equilibrium treatment. The size of the rebound effect on total energy use depends upon: the elasticity of substitution of energy in household consumption; the energy intensity of the different elements of household consumption demand; and the impact of changes in income, economic activity and relative prices. A general equilibrium model is required to capture these final three impacts. Rhodium Group. 2013. American Energy Productivity: The Economic, Environmental and Security
Benefits of Unlocking Energy Efficiency. Prepared for The Alliance to Save Energy. February 2013.

This study was designed to explore the implications of a doubling of U.S. "energy productivity" by 2030 for the U.S. (As a practical matter, this doubling was defined in terms of energy consumption per dollar of GDP, and not a doubling of energy efficiency as defined by the majority of energy analysts.).

The Rhodium Group used their own version of EIA's National Energy Modeling System (NEMS), (2012 version) along with a 2011 version of IMPLAN to develop their estimates of employment and income. The report indicates that IMPLAN was used to consider the job impacts (apparently) associated with the redirection of consumer bill savings, but that the employment results from the NEMS macroeconomic model was also considered. The excerpt below contains the relevant discussion from the report that deals with employment:

We combine the IMPLAN model of the US economy and the IHS Global Insight Macroeconomic Model integrated in NEMS to assess the net impact of this mix of factors on overall US employment. Investing \$166 billion in energy efficient buildings, industrial equipment, vehicles and transportation systems produces 2.28 million jobs (Table 3 ). The construction and manufacturing sectors see significant gains, and when workers in those industries spend their paychecks the service, wholesale and retail trade sectors get a boost. As households and businesses spend the $\$ 372$ billion in projected energy savings (net of investment costs), another 5.1 million jobs are created, primarily in the service, wholesale and retail trade sectors.

Offsetting these gains are employment declines resulting from a reduction in revenue to the energy industry. Mining employment (which includes coal, oil and natural gas) falls by 240,000 and wholesale and retail trade employment falls by 2.1 
million, primarily due to less demand for labor at gasoline stations. Finally, using the IHS Global Insight model we estimate that broader macroeconomic effects would reduce the employment gains of efficiency investment and energy savings by an additional 991,000 jobs. That leaves a net increase in US employment in 2030 of 1.3 million as a result of doubling American energy productivity.

The report does not break out the employment impacts from the energy savings generated in the major end-use sectors. Abstracting from the employment impacts from NEMS, the overall multiplier based on the economy-wide investment of $\$ 166$ billion and job impact of 2.28 million jobs is 13.7. From the second paragraph of the above excerpt and information provided in Table 3 in the report, the employment impact associated with an overall redirection of consumer bill savings was slightly negative. As intimated by the study authors, this overall result may be due to "less demand for labor at gasoline stations." Accordingly, for purposes of developing appropriate multipliers for the current (2014) DOE study, the study is of limited use.

Bell CJ. 2012c. "Understanding the True Benefits of Both Energy Efficiency and Job Creation," Community Development Investment Review, Vol. 10, Issue 1. Federal Reserve Bank of San Francisco.

This article in the Community Development Investment Review is primarily based upon Bell's white paper for the American Council for an Energy-Efficient Economy (Bell 2012a). The article lays out the general framework for ACEEE's employment impacts estimation, but is not quite as detailed as in the white paper.

American Council for an Energy-Efficiency Economy (ACEEE). 2012. "How Does Energy Efficiency Create Jobs?" ACEEE Fact Sheet. American Council for an Energy-Efficiency Economy, Washington D.C.

This three-page fact sheet lays out the analytical framework that ACEEE uses to estimate the jobs impacts associated with energy efficiency programs and measures. This material is essentially identical to Appendix A in the ACEEE white paper by Casey Bell (2012a). See discussion in that source below.

Bell CJ. 2012b. "How Does Energy Efficiency Create Jobs." American Council for an Energy-Efficient Economy. ACEEE blog posting. Available from: http://aceee.org/print/blog/2011/11/how-does-energyefficiency-create-job

The ACEEE blog article lays out the analytical framework that ACEEE uses to estimate the jobs impacts associated with energy efficiency programs and measures. It is essentially the same as Bell 2012a and ACEEE 2012. The last few paragraphs reference one earlier ACEEE study and one pending ACEEE study (Shaheen-Portman Senate bill) of the job impacts associated with several national energy efficiency initiatives. As a high-level summary piece, no detailed data are provided to permit calculation of employment impact multipliers.

At the end of this article, there is some discussion of the actual model that ACEEE uses to make employment and other macroeconomic estimates. This material is reproduced below: 
In recent years, ACEEE has explored how energy efficiency policies can drive net job creation using our in-house Dynamic Energy Efficiency Policy Evaluation Routine (DEEPER) modeling system. DEEPER evaluates the economy-wide impacts of a variety of energy efficiency, renewable energy, and climate policies at the local, state, and national level. It is a dynamic input-output (I-O) model of the U.S. economy that leverages information about how different institutions-households, industries, businesses, and governments - trade goods and services with one another to estimate the impact that a given policy or investment will have on the larger economy.

DEEPER utilizes jobs coefficients (e.g., the multipliers show in Figure 1) from the Impact Analysis for Planning (IMPLAN) Modeling System's data set. Our definition for jobs (see Table 1) is consistent with their definition, which they derive from the Bureau of Labor Statistics and the Bureau of Economic Analysis. Also, the IMPLAN multipliers account for leakages, or money that will be spent outside the region's economy.

Bell CJ. 2012a. "Energy Efficiency Job Creation: Real World Experiences." American Council for an Energy-Efficient Economy, Washington D.C. White paper. October 2012.

As indicated at the outset, "This report illustrates concrete ways in which energy efficiency has, in recent years, stimulated the creation of direct, indirect, and induced jobs. These vignettes [case studies] illustrate examples of job creation resulting from energy efficiency by profiling programs, policies, investments, partnerships, and business models that have catalyzed regional increases in employment." An extended appendix presents the overall analytical framework ACEEE uses to estimate the employment impacts from various energy efficiency policies and programs. At a very aggregate level, the author indicates that "on average, $\$ 1$ million spent in the U.S. economy supports approximately 17 total jobs (including direct, indirect, and induced jobs" (for all types of spending, not energy efficiency investments per se.) Notably, the white paper clearly discusses the opportunity cost of the funds used to support the efficiency investment (in the example, "the city's funds [that] otherwise would have been spent in a 'business-as-usual' spending pattern"). The difference in jobs associated with the original spending pattern and the energy efficiency spending pattern is appropriately defined as the "net" job impact. The paper distinguishes between the job impacts associated with the energy investment and the job impacts associated with re-allocation of spending resulting from lower energy expenditures. Thus, the paper clearly lays out the key elements of input-output based methodology, but provides little quantitative information with regard to typical elements of an energy efficiency policy analysis.

However, the paper does present labor intensity coefficients associated with various aggregate sectors of the U.S. economy, based on the 2009 IMPLAN data. Per million dollars of revenue the numbers of jobs by sector are as follows: total economy, 17.3; energy, 9.9; manufacturing, 13.8; construction, 20.3, trade and services, 18.8; and government, 21.0. (Thus, for example, if one considers the "opportunity cost" of an energy efficiency investment to be funded as a reduction of overall final demand spending in the economy, with a job multiplier of 17.3, then an energy efficiency investment consisting solely of construction would generate a net impact of three jobs per million dollars of investment ( 20.3 jobs -17.3 jobs). In addition to this "investment" impact, there would be additional jobs associated with the re-allocation of consumer spending as discussed in the white paper.) 
Burr A, C Majersik, S Stellberg, H Garrett-Peltier. 2012. Analysis of Job Creation and Energy Cost Savings from Building Energy Rating and Disclosure Policy Institute for Market Transformation, Washington D.C.

The Political Economy Research Institute (PERI) of University of Massachusetts, Amherst has published two relevant studies, one on energy efficiency retrofits for commercial buildings and the other on building energy data rating and disclosure policy. Both rely on the IMPLAN inputoutput model to estimate employment effects and utilize similar methodologies to apportion spending to industry categories within IMPLAN.

The first of these studies (Garrett-Peltier 2011) is described below. The second study, published in 2012 by the Institute for Market Transformation (IMT) and PERI, analyzed the potential of a national building energy rating and disclosure policy to create jobs and reduce energy-related expenditures in commercial and multi-family residential buildings. The analysis predicts such a policy would yield the following results:

Create more than 23,000 net new jobs in 2015 and more than 59,000 jobs in 2020, resulting from increased demand for energy efficiency services and technologies, and from the reinvestment of energy cost savings by consumers and businesses into the economy.

Building energy data rating and disclosure policy is assumed to affect employment in three ways: employment related to operational improvements, employment generated from the redirection of energy bill savings, and employment from the manufacture and installation of various energyefficient technologies.

Results indicate net job-creation rates of 15.74 jobs / \$1 million from operational improvements, $13.41 \mathrm{jobs} / \$ 1$ million and 12.94 jobs $/ \$ 1$ million for multi-family and commercial upgrades, respectively, and 9.88 jobs $\$ 1$ million and 9.70 jobs $/ \$ 1$ million for multi-family and commercial energy savings, respectively. Details are provided in the tables below.

Table 4: Employment Estimates per \$1 million in Expenditures, Operational Improvements

\begin{tabular}{|l|l|l|l|l|}
\hline & $\begin{array}{l}\text { Direct jobs } \\
\text { per \$1 million }\end{array}$ & $\begin{array}{l}\text { Indirect jobs } \\
\text { per \$1 million }\end{array}$ & $\begin{array}{l}\text { Induced jobs } \\
\text { per \$1 million }\end{array}$ & $\begin{array}{l}\text { Total jobs } \\
\text { per \$1 million }\end{array}$ \\
\hline Building operations & 7.80 & 4.30 & 4.84 & 16.94 \\
\hline Environmental Controls & 3.40 & 4.40 & 3.12 & 10.92 \\
\hline $\begin{array}{l}\text { Weighted average from } \\
\text { operational improvements } \\
\text { (80\% operations, 20\% } \\
\text { environmental controls) }\end{array}$ & 6.92 & 4.32 & 4.50 & 15.74 \\
\hline
\end{tabular}


Table 5: Employment Estimates per \$1 million in Expenditures, Capital Upgrades

\begin{tabular}{|l|l|l|l|l|}
\hline Multifamily Capital Upgrades & $\begin{array}{l}\text { Direct jobs } \\
\text { per \$1 million }\end{array}$ & $\begin{array}{l}\text { Indirect jobs } \\
\text { per \$1 million }\end{array}$ & $\begin{array}{l}\text { Induced jobs } \\
\text { per \$1 million }\end{array}$ & $\begin{array}{l}\text { Total jobs } \\
\text { per \$1 million }\end{array}$ \\
\hline Lighting & 4.82 & 4.24 & 3.62 & 12.68 \\
\hline HVAC & 5.03 & 4.31 & 3.74 & 13.08 \\
\hline Water Heating & 4.68 & 4.10 & 3.51 & 12.29 \\
\hline Appliance Upgrades & 3.91 & 4.38 & 3.32 & 11.61 \\
\hline Environmental Controls & 4.75 & 4.31 & 3.62 & 12.68 \\
\hline Envelope Improvements & 6.98 & 4.10 & 4.43 & 15.51 \\
\hline Weighted Average, Multifamily & 5.36 & 4.22 & 3.83 & 13.41 \\
\hline Commercial Capital & Direct jobs & Indirect jobs & Induced jobs & Total jobs \\
\hline Upgrades & per $\mathbf{\text { plillion }}$ & per \$1 million & per $\mathbf{\text { million }}$ & per $\mathbf{\text { million }}$ \\
\hline Lighting & 5.09 & 4.15 & 3.70 & 12.94 \\
\hline HVAC & 5.30 & 4.22 & 3.81 & 13.33 \\
\hline Motors and Drives & 4.53 & 3.94 & 3.39 & 11.86 \\
\hline Water Heating & 4.95 & 4.08 & 3.61 & 12.64 \\
\hline Office Equipment & 3.76 & 3.73 & 3.00 & 10.49 \\
\hline Environmental Controls & 5.00 & 4.30 & 3.70 & 13.00 \\
\hline Envelope Improvements & 7.70 & 3.90 & 4.70 & 16.30 \\
\hline Weighted Average, Commercial & 5.12 & 4.12 & 3.69 & 12.94 \\
\hline
\end{tabular}

Table 6: Employment Estimates per \$1 million, Energy Savings

\begin{tabular}{|l|l|l|l|l|}
\hline Jobs supported by energy spending & $\begin{array}{l}\text { Direct jobs } \\
\text { per \$1 million }\end{array}$ & $\begin{array}{l}\text { Indirect jobs } \\
\text { per \$1 million }\end{array}$ & $\begin{array}{l}\text { Induced jobs } \\
\text { per \$1 million }\end{array}$ & $\begin{array}{l}\text { Total jobs } \\
\text { per \$1 million }\end{array}$ \\
\hline Multifamily & 1.20 & 2.60 & 1.52 & 5.32 \\
\hline Commercial & 1.30 & 2.50 & 1.52 & 5.32 \\
\hline $\begin{array}{l}\text { Jobs created through consumption of non-energy } \\
\text { goods by building owners and tenants }\end{array}$ & $\begin{array}{l}\text { Direct jobs } \\
\text { per \$1 million }\end{array}$ & $\begin{array}{l}\text { Indirect jobs } \\
\text { per \$1 million }\end{array}$ & $\begin{array}{l}\text { Induced jobs } \\
\text { per \$1 million }\end{array}$ & $\begin{array}{l}\text { Total jobs } \\
\text { per \$1 million }\end{array}$ \\
\hline Multifamily & & & & \\
\hline Owners- High-income individuals (70\%) & 7.50 & 3.50 & 4.40 & 15.40 \\
\hline Owners- Real estate firms (30\%) & 7.20 & 3.60 & 4.32 & 15.12 \\
\hline Tenants & 7.00 & 3.60 & 4.24 & 14.84 \\
\hline Total (75\% owner/25\% tenant split) & 7.31 & 3.55 & 4.34 & 15.20 \\
\hline Commercial & & & & \\
\hline Owners- Real estate firms & 7.20 & 3.60 & 4.32 & 15.12 \\
\hline Tenants - Various types (see below) & 7.00 & 3.50 & 4.20 & 14.70 \\
\hline Total (75\% owner/25\% tenant split) & $\mathbf{7 . 1 5}$ & $\mathbf{3 . 5 8}$ & $\mathbf{4 . 2 9}$ & $\mathbf{1 5 . 0 2}$ \\
\hline $\begin{array}{l}\text { Net difference in jobs by shifting from energy } \\
\text { spending to non-energy spending (jobs created } \\
\text { through energy savings) }\end{array}$ & $\begin{array}{l}\text { Direct jobs } \\
\text { per \$1 million }\end{array}$ & $\begin{array}{l}\text { Indirect jobs } \\
\text { per \$1 million }\end{array}$ & $\begin{array}{l}\text { Induced jobs } \\
\text { per \$1 million }\end{array}$ & $\begin{array}{l}\text { Total jobs } \\
\text { per \$1 million }\end{array}$ \\
\hline Multifamily & 6.11 & 0.95 & 2.82 & 9.88 \\
\hline Commercial & 5.85 & 1.08 & 2.77 & 9.70 \\
\hline
\end{tabular}

http://www.peri.umass.edu/fileadmin/pdf/other_publication_types/PERI-IMT-2012Analysis Job_Creation.pdf

Burr, AC. 2012. Energy Disclosure \& the New Frontier for American Jobs. Institute for Market Transformation, Washington D.C.

This report provides a general discussion of the impacts from a national policy to create an energy rating system for U.S. nonresidential buildings. A general description of the report is provided on the Institute for Market Transformation website (www.imt.org) and excerpted below:

This report shows how a new kind of energy policy is creating skilled, export-proof jobs in cities across the United States. Under this type of policy, called building energy rating and disclosure, owners of large buildings track exactly how much energy their properties 
use. Armed with this information, they can make changes that reduce their utility bills and those of their tenants - helping everyone's bottom line.

When buildings' energy use is made transparent (given a grade that is published online or shared in a real estate transaction), it is like a fuel economy (MPG) sticker for buildings. Americans can shop for office space or a new apartment with an eye on how much it will cost them in utilities. That, in turn, spurs owners to make their buildings more efficient, creating demand for specialists who can help reduce energy use: energy managers and auditors, sustainability consultants, and HVAC professionals.

Energy Disclosure \& the New Frontier for American Jobs profiles business leaders who are adding jobs and expanding their client rosters. These are mostly small business owners who are pioneers in the emerging field of building energy management.

The Rockefeller Foundation. 2012. The United States Building Energy Efficiency Retrofits: Market Sizing and Financing Models. The Rockefeller Foundation and DB Climate Change Advisors (Deutsche Bank Group). March 2012.

This report presents estimates of energy savings and employment impacts that would result from an aggressive 10-year program to retrofit the nation's stock of residential, commercial and institutional buildings. According to the executive summary, this effort could result in a 30 percent reduction of total U.S. electricity consumption.

With regard to employment impacts, the report straightforwardly uses IMPLAN-based multipliers to estimate the job-creation impacts for various building subsectors. Figure 7 in the report shows the overall results by each of these subsectors for: a) energy savings, b) cumulative investment, c) total employment (job-years), and d) greenhouse gas emission reductions.

The report indicates that it used employment multipliers from a 2009 study - the Pollin et al. 2009 study shown in Section C4. However, as indicated in the notes to a key figure in the report, it seems more accurate to say that the report was based upon a methodology similar to Pollin et al. The implied multipliers do in fact differ slightly by building subsector.

As discussed in the excerpt below, the authors indicate that the underlying multipliers do not include "induced" effects. It appears that there is some confusion between the typical use of the term of "induced" in the context of "closed" input-output modeling approaches and the effect due to the "redirection" of energy expenditure savings from energy to non-energy goods. From the report (p.31):

It should be noted that the above estimates do not include induced employment effects (in other words, the employment effects that arise when people employed in direct and indirect jobs spend their salaries) due to the challenges in modeling these effects. The estimates in this study capture both direct and indirect employment impacts, the direct employment being related to the CIM (construction, installation and manufacture) phase of the projects, as well as their ongoing O\&M (operations and maintenance) requirements. The indirect employment is an estimate of the supply chain impacts that stem from the CIM phase (jobs that are created by suppliers who are providing the new equipment). We do not include the potential "induced" employment impacts with respect 
to energy efficiency initiatives that are designed to reduce the rate of growth in power demand over the forecast period. That is, reduced energy consumption by households and businesses saves them money which, in turn, allows them to spend more, creating further employment demand in the economy not specifically attributable to the assumed change in energy supply mix. Although there is an expected positive effect of induced job creation, we do not include it here because it is difficult to accurately measure without a complex integrated economy-wide input/output model. As such, these may represent more conservative estimates than have been published elsewhere.

Clearly the report only includes the investment pathway by which job creation occurs. There is no recognition in the report of the opportunity cost of this investment in terms of any offsetting job losses in the economy.

Laitner J, S Nadel, RN Elliott, H Sachs, and A Siddiq Khan. 2012. “The Long-Term Energy Efficiency Potential: What the Evidence Suggests." Report No. E121. American Council for an EnergyEfficiency Economy. Washington, D.C. January 2012.

This ACEEE study by Laitner et al. (2012) examined the long-term economic consequences of efforts to substantially lower its energy consumption and expenditures by 2050 . Two scenarios, encompassing all major end-use sectors in the economy, were considered in the report:

- Advanced Scenario: includes penetration of known advanced technologies, and

- Phoenix Scenario: includes greater infrastructural improvements and accelerated replacement of existing stock of energy-using equipment and buildings

While the study uses the ACEEE DEEPER model (input-output based, with IMPLAN data), it does not explicitly break out the separate channels of employment impact that were emphasized in immediately succeeding reports and papers produced by Bell and others at ACEEE. Moreover, as implied above, the study also includes a transportation analysis. While the report produces detailed energy savings by sector and for two efficiency scenarios, there is no presentation of the economic or employment impacts attributable to the individual end-use sectors (i.e., buildings vs. industry vs. transportation).

In the second line associated with this study, total energy bill savings of $\$ 723$ billion is shown, as derived from Appendix Figure B-2 in the report. Using the reported impact of an additional1.3 million jobs in 2050, an implied consumer bill savings redirection multiplier of 1.8 is calculated. Obviously, this value is considerably smaller than many of those in other reports considered. One hint provided by the report for this result is that the transportation policy yields an increase in electric powered vehicles. Thus, the job increases that are typically associated with building-related energy efficiency programs are offset when electricity production is spurred by a program in another sector.

As indicated clearly in the report, the macroeconomic (employment) impacts were developed using ACEEE's DEEPER model. Unfortunately, the report as it stands does not provide a detailed discussion of how the elements of that model were used to represent the separate channels of impact on jobs in 2050.

Saha, D. 2012. "Enact Legislation Supporting Residential Property Assessed Clean Energy Financing (PACE)." The Brookings Institution, Metropolitan Policy Program. Washington D.C. November 2012. 
Studies analyzing the economic effects of Residential Property Assessed Clean Energy Financing (PACE) programs suggest that they have the potential of generating significant positive economic and fiscal benefits. One study found that $\$ 4$ million in total PACE spending can generate on average \$10 million in gross economic output; \$1 million in combined federal, state, and local tax revenue; and 60 new jobs. The Brookings Institute extrapolated from this study, estimating that if just one percent of the 75 million owner-occupied homes in the U.S. were to invest in a PACE project that cost an average of $\$ 20,000$ each, the economic impact would translate to $\$ 15$ billion in gross economic output; $\$ 4$ billion in combined federal, state, and local tax revenue; and 226,000 new jobs.

The report addresses only the direct employment from the energy efficiency investment. From the "one study" that spending yields approximately 15 jobs [job-years] per million dollars of PACE spending, it is not clear as to how this value was derived. As a very short policy paper, it necessarily omits considerations as to how the investment will be financed (i.e., the foregone spending on other goods and services by people buying the municipal PACE bonds), nor does it consider the consumption spending re-allocation by households after the investment is made. It is not clear the extent to which the report drew upon the Brookings 2011 study "Sizing the Clean Economy: A National and Regional Green Jobs Assessment" - See below. http://www.brookings.edu/ /media/Research/Files/Papers/2012/11/13\%20federalism/13\%20hous ing $\% 20$ energy $\% 20$ efficiency.pdf

Gold R, S Nadel, JA Laitner, and A deLaski. 2011. Appliance and Equipment Efficiency Standards: A Money Maker and Job Creator. American Council for an Energy-Efficient Economy. Washington, D.C. January 2011.

For employment impacts, this ACEEE report used the DEEPER model. As a summary of overall impact, the report indicates that about 10 jobs are created for every million dollars of consumer energy bill savings. From Table 5 in the report, prospective appliance and efficiency standards (from the 2011 perspective) were estimated to save 0.58 quadrillion Btu (QBtu) in 2020 and 1.59 QBtu in 2030. The job impacts associated with those savings, primarily (see below) due to reallocation between energy and non-energy goods and services, were estimated to be 42 thousand and 98 thousand jobs in those two years, respectively (from Table 6). No aggregate investment with regard to the increased costs of more efficient appliances was provided in the report. The report suggests that the "employment outcomes are driven primarily by the changes in the demand for energy services as a result of appliance standards energy savings" (emphasis added).

Garrett-Peltier, H. 2011. Employment Estimates for Energy Efficiency Retrofits in Commercial Buildings. Research Brief, Political Economy Research Institute, University of Massachusetts-Amherst, Amherst, Massachusetts. June 2011.

The Political Economy Research Institute (PERI) of University of Massachusetts-Amherst has published two recent and relevant studies, one on building energy data rating and disclosure 
policy (Burr et al. 2012) and an earlier one on energy efficiency retrofits for commercial buildings (Garrett-Peltier 2011, as discussed here). Both rely on the IMPLAN input-output model to estimate employment effects and utilize similar methodologies to apportion spending to industry categories within IMPLAN.

The analysis of commercial building retrofit policy developed impact multipliers with a 2009 version of IMPLAN. Employment impacts were quantified for purchases of energy efficiency technologies, increased spending for facilities services, and decreased energy expenditures. The study did not specify net or gross employment impacts. Results indicate purchases of energyefficient technologies contribute 13.6 jobs/ $\$ 1$ million, increased facilities services contribute 17.4 jobs $/ \$ 1$ million, and reduced energy expenditures contribute 13.9 jobs $/ \$ 1$ million. The values are shown below as the (weighted) averages in the rightmost columns of the tables extracted from the report (Tables 7, 8, and 9 reproduced below). 
Table 7 Employment Impacts of Energy-Efficient Technology Manufacture and Installation

\begin{tabular}{|l|c|c|c|c|}
\hline EE technology group & $\begin{array}{c}\text { Direct employment } \\
\text { per \$1 million }\end{array}$ & $\begin{array}{c}\text { Indirect employment } \\
\text { per \$1 million }\end{array}$ & $\begin{array}{c}\text { Induced employment } \\
\text { per \$1 million }\end{array}$ & $\begin{array}{c}\text { Total employment } \\
\text { per \$1 million }\end{array}$ \\
\hline Lighting & 5.1 & 4.2 & 3.7 & 12.9 \\
\hline HVAC & 5.3 & 4.2 & 3.8 & 13.3 \\
\hline Motors and drives & 4.5 & 3.9 & 3.6 & 1.9 \\
\hline Water heating & 5.0 & 4.1 & 3.0 & 10.5 \\
\hline Office equipment & 3.8 & 3.7 & 3.7 & 13.0 \\
\hline Environmental controls & 5.0 & 4.3 & 4.7 & 16.3 \\
\hline Envelope improvements & 7.7 & 3.9 & 3.7 & 12.8 \\
\hline Straight average & 5.1 & 4.0 & 3.9 & 13.6 \\
\hline Weighted average & 5.7 & 4.1 & & 16 \\
\hline
\end{tabular}

\begin{tabular}{|l|c|c|c|c|}
\hline EE technology group & $\begin{array}{c}\text { Direct employment } \\
\text { per \$1 million }\end{array}$ & $\begin{array}{c}\text { Indirect employment } \\
\text { per \$1 million }\end{array}$ & $\begin{array}{c}\text { Induced employment } \\
\text { per \$1 million }\end{array}$ & $\begin{array}{c}\text { Total employment } \\
\text { per \$1 million }\end{array}$ \\
\hline Lighting & 5.1 & 4.2 & 3.7 & 12.9 \\
\hline HVAC & 5.3 & 4.2 & 3.8 & 13.3 \\
\hline Motors and drives & 4.5 & 3.9 & 3.4 & 12.6 \\
\hline Water heating & 5.0 & 4.1 & 3.0 & 10.5 \\
\hline Office equipment & 3.8 & 3.7 & 3.7 & 13.0 \\
\hline Environmental controls & 5.0 & 4.3 & 4.7 & 16.3 \\
\hline Envelope improvements & 7.7 & 3.9 & 3.7 & 12.8 \\
\hline Straight average & 5.1 & 4.7 & 3.9 & 13.6 \\
\hline Weighted average & 5.7 & 4.1 & & 16 \\
\hline
\end{tabular}

\begin{tabular}{|l|c|c|c|c|}
\hline EE technology group & $\begin{array}{c}\text { Direct employment } \\
\text { per \$1 million }\end{array}$ & $\begin{array}{c}\text { Indirect employment } \\
\text { per \$1 million }\end{array}$ & $\begin{array}{c}\text { Induced employment } \\
\text { per \$1 million }\end{array}$ & $\begin{array}{c}\text { Total employment } \\
\text { per \$1 million }\end{array}$ \\
\hline Lighting & 5.1 & 4.2 & 3.7 & 12.9 \\
\hline HVAC & 5.3 & 4.2 & 3.8 & 13.3 \\
\hline Motors and drives & 4.5 & 3.9 & 3.4 & 11.9 \\
\hline Water heating & 5.0 & 4.1 & 3.0 & 10.5 \\
\hline Office equipment & 3.8 & 3.7 & 3.7 & 13.0 \\
\hline Environmental controls & 5.0 & 4.3 & 4.7 & 16.3 \\
\hline Envelope improvements & 7.7 & 3.9 & 3.7 & 12.8 \\
\hline Straight average & 5.1 & 4.7 & 3.9 & 13.6 \\
\hline Weighted average & 5.7 & & \\
\hline
\end{tabular}




\begin{tabular}{|l|c|c|c|c|}
\hline EE technology group & $\begin{array}{c}\text { Direct employment } \\
\text { per \$1 million }\end{array}$ & $\begin{array}{c}\text { Indirect employment } \\
\text { per \$1 million }\end{array}$ & $\begin{array}{c}\text { Induced employment } \\
\text { per \$1 million }\end{array}$ & $\begin{array}{c}\text { Total employment } \\
\text { per \$1 million }\end{array}$ \\
\hline Lighting & 5.1 & 4.2 & 3.7 & 12.9 \\
\hline HVAC & 5.3 & 4.2 & 3.8 & 13.3 \\
\hline Motors and drives & 4.5 & 3.9 & 3.4 & 11.9 \\
\hline Water heating & 5.0 & 4.1 & 3.6 & 12.6 \\
\hline Office equipment & 3.8 & 3.7 & 3.0 & 10.5 \\
\hline Environmental controls & 5.0 & 4.3 & 3.7 & 13.0 \\
\hline Envelope improvements & 7.7 & 3.9 & 4.7 & 16.3 \\
\hline Straight average & 5.1 & 4.0 & 3.7 & 12.8 \\
\hline Weighted average & 5.7 & 4.1 & 3.9 & 13.6 \\
\hline
\end{tabular}




\section{Table 8 Employment Impacts of Facility Operations}

\begin{tabular}{|c|c|c|c|c|}
\hline Category & $\begin{array}{l}\text { Direct employment } \\
\text { per } \$ 1 \text { million }\end{array}$ & $\begin{array}{l}\text { Indirect employment } \\
\text { per } \$ 1 \text { million }\end{array}$ & $\begin{array}{l}\text { Induced employment } \\
\text { per } \$ 1 \text { million }\end{array}$ & $\begin{array}{c}\text { Total employment } \\
\text { per } \$ 1 \text { million }\end{array}$ \\
\hline \multirow{3}{*}{$\begin{array}{l}\text { Facility } \\
\text { operations }\end{array}$} & 8.0 & 4.4 & 5.0 & 17.4 \\
\hline & Industry composition (direct spending) & \multicolumn{3}{|c|}{ Industries indirectly impacted } \\
\hline & $\begin{array}{l}95 \% \text { facility support services, } \\
2.5 \% \text { belts and hoses, } 2.5 \% \\
\text { transformers, coils, inductors }\end{array}$ & \multicolumn{3}{|c|}{$\begin{array}{l}\text { Scientific and technical consulting, real estate, } \\
\text { telecommunications, architecture and engineering }\end{array}$} \\
\hline
\end{tabular}

\begin{tabular}{|l|c|c|c|c|}
\hline \multirow{2}{*}{ Category } & $\begin{array}{c}\text { Direct employment } \\
\text { per \$1 million }\end{array}$ & $\begin{array}{c}\text { Indirect employment } \\
\text { per \$1 million }\end{array}$ & $\begin{array}{c}\text { Induced employment } \\
\text { per \$1 million }\end{array}$ & $\begin{array}{c}\text { Total employment } \\
\text { per \$1 million }\end{array}$ \\
\hline \multirow{4}{*}{$\begin{array}{l}\text { Facility } \\
\text { operations }\end{array}$} & 8.0 & 4.4 & 5.0 & 17.4 \\
\cline { 2 - 5 } & \begin{tabular}{c} 
Industry composition (direct spending) \\
\cline { 2 - 5 }
\end{tabular} & $\begin{array}{c}95 \% \text { facility support services, } \\
2.5 \% \text { belts and hoses, 2.5\% } \\
\text { transformers, coils, inductors }\end{array}$ & \multicolumn{2}{|c|}{$\begin{array}{c}\text { Industries indirectly impacted } \\
\text { Scientific and technical consulting, real estate, } \\
\text { telecommunications, architecture and engineering }\end{array}$} \\
\hline
\end{tabular}

\begin{tabular}{|l|c|c|c|c|}
\hline \multirow{2}{*}{ Category } & $\begin{array}{c}\text { Direct employment } \\
\text { per \$1 million }\end{array}$ & $\begin{array}{c}\text { Indirect employment } \\
\text { per \$1 million }\end{array}$ & $\begin{array}{c}\text { Induced employment } \\
\text { per \$1 million }\end{array}$ & $\begin{array}{c}\text { Total employment } \\
\text { per \$1 million }\end{array}$ \\
\hline \multirow{4}{*}{$\begin{array}{l}\text { Facility } \\
\text { operations }\end{array}$} & 8.0 & 4.4 & 5.0 & 17.4 \\
\cline { 2 - 5 } & \begin{tabular}{c} 
Industry composition (direct spending) \\
\cline { 2 - 5 }
\end{tabular} & \multicolumn{2}{|c|}{$\begin{array}{c}\text { Industries indirectly impacted } \\
2.5 \% \text { facility support services, } \\
\text { transformers, coils, inductors }\end{array}$} & \multicolumn{2}{|c|}{$\begin{array}{c}\text { Scientific and technical consulting, real estate, } \\
\text { telecommunications, architecture and engineering }\end{array}$} \\
\hline
\end{tabular}

\begin{tabular}{|c|c|c|c|c|}
\hline Category & $\begin{array}{l}\text { Direct employment } \\
\text { per } \$ 1 \text { million }\end{array}$ & $\begin{array}{l}\text { Indirect employment } \\
\text { per } \$ 1 \text { million }\end{array}$ & $\begin{array}{l}\text { Induced employment } \\
\text { per } \$ 1 \text { million }\end{array}$ & $\begin{array}{l}\text { Total employment } \\
\text { per } \$ 1 \text { million }\end{array}$ \\
\hline \multirow{3}{*}{$\begin{array}{l}\text { Facility } \\
\text { operations }\end{array}$} & 8.0 & 4.4 & 5.0 & 17.4 \\
\hline & Industry composition (direct spending) & \multicolumn{3}{|c|}{ Industries indirectly impacted } \\
\hline & $\begin{array}{l}95 \% \text { facility support services, } \\
2.5 \% \text { belts and hoses, } 2.5 \% \\
\text { transformers, coils, inductors }\end{array}$ & \multicolumn{3}{|c|}{$\begin{array}{l}\text { Scientific and technical consulting, real estate, } \\
\text { telecommunications, architecture and engineering }\end{array}$} \\
\hline
\end{tabular}


Table 9 Employment Impacts of Reduced Energy Expenditures

\begin{tabular}{|l|c|c|c|c|}
\hline \multirow{2}{*}{ Category } & $\begin{array}{c}\text { Direct employment } \\
\text { per \$1 million }\end{array}$ & $\begin{array}{c}\text { Indirect employment } \\
\text { per \$1 million }\end{array}$ & $\begin{array}{c}\text { Induced employment } \\
\text { per \$1 million }\end{array}$ & $\begin{array}{c}\text { Total employment } \\
\text { per \$1 million }\end{array}$ \\
\hline \multirow{2}{*}{$\begin{array}{l}\text { Real estate } \\
\text { establish- } \\
\text { ment } \\
\text { spending }\end{array}$} & 6.5 & 3.4 & 4.0 & 13.9 \\
\cline { 2 - 5 } & $\begin{array}{c}100 \% \text { industry spending (industry } \\
\text { is all real estate establishments, } \\
\text { including commercial) }\end{array}$ & \multicolumn{2}{|c|}{$\begin{array}{c}\text { Industries indirectly impacted } \\
\text { Wholesale trade, truck transportation, services to } \\
\text { buildings, accounting, maintenance and repair } \\
\text { construction, architecture and engineering }\end{array}$} \\
\hline
\end{tabular}

\begin{tabular}{|l|c|c|c|c|}
\hline \multirow{2}{*}{ Category } & $\begin{array}{c}\text { Direct employment } \\
\text { per \$1 million }\end{array}$ & $\begin{array}{c}\text { Indirect employment } \\
\text { per \$1 million }\end{array}$ & $\begin{array}{c}\text { Induced employment } \\
\text { per \$1 million }\end{array}$ & $\begin{array}{c}\text { Total employment } \\
\text { per \$1 million }\end{array}$ \\
\hline \multirow{2}{*}{$\begin{array}{l}\text { Real estate } \\
\text { establish- } \\
\text { ment } \\
\text { spending }\end{array}$} & 6.5 & 3.4 & 4.0 & 13.9 \\
\cline { 2 - 5 } & $\begin{array}{c}100 \% \text { industry spending (industry } \\
\text { is all real estate establishments, } \\
\text { including commercial) }\end{array}$ & \multicolumn{2}{|c|}{$\begin{array}{c}\text { Industries indirectly impacted } \\
\text { buildings, accounting, maintenance and repair } \\
\text { construction, architecture and engineering }\end{array}$} \\
\hline
\end{tabular}

\begin{tabular}{|l|c|c|c|c|}
\hline \multirow{2}{*}{ Category } & $\begin{array}{c}\text { Direct employment } \\
\text { per \$1 million }\end{array}$ & $\begin{array}{c}\text { Indirect employment } \\
\text { per \$1 million }\end{array}$ & $\begin{array}{c}\text { Induced employment } \\
\text { per \$1 million }\end{array}$ & $\begin{array}{c}\text { Total employment } \\
\text { per \$1 million }\end{array}$ \\
\hline \multirow{3}{*}{$\begin{array}{l}\text { Real estate } \\
\text { establish- } \\
\text { ment } \\
\text { spending }\end{array}$} & 6.5 & 3.4 & 4.0 & 13.9 \\
\cline { 2 - 5 } & $\begin{array}{c}\text { Industry composition (direct spending) } \\
\text { 100\% industry spending (industry } \\
\text { is all real estate establishments, } \\
\text { including commercial) }\end{array}$ & \multicolumn{2}{|c|}{$\begin{array}{c}\text { Industries indirectly impacted } \\
\text { Wholesale trade, truck transportation, services to } \\
\text { buildings, accounting, maintenance and repair } \\
\text { construction, architecture and engineering }\end{array}$} \\
\hline
\end{tabular}

\begin{tabular}{|c|c|c|c|c|}
\hline Category & $\begin{array}{l}\text { Direct employment } \\
\text { per } \$ 1 \text { million }\end{array}$ & $\begin{array}{c}\text { Indirect employment } \\
\text { per } \$ 1 \text { million }\end{array}$ & $\begin{array}{c}\text { Induced employment } \\
\text { per } \$ 1 \text { million }\end{array}$ & $\begin{array}{c}\text { Total employment } \\
\text { per } \$ 1 \text { million }\end{array}$ \\
\hline \multirow{3}{*}{$\begin{array}{l}\text { Real estate } \\
\text { establish- } \\
\text { ment } \\
\text { spending }\end{array}$} & 6.5 & 3.4 & 4.0 & 13.9 \\
\hline & Industry composition (direct spending) & \multicolumn{3}{|c|}{ Industries indirectly impacted } \\
\hline & $\begin{array}{l}100 \% \text { industry spending (industry } \\
\text { is all real estate establishments, } \\
\text { including commercial) }\end{array}$ & \multicolumn{3}{|c|}{$\begin{array}{l}\text { Wholesale trade, truck transportation, services to } \\
\text { buildings, accounting, maintenance and repair } \\
\text { construction, architecture and engineering }\end{array}$} \\
\hline
\end{tabular}

http://www.peri.umass.edu/fileadmin/pdf/research_brief/PERI_USGBC_Research_Brief.pdf

This report is useful in providing a defensible characterization of the most common types of commercial building retrofit activities, and how those activities might translate into employment impacts.

Garrett-Peltier, H. 2010. "The Employment Impacts of Economy-wide Investments in Renewable Energy and Energy Efficiency.” Ph.D. Dissertation, University of Massachusetts-Amherst. Amherst, Massachusetts. September 2010. 
This dissertation examines the employment impacts of investments in renewable energy and energy efficiency in the U.S. The literature to date consists mainly of input-output (I-O) studies or case studies of renewable energy and energy efficiency (REEE). Ability to use the I-O model to study REEE is constrained since current industrial codes do not recognize this industry as such. The dissertation presents two methods to address the limitation, synthetic and integrated. Synthetic method relies on creating a vector of final demand (by assigning industries and weighs to the various REEE components) to proxy the REEE industry based on the industrial spending patterns of REEE firms. Integrated method formally incorporates REEE as a separate set of sectors into the I-O table. Estimates of the employment impacts from both methods are compared with similar estimates from the relevant literature. This analysis calculates an employment requirements matrix and employment multipliers.

Garrett-Peltier also considered a subsector of the REEE industry termed "Green Building and Retrofitting," which is of most relevance to the study here as it excludes renewable energy investment. "Green Building and Retrofitting," as stated by Garrett-Peltier, includes "green design (architecture and engineering), new construction and repair construction, construction education, and EE installation." When she develops a vector of final demand using the survey weights to define this subsector (the "synthetic method" as defined above), the total employment multiplier is 9.15. When this sector is integrated into the input-output structure ("integrated method), the calculated employment multiplier is 10.17. Note that neither of these multipliers incorporates any type of "induced" impact, as captured by the conventional use of IMPLAN employment multipliers. Garrett-Peltier's work provides a good discussion of how changes in the underlying data and methodology can yield a range of multipliers as well as showing the difficulty in assigning precise weighting of input-output sectors to represent a given policy of energy efficiency investments.

Houser T, S Mohan, and I Hoffman. 2010. “Assessing the American Power Act: The Economic, Employment, Energy Security, and Environmental Impact of Senator Kerry and Senator Lieberman's Discussion Draft.” Peterson Institute for International Economics. Washington, D.C. May 12, 2010.

This report developed an economic analysis of the proposed American Power Act sponsored by Senators Kerry and Lieberman. This bill represented a comprehensive energy and climate change strategy for the U.S.; details of the bill were made public in the spring of 2010. Trevor Houser, a partner at the Rhodium Group, was a visiting fellow at the Peterson Institute when this analysis was conducted. His co-authors were all associated with the Rhodium Group, an economics and investment consulting group headquartered in New York City.

The approach used in the study was to employ a modified version of the National Energy Modeling System (NEMS), (2009 version) to analyze key provisions of American Power Act. The authors made some modifications of the model to better represent the employment impacts of the proposed legislation. As they state, "Given that job creation is one of the principle objectives Senators Kerry and Lieberman seek to achieve with their proposal, we enhanced the model to provide a more accurate picture of the bill's potential employment impacts." 
As part of a comprehensive climate change bill, the American Power Act called for a system of trading carbon emission permits. Along with other incentives to increase production of renewable (and nuclear) electricity production, a major impact of the act is expected to be a substantial increase in investment by the electric utility industry. To better represent the employment stimulated by this investment, the value of additional investment by the utility sector was passed to the NEMS macroeconomic model. When all the complex interactions throughout the model were taken into effect, an average 206,000 additional jobs were projected to be generated over the first decade after implementation of the legislation. (In the subsequent decade, the impact was much lower, only about 6,000 jobs annually, due to higher energy prices and interest rates caused by the Act.)

Figure 3 in the report attributes an average of about 70,000 annual jobs to the energy efficiency provisions of the Act during the first 10 years. However, there are no other metrics in the report that would allow the calculation of an "employment multiplier" along the lines of the studies using IMPLAN or similar input-output modeling approach. As a final note, the report contains a very good general discussion (in several pages) of the overall methodologies that are available to estimate employment impacts from comprehensive climate change initiatives of the type considered.

Mehling M, A Best, D Marcellino, M Perry, and K Umpfenbach. 2010. Transforming Economies through Green Investment. The German Marshall Fund of the United States, Washington, D.C. January 2010.

This report considers the investment required to significantly reduce annual greenhouse gas emissions by 2035. The report relied on recent energy-investment estimates made by the International Energy Agency, the Stern Review and McKinsey \& Company. These studies - each widely recognized and of broad political impact — arrive at similar estimates of the investment needed. Based upon the investment requirements, the report examines various policy options to achieve these goals. There is no discussion of employment in quantitative terms in the report.

Wei M, S Patadia, and DM Kammen. 2009. "Putting Renewables and Energy Efficiency to Work: How Many Jobs can the Clean Energy Economy Generate in the United States." Energy Policy 38(2010):918-931.

From the Energy Journal abstract:

An analytical job-creation model for the U.S. power sector from 2009 to 2030 is presented. The model synthesizes data from 15 job studies covering renewable energy (RE), energy efficiency (EE), carbon capture and storage (CCS) and nuclear power. The paper employs a consistent methodology of normalizing job data to average employment per unit energy produced over plant lifetime. Job losses in the coal and natural gas industry are modeled to project net employment impacts. Benefits and drawbacks of the methodology are assessed and the resulting model is used for job projections under various renewable portfolio standards (RPS), EE, and low carbon energy scenarios. We find that all non- fossil fuel technologies (renewable energy, EE, low carbon) create more jobs per unit energy than coal and natural gas. Aggressive EE measures combined with a $30 \%$ RPS target in 2030 can generate over 4 million full-time-equivalent job-years by 
2030 while increasing nuclear power to $25 \%$ and CCS to $10 \%$ of overall generation in 2030 can yield an additional 500,000 job-years.

The method by these authors (at the University of California-Berkeley) to estimate jobs created from energy efficiency is succinctly described in the following paragraph extracted from the report:

In the energy efficiency sector we used a multiplier of 0.38 job-years/GWh of energy savings that is the average of Goldemberg (2009) and Laitner and McKinney (2008). We assume that the majority of jobs are induced jobs (90\%) and only $10 \%$ are direct jobs associated with energy efficiency products or installation, an assumption used by the ACEEE in the past (Geller, 1992). The business-as-usual (BAU) case of energy demand already assumes a certain amount of energy savings and energy efficiency-induced jobs due to existing building codes and appliance standards, industry improvement, and implicit programs (EPRI, 2009), so our energy efficiency net job gains are additional jobs above and beyond this implicit baseline level.

Scott MJ, OV Livingston, JM Roop, RW Schultz, and PJ Balducci. 2009. Impact of Sector Energy Technologies Model Description and User's Guide. PNNL-18412, Pacific Northwest National Laboratory, Richland, Washington.

This report is an update to Roop et al. (2005). The report describes some enhanced flexibility to the ImSET model brought about by recoding from FORTRAN to $\mathrm{C}++$. The sectoring plan was also modified from the previous version (2) of ImSET.

Scott MJ, JM Roop, RW Schultz, DM Anderson, KA Cort. 2008. “The impact of DOE building technology energy efficiency programs on U.S. employment, income, and investment." Energy Economics, 30 (5): 2283-2301.

From the article abstract:

The U.S. Department of Energy's Office of Energy Efficiency and Renewable Energy (EERE) analyzes the macroeconomic impacts of its programs that are designed to increase the energy efficiency of the U.S. residential and commercial building stock. The analysis is conducted using the Impact of Sector Energy Technologies (ImSET) model, a special-purpose 188-sector input-output model of the U.S. economy designed specifically to evaluate the impacts of energy efficiency investments and saving. For the analysis described in the paper, ImSET was amended to provide estimates of sector-bysector capital requirements and investment. In the scenario of the Fiscal Year (FY) 2005 Building Technologies (BT) program, the technologies and building practices being developed and promoted by the BT program have the potential to save about $2.9 \times 10^{15}$ Btu in buildings by the year 2030 , about $27 \%$ of the expected growth in building energy consumption by the year 2030 . The analysis reported in the paper finds that, by the year 2030 , these savings have the potential to increase employment by up to 446,000 jobs, increase wage income by $\$ 7.8$ billion, reduce needs for capital stock in the energy sector and closely related supporting industries by about $\$ 207$ billion (and the corresponding annual level of investment by $\$ 13$ billion), and create net capital savings that are available to grow the nation's future economy.

The application of ImSET clearly lays out the two primary pathways by which energy efficiency influences the number of jobs. As the first figure in the report shows, "new investments in these 
technologies affect the level of employment and earned income in the economy by multiple pathways. First, the manufacture and installation of this equipment itself create jobs and income in some industries, while diverting funds that otherwise would have been spent for other goods and services by businesses and households." The second pathway is through energy cost savings. The authors state that "reducing energy consumption reduces energy purchases (which in turn reduces employment and income in the energy-supplying sectors) and produces dollar savings that can be spent on any good or service."

In terms of job impacts associated with the diversion of funds to undertake the energy efficiency investment, the application of ImSET assumed that the "financing for the energy-efficient investments is drawn proportionately from the rest of the U.S. economy." Thus, the report implies that the net job impacts associated with energy efficiency investment depend upon the difference in the overall labor intensity (jobs/dollar)for the bill of goods that comprise that investment as compared to the labor intensity for the economy as a whole.

The report presents estimates of the employment impacts for selected years between 2005 and 2030 , both with and without the consideration of the investment pathway. The report indicates that the impact on total employment is just slightly lower when the impact of the energyefficiency investment is included along with the impact from the energy cost savings. The paper does not present an actual value for the energy cost savings; and so an overall multiplier from this pathway cannot be derived from the report. (For 2030, in the case labeled "impact of energy savings alone", total savings are shown to be 2,865 Trillion Btu, and the employment impact was 446,000 jobs. Thus, assuming average energy prices of either $\$ 15$ or $\$ 20$ per MMBtu (saved) as lower or upper bounds, the implied employment multipliers would be 10.4 jobs/million $2005 \$$, or 7.8 jobs/million 2005\$, respectively, of cost savings.)

Roop JM, M J Scott, and RW Schultz. 2005. ImSET: Impact of Sector Energy Technologies. PNNL15273. Pacific Northwest National Laboratory, Richland, Washington.

The ImSET model developed by economists at the Pacific Northwest National Laboratory relies on the I-O framework derived from the BEA national input-output tables, re-sectored down to a 188 -sector model to focus the analysis on the industries closely related to energy efficiency activities.

The model is capable of capturing changes in the energy use as well as capital stock, investment and productivity. Analysis findings show that the impacts of the FY 2005 Building Technologies program in the U.S. Department of Energy would lead to $27 \%$ savings in building energy use by 2030 , creating 446,000 jobs and increasing wage income by $\$ 7.8$ billion. Additional findings show that resulting significant energy and capital cost savings which can be channeled into consumption (residential savings) or productive investment (commercial savings).

The model is a static I-O model, but it allows ample flexibility regarding the types of energyefficiency effects that can be accommodated. For example, ImSET tracks the detailed effects of inter-industry purchases of goods and services (and energy in particular), and recalculates the use matrix and the consequent changes to the input-output structure of the economy in each forecast year. Some energy-efficiency investments will not only reduce the quantities of energy required 
but also the requirements for labor and other goods and services. In the economics terminology, ImSET both accounts for investment-specific increases in productivity and value-added, and the changes to the I-O structure brought about by increased energy efficiency. The improvement in productivity is a desired effect at the core of many investment decisions. Savings in the energy, labor, materials, and services from improved productivity are the source of subsequent rounds of investment and economic growth. Therefore the model analyzes job creation both from initial investments in efficiency as well as from energy savings and resulting shifts in spending.

Barrett JP and JA Hoerner. 2002. Clean Energy and Jobs: A Comprehensive Approach to Energy and Jobs. Economic Policy Institute and Center for a Sustained Economy. Washington, D.C.

ISBN: 0-944826-97-0.

Energy efficiency promotion policies are diverse and sector specific, so to identify a credible package of technology initiatives, the Economic Policy Institute adopted (with some modifications) the technology policy package from Scenarios for a Clean Energy Future (henceforth the "CEF" report by the Interlaboratory Working Group 2000). This Economic Policy Institute study identified and evaluated four CEF policy scenarios, involving energy efficiency efforts through buildings, industry, transportation, and electric generation (see Table 1, below).

\begin{tabular}{|c|c|}
\hline & $\begin{array}{l}\text { TABLE } 1 \\
\text { Major policies in the CEF advanced scenario* }\end{array}$ \\
\hline Buildings & $\begin{array}{l}\text { - Efficiency standards for equipment } \\
\text { - Labeling and deployment programs }\end{array}$ \\
\hline Industry & $\begin{array}{l}\text { - Voluntary programs } \\
\text { - Agreements with individual industries and trade associations }\end{array}$ \\
\hline Transportation & $\begin{array}{l}\text { - Tax incentives for super-efficient vehicles } \\
\text { - Increased CAFE standards } \\
\text { - "Pay-at-the-pump" auto insurance }\end{array}$ \\
\hline Electric generation| & $\begin{array}{l}\text { - Renewable energy portfolio standards and production tax credits } \\
\text { - Electric industry marginal cost pricing }\end{array}$ \\
\hline Cross-sector policies & $\begin{array}{l}\text { - Doubled federal research and development } \\
\text { - Domestic carbon market mechanism (auctioned permit or tax, \$50/ton of carbon) }\end{array}$ \\
\hline \multicolumn{2}{|c|}{$\begin{array}{l}\text { "The scenarios are defined by approximately } 50 \text { policies; the } 11 \text { listed here are the most important ones in the advanced } \\
\text { scenario. Each policy is specified in terms of magnitude and timing. For instance, "efficiency standards for equipment" } \\
\text { comprises } 16 \text { new equipment standards introduced in various years with specific levels of minimum efficiencies. For details, } \\
\text { see the CEF report. }\end{array}$} \\
\hline \multicolumn{2}{|c|}{$\begin{array}{l}\text { "Note that the CEF assumes that marginal cost pricing will be implemented through electric utility industry restructuring. We do } \\
\text { not make this assumption, as the same policies could also be implemented through regulatory reforms. }\end{array}$} \\
\hline Source: CEF report (Interlab & oratory Working Group 2000). \\
\hline
\end{tabular}

Energy savings from CEF policy scenarios were integrated and results estimated using the LIFT model. The LIFT model is a sophisticated 92-sector macroeconomic model of the United States built and operated by the Inforum research and consulting group at the University of Maryland. The model was first calibrated to the economic and energy assumptions used in the 2001 Annual Energy Outlook of the U.S. Energy Information Administration. The macroeconomic and sectoral forecasts of the baseline and policy package were then prepared for the period 2001-20, focusing primarily on the effects on gross domestic product, employment, energy security, and greenhouse gas emissions. 
Relative to the base case, this 2002 analysis estimated that the policy package would result in:

- U.S. carbon emissions decline by $27 \%$ in 2010 and by $50 \%$ in 2020 . Other greenhouse gases and pollutants would also decline.

- GDP increases by a modest $0.24 \%$ in 2010 and by $0.6 \%$ in 2020 .

- Additional 660,000 net jobs created in 2010, 1.4 million in 2020. This would increase employment in the service sector and reduce the rate of decline in employment in manufacturing.

- Unemployment falls and real after-tax wages rise.

- Oil imports in 2020 fall from the baseline forecast by an amount slightly higher than total current U.S. purchases of oil from OPEC.

- Household energy bills fall in every year, by a steadily rising amount.

- Slightly progressive effect on income distribution.

\section{TABLE 2}

Impact of the policy package for GDP, emissions, and employment

\begin{tabular}{|c|c|c|c|c|c|c|c|}
\hline & \multirow[b]{2}{*}{2000} & \multicolumn{2}{|c|}{ Baseline } & \multicolumn{2}{|c|}{ Policy scenario } & \multicolumn{2}{|c|}{$\begin{array}{l}\text { Percent change } \\
\text { from baseline }\end{array}$} \\
\hline & & 2010 & 2020 & 2010 & 2020 & 2010 & 2020 \\
\hline GDP & 9,545 & 12,863 & 16,771 & 12,896 & 16,878 & $0.26 \%$ & $0.64 \%$ \\
\hline Carbon emissions & 1,538 & 1,814 & 2,054 & 1,325 & 1,018 & -26.99 & -50.40 \\
\hline Total employment & 141,343 & 154,263 & 164,119 & 154,917 & 165,547 & 0.42 & 0.87 \\
\hline Manufacturing industries & 19,798 & 19,082 & 18,210 & 19,131 & 18,459 & 0.26 & 1.37 \\
\hline Coal mining & 88 & 53 & 46 & 24 & 12 & -54.14 & -73.91 \\
\hline Ferrous metals & 426 & 425 & 354 & 425 & 354 & -0.08 & 0.00 \\
\hline Service industries & 103,849 & 115,026 & 123,539 & 115,644 & 124,835 & 0.54 & 1.05 \\
\hline
\end{tabular}

Note: GDP figures are in billions of 1997 dollars, carbon emissions are in millions of metric tons, and employment figures are in thousands of jobs.

This reference cannot be used to define multipliers to be of help in the overall effort in the present study. First, the report presents only the employment impact by industry sector, with no attribution to the particular end-use sector affected by specific elements of the policy. Second, the report does not present energy savings in any year, rather only emissions reductions as (reproduced in) Table 2 above shows.

http://www.epi.org/publication/studies_cleanenergyandjobs/

\section{C.2 National Studies of State-Level Impacts}

Hayes S, G Herndon, JP Barrett, J Mauer, M Molina, M Neubauer, D Trombley, and L Ungar.

2014. Change Is in the Air: How States Can Harness Energy Efficiency to Strengthen the Economy and Reduce Pollution. Report E1401, American Council for an Energy-Efficient Economy. Washington, D.C. April 2014.

This study is summarized as the first entry in Section B.1.2. The study contains both nationallevel and state-level estimates of impacts. 
National Governors Association (NGA). 2013. “An Energy Efficiency Primer for Governors.” NGA paper prepared by Greg Dierkers , NGA's Program Director for Environment, Energy, and Transportation. Washington D.C. September 2013.

From the Executive Summary of the National Governors Association (NGA) paper: Governors play a critical role in advancing energy efficiency. Although actions vary by state, governors have available a wide variety of tools to deploy energy efficiency. Since 2008, governors have worked with legislators, regulators, and others to develop or advance nearly 300 actions to improve energy efficiency. Examples of those and other recent state actions include:

- Conducting energy planning and analysis to examine state energy issues, analyze potential energy savings, and explore policy options and best practices.

- Incentivizing spending by utilities to provide increased energy efficiency.

- Supporting innovative financing and repayment mechanisms to increase investment in energy efficiency.

- Creating new outreach and education efforts

- Supporting research and development

The primer describes successful actions governors have taken to further cost-effective energy efficiency. It is intended to share examples for other states to consider as they develop their own efforts to capture the multiple benefits of energy efficiency.

New York's Energy Smart Program was highlighted as an example of a state program with significant economic benefits. As described in the report, "New York's Energy Smart Program is a statewide program that invests in energy savings measures across all sectors of the economy. The state analyzed the program's economic impacts over 12 years and found that it increased state economic output by an average of $\$ 270$ million annually. Positive economic effects included energy bill savings and direct purchases made by companies that were co-funded by the state's program.”

While the primer discusses a number of strategies that states can pursue to increase energy efficiency, it does not include any discussion on how the economic and employment impacts can be evaluated.

Environmental Protection Agency. 2011. Assessing the Multiple Benefits of Clean Energy: A Resource for States. EPA-430-R-11-014. Environmental Protection Agency, Washington D.C. September 2011.

From the preface of the report:

This Resource [report] identifies the multiple benefits of clean energy and explains why they should be quantified and considered along with costs. It starts by presenting clear, easy-to-understand background information on each type of benefit to help nonspecialists understand how the benefits are generated and what can be done to maximize them. Building on that foundation, the Resource describes analytic options that states can explore as they conduct and review analyses of clean-energy initiatives. It provides a framework for assessing multiple benefits, presenting detailed information on basic and more sophisticated approaches along with descriptions of tools for quantifying each type 
of benefit. It also includes many examples of how states have used multiple benefits approaches, along with additional resources for more information.

The most relevant section of the EPA to the study here is Chapter Five: "Assessing the Economic Benefits of Clean Energy Initiatives." With respect to employment impact the report explicitly mentions the need to consider the opportunity cost associated with energy efficiency investments. As stated in the report, "When a state implements a program for energy efficiency through surcharges to rate payers, it is taking money away from the consumers that they would have spent on other goods, possibly creating job losses, and investing them into the energy efficiency program, possibly creating job increases."

As a handbook for use by states, the EPA report describes various tools, models, and methods by which states could use to quantify benefits of clean-energy policies, whether they come from renewable energy production or energy efficiency. Chapter five includes brief discussions of selected state-level studies related to economic assessment of clean energy programs. However, the summary information presented in the case studies is not sufficient to derive the underlying employment multipliers.

KEMA, Inc. 2011. Detailed Study Plan: Final National Evaluation of the United States Department of Energy's State Energy Program, Prepared for Oak Ridge National Laboratory, Oak Ridge, TN. June 30, 2011.

The proposed approach for this study includes an 8-region (state) version of the REMI Policy Insight simulation model. Information describing the short-term and long-term project-related effects will be introduced into this economic model to identify the annual projection of job impacts. This analysis system has been applied to numerous energy and environmental policy/program analyses, some applications specifically within evaluation activities. A brief overview of the REMI model capabilities follows below. http://weatherization.ornl.gov/pdfs/DetailedSEPEvaluationPlanFinal063011.pdf

\section{U.S. Department of Energy. 2011. Energy Efficiency and Conservation Block Grant (EECBG) Program Evaluation Plan (before peer review and edits). Washington, D.C.}

This Department of Energy (DOE) report outlines the scope and methodological approach that will be used in an evaluation of DOE's \$2.7 billion Formula Grant investment in energy efficiency and renewable energy. As indicated in the report, the evaluation budget does not allow for a fully-calibrated economic impact analysis, such as a calibrated state- and industry-specific REMI-like modeling assessment. However, an analysis can be conducted using industry standard job counts for the types of equipment installed, supplemented with interview data from equipment manufacturers, distributors, wholesalers, retailers, contractors and activity managers when industry-specific job metrics are not available. 
The approach used should include an assessment of jobs associated with the various job-creation and job-loss sources listed above. For example, job creation estimates for equipment manufacturing can be estimated from the typical jobs required per unit of production for the technologies installed, supplemented with industry standard job metrics for storage and distribution of those technologies from the point of manufacture to the point of sale. New jobs associated with the installation of the technologies can be derived by using industry standards for the types and size of equipment installed, or from interviews with a sample of contractors installing the kinds of equipment associated with the EECBG funded activities. The jobs created from additional expenditures allowed by annual energy cost savings can be estimated using information from the job impact literature or the results of more rigorous energy impact economic model studies, such as the one conducted for Focus on Energy in Wisconsin. Job losses in the energy industry due to reduced consumption can likewise be taken from the job impact literature or other economic-modeling efforts. http://weatherization.ornl.gov/EECBGEvaluationPlanFINAL.pdf

Nayek N. 2005. Redirecting America's Energy: The Economic and Consumer Benefits of Clean Energy Policies. U.S. PIRG Education Fund, Washington, D.C.

This report examined the economic and consumer impacts of a significant shift from reliance on fossil fuels and toward greater energy efficiency and renewable energy sources. In the study, two policies were examined:

- Enacting a 20 percent national renewable energy standard (RPS)

- Shifting current subsidies for fossil fuels and nuclear power, \$35 billion toward renewable energy and energy efficiency

The overall findings were that by pursuing these policies (termed in the report as the "Clean Energy Package"), the nation would:

- Create 215,000 (net) jobs by 2020

- Save all consumers $\$ 11$ billion on natural gas bills in 2020

- Save all consumers $\$ 16$ billion on electricity bills in 2020

- Increase gross domestic product by an average of $\$ 5.9$ billion between 2015 and 2020

The approach by which these impacts were estimated was through an IMPLAN-based model developed by Economic Research Associates (ERA). The principal at ERA at the time was John Laitner, who has been the author of many studies related to estimating the economic impacts of energy efficiency policies. For a discussion of the modeling framework used to support the PIRGEducation Fund estimate, see Economic Research Associates (2005) in this bibliography. That entry was cited in the Nayek (2005) report.

The methodology used to develop the national estimates appears to have been an aggregation of results across state-level models. The specifics of how this approach was implemented were not spelled out in the report. 
From the discussions in the Nayek (2005) report and the ERA (2005) working paper, it is clear that employment was affected by both the energy efficiency investment and the resulting energy bill savings. The figures in the report show that net job creation in each year shows a marked jump in total jobs over the first three years of the scenario, consistent with an initial ramping up of energy efficiency investment. No explicit values for the year-by-year investment were provided in the report (nor in the ERA working paper). Assuming the bulk of the net job creation is due to the savings in natural gas and electricity bills, the implied consumer bill saving multiplier in 2020 is just under eight jobs per million (2001) dollars of savings ( $=215,000 \mathrm{jobs} /(\$ 11,000+\$ 16,000$ million). This multiplier is somewhat lower than in some other recent national studies (see Table B.1), but may reflect several factors: 1) the report indicates that "induced" spending effects on jobs are not considered, 2) there may be some offsetting negative impacts from repayment of energy efficiency loans in 2020, and 3) the aggregation of state-level models may not yield the same impact as a single national model (this effect was observed in Hayes et al. 2014).

Economic Research Associates. 2005. "Modeling the Economic Impacts of National and State Energy Policy Scenarios." A Working Paper for the U.S. PIRG Education Fund (Review draft). Alexandria, VA. January 2005. [Cited in Nayek 2005].

This paper describes the input-output analytical approach that was used in earlier released report by the U.S. PIRG Education Fund, "Redirecting America's Energy: The Economic and Consumer Benefits of Clean Energy Policies." The paper describes the model developed by the Public Interest Research Group (PIRG) and Economic Research Associates as a template that can be adapted by states to perform their own assessments of alternative energy policies and programs. The underlying data for the model was taken from the 2001 IMPLAN database.

The paper presents the basic elements of an input-output based approach to conducting an assessment of energy efficiency policies. In terms of employment, the paper indicates that its magnitude is "ultimately generated by energy bill savings and expenditures for energy efficiency [and] depend on the structure of the local economy."

The paper makes a very transparent illustration of a hypothetical energy efficiency improvement - a \$1 million investment in retrofitting a large government office building. The assumed payback for this investment is 4 years, and thus $\$ 250,000$ of energy bill savings are achieved. The analysis period is assumed to be 10 years, roughly the (average) life of the efficiency measures installed. Accordingly, over 10 years, the bill savings are $\$ 2.5$ million. Table 1 is excerpted from the paper and shows the various elements that make up the estimate of total job-years over the assumed 10 year period. The top two rows show the (hypothetical) job impacts associated with the efficiency investment. The second row labeled "Revenue impacts" is not discussed in detail, but reflects the "opportunity" cost of the funds (in essence, implying an increase in taxes that reduces spending by consumers). The energy savings, in the same manner, are assumed to ultimately be reflected in lower taxes for consumers over the 10 -year period of the analysis. Both of these effects are assumed to have the same impact per dollar of expenditures, 31.5 jobs per million dollars. The final impact is on revenue of energy utilities, which has much lower labor intensity than the spending in the other categories. As shown in the last column of the table, the next impact of all these changes is computed to 56.6 job-years. 
An important point from this illustration, even with its hypothetical nature, is that the net effect of the efficiency investment is shown to be very small, and in this case, negative. The long-term positive employment impacts are exclusively related to the redirection of money formerly spent on energy to a mix of goods and services that support a larger number of jobs per dollar spent.

Table 1. Estimating Job Impacts from Efficiency Improvements in Government Buildings (Hypothetical example)

\begin{tabular}{|l|c|c|c|c|c|c|}
\hline \multicolumn{2}{|c|}{} & \multicolumn{2}{|c|}{ Influences on Final Demand } & \\
\hline Expenditure & $\begin{array}{l}\text { Amount } \\
\text { (\$millions) }\end{array}$ & $\begin{array}{l}\text { Job } \\
\text { Multipliers }\end{array}$ & $\begin{array}{l}\text { Labor } \\
\text { Produc- } \\
\text { tivity }\end{array}$ & $\begin{array}{l}\text { Energy } \\
\text { Prices }\end{array}$ & $\begin{array}{l}\text { Chg. In } \\
\text { Interest } \\
\text { rates }\end{array}$ & $\begin{array}{l}\text { Impact } \\
\text { (Job- } \\
\text { years) }\end{array}$ \\
\hline $\begin{array}{l}\text { Building } \\
\text { Improvements }\end{array}$ & 1.0 & 29.0 & 0.98 & 1.00 & 1.02 & 29.0 \\
\hline $\begin{array}{l}\text { Revenue } \\
\text { Impacts }\end{array}$ & -1.0 & 31.5 & 0.99 & 1.00 & 1.02 & -31.8 \\
\hline Energy Savings & 2.5 & 31.5 & 1.02 & 1.08 & 1.00 & 86.8 \\
\hline Utility Revenues & -2.5 & 12.0 & 0.97 & 0.94 & 1.00 & -27.4 \\
\hline \multicolumn{1}{|c|}{ Net Change } & & & & & & 56.6 \\
\hline
\end{tabular}

\section{C.3 Regional and State-Specific Impact Studies}

Roland-Holt, D. 2008. Climate Action, Energy Efficiency, and Job Creation in California. Department of Agricultural and Resource Economics, University of California, Berkeley. September 2008.

As stated in the report's introduction, "This report contributes to the policy dialog by examining economy-wide employment effects of California's historical experience with energy efficiency policies, comparing this with forward looking projections of the economic impacts of new climate policy, as represented by the state's Global Warming Solutions Act (AB32)." The report estimates the job creation associated with the various policies since 1972 in California that were designed to slow the growth in statewide energy consumption, particularly electricity. The approach in the report was to develop a counterfactual estimate of the sectoral composition of household goods and services over the period 1992 through 2005. The counterfactual estimate was made by comparing the changes in the composition of household consumption at the national level, as implied by the input-output tables produced by the Bureau of Economic Analysis, with that in California. The California composition of household consumer goods and services was available from a California-specific input-output table for 2002. The input-output table for 2002 was then used estimate the (lower) number of California jobs that would have resulted had the 
distribution of household consumption in California followed the same trajectory as that for the U.S. as a whole. Using this methodology, the report estimated an employment impact of approximately 1.5 million jobs over the period 1972-2005. The methodology precluded the need to translate the impacts of specific historical California energy efficiency programs to changes in the household composition of good and services. Thus, this report contains no direct information (e.g. job multipliers of any kind) that can be used assess future energy-efficiency programmatic impacts for any state. The report can be accessed from: http://www.irle.berkeley.edu/vial/publications/CAEfficiency_Jobs_DRH080901.pdf

Cadmus Group, Inc. 2013. Energy Pro3: The Economic Impact of Energy Efficiency Investments in the Southeast. Prepared for Southeast Energy Efficiency Alliance, Atlanta, Georgia.

This report provides an independent analysis by the Cadmus Group of the economic performance of SEEA's 16-city, U.S. Department of Energy-funded energy efficiency retrofit consortium from 2010 to 2013. To create this analysis, the Cadmus Group applied SEEA's program data to an economic-modeling program known as Impact Analysis for Planning (IMPLAN) v3.1, a widely used and well known platform for predicting economic impacts. Cadmus then calculated the net impacts of SEEA's energy efficiency programs on the economy of the southeast region as a whole, and on the economies of the states with participating programs. This report provides a detailed description of the methodology used by the Cadmus Group, as well as regional and statelevel findings. These are presented in the form of a total economic impact summary, employment impacts and return on investment, by region and by state. Participant states include Alabama, Florida, Georgia, Louisiana, North Carolina, South Carolina, Tennessee and Virginia.

Center for Resilience, Ohio State University. 2013. Economic Analysis of Ohio's Renewable and Energy Efficiency Standards. Prepared for Advanced Energy Economy Ohio Institute, Columbus, Ohio. September 25, 2013.

Increased investments in the energy sector stimulated GDP by $\$ 160$ million in 2012, and created over 3,200 Ohio jobs in the period from 2008 to 2012. Energy efficiency was estimated to have reduced electricity consumption by $2.2 \%$ in the same period. Looking forward, the study indicated that if Ohio maintains its current standards, approximately 3,000 additional jobs would be created. The estimate is based solely on a comparison of the labor intensity of renewable electricity sources versus conventional thermal plants.

For purposes of this project, OSU utilized a state--of--the--art model called Dynamic Energy-Economic Policy Simulation (DEEPS). DEEPS was developed by OSU for the State of Ohio, in collaboration with the Consortium for Energy, Economics and the Environment at Ohio State University, with funding and guidance from the Ohio Department of Development, and in partnership with the Public Utilities Commission of Ohio and the Ohio Environmental Protection Agency. Further information about the DEEPS model is available at www.OhioEnergyResources.com.

The economic analysis report can be accessed via: http:/www.ohiomfg.com/wpcontent/uploads/2013-10-04_lb_energy_deeps_sept25_2013_model_results.pdf 
Aden N, J Bradbury, and F Thompson. 2013. Energy Efficiency in U.S. Manufacturing: The Case of Midwest Pulp and Paper Mills. World Resources Institute, Washington, D.C. ISBN 978-1-56973-806-1.

This WRI 2013 analysis involved a facility-level study of Midwest pulp and paper mills - the third-largest energy user in U.S. manufacturing. It estimated that facilities could save $\$ 240$ million per year in total energy costs by improving their performance to existing, ENERGY STAR ${ }^{\circledR}$ levels. These efficiency-derived savings could help preserve the 370,000 jobs associated with Midwest pulp and paper mills. Cost-effective reductions in energy use by Midwest pulp and paper mills assumed 25 percent efficiency improvements through use of existing technologies.

Appendixes I, II, and III contained a detailed description of the data, assumptions, and methods that went into the benchmarking and analysis for this Midwest pulp and paper mills study.

In the preface to the report, it is stated that "The experiences of forward-thinking pulp and paper companies make it clear: energy efficiency can make all the difference in keeping companies competitive and protecting jobs." However, the report presents no quantitative estimates of the employment impact that would be associated with any level of efficiency improvement in Midwest pulp and paper mills.

\section{http://pdf.wri.org/energy-efficiency-in-us-manufacturing-midwest-pulp-and-paper.pdf}

Laitner JA, Dylan Sullivan, Lauren Kubiak, and Nolan Moser. 2012. Energy Productivity: Efficiency Benefits to Power Ohio Jobs and the Economy. NRDC Issue Brief IB:12-05-D, prepared for the Natural Resources Defense Council (NRDC) and the Ohio Environmental Council, Columbus, Ohio. May 2012.

This brief report was prepared to examine the consumer savings and employment impact associated with an energy efficiency portfolio standard that was included in the Senate Bill 221, passed in 2008. The report indicates that the standard would result in energy bill savings $\$ 3.2$ billion in 2025 and net increase in jobs of 32,300.

The report uses employment multipliers based on 2011 IMPLAN data for Ohio. With regard to the jobs created by the redirection of energy bill savings, the relevant figures from Figure 1 in the report are:

\begin{tabular}{|c|c|c|}
\hline Sector & $\begin{array}{c}\text { Direct Jobs per } \\
\text { Million Dollars }\end{array}$ & $\begin{array}{c}\text { Direct, Indirect, and Induced Jobs per } \\
\text { Million Dollars }\end{array}$ \\
\hline Natural Gas Utilities & 1.2 & 4.7 \\
\hline Electric Utilities & 2.0 & 4.8 \\
\hline Manufacturing & 2.4 & 8.0 \\
\hline Construction & 8.4 & 15.7 \\
\hline All Other Sectors & 10.5 & 17.9 \\
\hline
\end{tabular}


While the report seems to imply that jobs are created from both investment activity and the resulting redirection of energy bill savings, it does not provide the specific multipliers that were used to represent these separate channels of influence on employment.

Optimal Energy, Inc. and Synapse Energy Economics, Inc. 2011. Economic Impacts of Energy Efficiency Investments in Vermont - Final Report. Prepared for the Vermont Department of Public Service, Bristol, Vermont. August 2011.

This study estimates the impact of a single year (2012) of additional energy efficiency spending on the State's economy in comparison to having no spending for energy efficiency programs in that year. The installation of efficient equipment and practices due to Vermont's efficiency programs results in savings in electricity, heating and process fuels (mostly oil and propane), water, and operation and maintenance costs. These savings and their economic benefits continue for as long as the efficiency measures are operational, which can be up to 20 years or more for the most durable measures.

Center for Energy and Environmental Policy. 2011. Delaware's Energy Efficiency Potential and Program Scenarios to Meet Its Energy Efficiency Resource Standard. University of Delaware, Newark, Delaware. May 2011.

This report presents an energy and economic analysis of an energy efficiency resource standard (EERS) that was enacted by the Delaware legislature in 2009. This legislation mandated a $15 \%$ reduction in Delaware electricity consumption and a $10 \%$ reduction in natural gas consumption by 2015 , relative to 2007 levels of energy use.

According to the report, "EERS implementation is estimated to create 2,323-4,045 jobs if participation rates are similar to those experienced by leading states in achieving energy savings (during the five-year timeframe) of SB 106." The multipliers used in the study were derived from an earlier report (American Solar Energy Society (ASES), 2007. Renewable Energy and Energy Efficiency: Economic Drivers for the 21st Century. Roger Bezdek, Principal Investigator, Available online at: http://www.ases.org/images/stories/ASES-JobsReport-Final.pdf.)

A concise description of the method used to generate job impacts was presented in Section 6 of the report. The relevant text from that section is:

Employment benefits will appropriately vary by sector and by energy end-use technology; with the range by sectors averaging $9-16$ permanent new jobs per one million dollars of investment. Roger Bezdek's 2007 study found that for every one million dollar investment in energy-efficient appliances, lighting and HVAC systems, about five jobs are created, whereas 12-16 jobs are created in the insulation, energy service companies, utilities, and construction industries (ASES, 2007). For the values seen in Table 31, 12.5 jobs per million dollars of investment was used to estimate Delaware's job creation potential, a calculation that includes direct and indirect employment. 
Angelou Economics. 2011. "The Texas Economic Impact of Energy Efficiency Programs Administered by Investor-Owned Utilities." Angelou Economics, Austin, Texas.

This study examined the economic impact generated by energy efficiency programs sponsored by investor-owned transmission and distribution companies within the state of Texas. The study focused on the impacts of these programs over the 2009-2011 timeframe. The programs were primarily directed toward residential and commercial customers, including building retrofits, Energy Star new home construction, and retro-commissioning of commercial and institutional buildings. In broadest terms, the study concluded that the spending by utilities and matching partners yielded an annual impact of approximately $\$ 500$ million statewide. Total full-time equivalent jobs (more precisely, job-years) retained or created over this period were estimated to total nearly 12,000 .

The study employed IMPLAN as its analytical tool to estimate employment impacts from the energy efficiency programs. Of the total 11,940 job-years of employment, nearly 7,000 were categorized as direct jobs, slightly more 1,800 as indirect, and about 3,100 as induced. The report indicates that total spending by utilities and "private and institutional" investors (including consumers) over the period was $\$ 808.7$ million. Thus, the implied employment multiplier, jobyears per million dollars of investment spending, can be calculated as $14.7(=11,940 / 808.7)$. This estimate can be considered the impact from the energy efficiency investment alone; the authors state that "indirect and induced impacts are not calculated for the cash savings realized from reduced energy costs."

The overall (gross) employment multiplier related to energy efficiency investment is somewhat higher than those from national studies during the same time period (see Table B.1 in this report). This observation may reflect the lower level of overall wages in Texas as compared to the U.S. as a whole. The report does not consider any offsetting losses in jobs that would accompany any redirection of spending away from other goods and services in the Texas economy.

Howland J, D Murrow, L Petraglia, and T Comings. 2009. Energy Efficiency: Engine of Economic Growth. Environment Northeast and Economic Development Research Group, Inc. Washington, D.C. October 2009.

As stated in this report's Executive Summary, "This study quantifies macroeconomic impacts of increased energy efficiency investments in New England, where efficiency has assumed a leading role in energy policy." The study analyzed several 15-year future scenarios where the goal is to capture all "cost-effective efficiency" investments. The general approach as described in the report, "utilizes a multi-state policy forecasting model by Regional Economic Models, Inc. (REMI) to project macroeconomic impacts of expanded efficiency programs in comparison to a scenario where no programs exist. The study analyzes efficiency programs for electricity, natural gas, and "unregulated fuels," (fuel oil, propane, and kerosene), using very conservative estimates 
of investment levels needed to capture all cost-effective efficiency (efficiency that is lower cost than supplying additional energy)."

The study strongly indicates the employment impacts stem from both the efficiency investment itself and the resulting consumer energy bill savings. Table ES2 below is extracted from the table in report's Executive Summary. As show in the second-to-last row, the analysis showed that more than $80 \%$ of the employment impacts could be attributed to the energy bill savings.

Table ES2. Summary of New England Economic Impacts.

\begin{tabular}{|l|c|c|c|}
\hline & Electric & Gas & $\begin{array}{l}\text { Unregulated } \\
\text { Fuels }\end{array}$ \\
\hline Total Efficiency Program Costs (\$Billions) & 16.8 & 4.1 & 6.3 \\
\hline Increase in GSP (\$Billions) & 99.4 & 30.6 & 53.1 \\
\hline Maximum annual GSP Increase (\$ billions) & 5.6 & 1.8 & 2.9 \\
\hline $\begin{array}{l}\text { Percent of GSP Increase Resulting from } \\
\text { Efficiency Spending }\end{array}$ & $12 \%$ & $11 \%$ & $9 \%$ \\
\hline $\begin{array}{l}\text { Percent of GSP Increase Resulting from Energy } \\
\text { Savings }\end{array}$ & $88 \%$ & $89 \%$ & $91 \%$ \\
\hline $\begin{array}{l}\text { Dollars of GSP Increase per \$1 of Program } \\
\text { Spending }\end{array}$ & 5.9 & 7.4 & 8.5 \\
\hline Increase in Employment (Job-Years) & 767,011 & 207,924 & 417,061 \\
\hline Maximum annual Employment Increase (Jobs) & 43,193 & 12,907 & 24,036 \\
\hline $\begin{array}{l}\text { Percent of Employment Increase from Efficiency } \\
\text { Spending }\end{array}$ & $16 \%$ & $15 \%$ & $12 \%$ \\
\hline $\begin{array}{l}\text { Percent of Employment Increase from Energy } \\
\text { Savings }\end{array}$ & $84 \%$ & $85 \%$ & $88 \%$ \\
\hline Job-Years per \$Million of Program Spending & 46 & 50 & 66 \\
\hline
\end{tabular}

Given the data in Table ES2 and the other values shown in the text, an effort was made to derive the implied employment multipliers associated with the report. The effort was restricted to electricity savings. Over the period, 2009-2030, the report (p.16) indicates that cumulative electricity cost savings would be $\$ 29$ billion. From Table ES2, if one multiplies 767,011 jobyears times $84 \%$ ( $\%$ of employment increase from savings), and then divides by $\$ 29$ billion (converted $\$ 29,000$ million), the implied multiplier is 22.2 job-years per million dollars of energy bill savings (across the entire scenario through 2030). To extract a multiplier for the investmentrelated channel of influence on jobs, and following the same procedure using 16.8 billion in program costs and $16 \%$ of the total job-years, the result is 7.3 job-years per million dollars of program cost. This multiplier is lower when participant costs are added to program costs, estimated to add another $34 \%$ to total costs. The resulting multiplier then becomes 5.45 . 
It is clear that the implied multipliers from this interpretation of the study results are somewhat different from those implied in studies based on the IMPLAN model. Compared to the static I-O approach (of IMPLAN), the REMI analysis model is a more responsive and comprehensive impact framework as described earlier in Appendix A, (actually it is an annual forecasting structure). Its adjustment processes correct for the "over statement of impacts" that occur in a static I-O setting. Another possible reason for the lower " 5.45 " job value points to how the shortterm impacts were crafted for investment spending. If authors of the IMPLAN driven studies assumed $100 \%$ of the investment spending was fulfilled within the region-of-impact (which the ENE_EDR group study did not assume), then more pronounced job impacts would be produced.

Tharp W and L Quillen. 2009. An Analysis of the Economic Impact of Energy Efficiency and Renewable Energy in the East Kentucky Power Cooperative Region. Ochs Center for Metropolitan Studies, Chattanooga, Tennessee. July 2009.

This report examined a set of renewable energy and energy efficiency initiatives as an alternative to building a new coal-fired electricity generation plant in east Kentucky. Using the IMPLAN model, the authors indicated that, over a three-year period, these initiatives would generate over 8,750 new jobs for Kentucky residents and have a total impact of $\$ 1.7$ billion on the regional economy. The report attributes all of the employment impacts to investment, without considering any impact from consumer bill savings from greater energy efficiency. The report does not break out the employment impacts from the renewable electricity (wind and hydro) investment relative to the efficiency investment. For the east Kentucky region considered in the report, a total of $\$ 946$ million was assumed, $\$ 634.2$ million for energy efficiency and $\$ 311.8$ million for new small scale hydropower generation. Based on the total $\$ 946$ million investment and the total number of jobs reported in the study, the implied overall employment multiplier is 9.3.

Geller, $\mathbf{H}$ and $M$ Goldberg. 2009. Energy Efficiency and Job Creation in Colorado. Southwest Energy Efficiency Project and MRG Associates. Boulder, CO and Nevada City, California. April 2009.

This report examines the impacts that increasing the efficiency of electricity, natural gas, and gasoline use could have on jobs and personal income in Colorado by 2015, 2020 and 2025. The energy efficiency policies and key assumptions for those policies are based mainly on the energy efficiency initiatives included in the Colorado Climate Action Plan issued by Governor Bill Ritter in November 2007. The energy efficiency policies included in this study are consistent with those proposed in the American Clean Energy and Security Act of 2009, the comprehensive energy and climate change legislation introduced by Representatives Waxman and Markey.

The following policies and programs are included in this study: 1) Expand Electric Utility DSM programs, 2) Expand Gas Utility DSM Programs , 3) Update and Enforce Building Energy Codes, 4) Implement Lamp Efficiency Standards, 5) Undertake an Industrial Energy Efficiency Program, and 6) Adopt the Clean Car Standards. Of most relevance in the current study are 3) and 5) in this list: 
Building Codes: The analysis considers both electricity and natural gas savings in all new residential and commercial buildings. Most of the electricity savings come from commercial buildings but most of the gas savings come from residences. By 2025, the savings reach 3,185 GWh of electricity and 15.9 million decatherms of gas. The report estimates that about $\$ 3.0$ billion would need to be invested in efficiency measures during 2007-2025 in order to achieve these levels of energy savings.

Industrial Energy Efficiency Program: It is assumed that this policy is effective in engaging industries and stimulating increased investment in energy efficiency measures and practices. Energy savings across the industrial sector, for both electricity and natural gas, are assumed to reach 6.5 percent by $2015,11.5$ percent by 2020 , and 16.5 percent by 2025 . Total projected electricity savings in 2025 is $2,190 \mathrm{GWh}$ and projected gas savings is 21.5 million decatherms. It is estimated that about $\$ 925$ million would need to be invested in efficiency measures and practices during 2007-2025 in order to achieve these levels of energy savings in the industrial sector.

The report relies upon IMPLAN with 2007 data to develop estimates of economic and employment impacts from these initiatives. However, the employment impacts from specific initiatives are not presented in the report. Overall, the total investment over the 2007 through 2025 period was projected to be 12.4 billion (2007) dollars, yielding 2025 energy savings of 375 TBtu. The employment impact in 2025 was estimated to be 11,600 jobs. The report suggests that the primary impact on jobs (as we might surmise) is due to the re-allocation of spending between energy and non-energy goods and services. ("As it turns out, much of the net job creation from energy efficiency programs is derived from the difference between the number of jobs lost within the utility and fuel supply sectors offset by the number of other jobs supported by the spending of energy bill savings throughout the economy.") Unfortunately, the report does not present the magnitude of the bill savings for any year. For comparison with multipliers from other studies, the 2007 IMPLAN employment multipliers for Colorado are reproduced below from Table 1 in the report.

Table 3. Colorado Employment Multipliers for Selected Economic Sectors

\section{Sector}

Oil Refining

Natural Gas Utilities

Electric Utilities

Motor Vehicles

Primary Metals

Oil and Gas Production

Coal Mining

Transportation, Communication \& Utilities

Other Mining

Other Manufacturing

Food

Insurance/Real Estate

Finance

Wholesale Trade

Construction

\section{Employment Multipliers}

2.1

2.5

2.7

2.8

3.1

3.5

4.1

5.1

5.3

5.3

5.9

7.1

7.6

7.6

9.6 
Agriculture

10.5

Government

11.3

Services

12.4

Retail Trade

17.6

Source: Adapted from the 2007 IMPLAN database for Colorado. The employment multipliers represent the direct and indirect jobs supported by one million dollars of expenditure for the goods or services from a given sector.

Oppenheim J and T MacGregor. 2008. Energy Efficiency Equals Economic Development: The Economics of Public Utility Benefit Funds. Available at http://www.entergy.com/global/our_community/advocate/Poverty_book.pdf. June 2008.

This report compared the economic impacts from promotion of new manufacturing facilities to those stemming from the public benefits fund to support energy efficiency in low-income households. The report applies output and employment "multipliers from the Department of Commerce (associated with its Regional Input-Output Modeling, or RIMS program) to activities for key sub-regions of the Entergy service territories in the southeastern U.S. As an overall result of the study the authors conclude:

Because of the nature of the Commerce Department data, we report our results as point estimates. It would be more realistic, however, to treat all such multiplier results as bandwidths. Thus, while we report an economic output multiplier, using conservative assumptions, of 23 for low-income energy efficiency (2.7 times the multiplier for manufacturing), even reducing the efficiency multiplier - and increasing the manufacturing multiplier - by a third, would result in a low-income energy efficiency multiplier that is more than 30 percent higher than that for manufacturing. In this way, our overall conclusion about the potent economic value of low-income energy efficiency is extremely robust.

With regard to employment impacts, the report compares the impacts in the Entergy Service Area with national multipliers. For the purposes of the current study, the national multipliers are the most relevant, and are shown as follows:

National multipliers

For every \$1,000,000 in investment Increased economic output Jobs

\section{ENERGY EFFICIENCY}

Net effect of investment $\$ 5,773,943$ in output, and 47 jobs

Net effect of bill savings $\$ 5,217,648$, and 105 jobs

Effect of environmental improvement $\$ 5,743,952$ in output, and 36 jobs

Effect of non-energy benefits $\$ 17,437,091$ in output, and $150 \mathrm{jobs}$.

\section{ASSISTANCE}

Net effect of investment $\$ 2,686,702$ in output and 83 jobs

Effect of non-energy benefits $\$ 2,708,579$ in output, and 21 jobs

\section{MANUFACTURING PLANT}


Net effect of investment $\$ 16,510,983$ in output, and 127 jobs

Effect of environmental detriment $-\$ 5,110,207$ in output, and -29 jobs

With regard to a national employment multiplier related to energy efficiency investment, the implied RIMS multiplier is about 8 ( 47 jobs divided by $\$ 5.8$ million).

Eldridge M, N Elliott, W Prindle, K Ackerly, J Laitner, V McKinney, S Nadel, M Neubauer, A Silverstein, B Hedman, A Hampson, and K Darrow. 2008. "Energy Efficiency: The First Fuel for a Clean Energy Future." Report No. E082, American Council for an Energy-Efficient Economy, prepared for Resources for Meeting Maryland's Electricity Needs, Washington, D.C. February 2008.

Eldridge et al. (2008) examined the energy and economic impacts associated with a suite of policy proposals aimed at enhancing energy efficiency in Maryland. In modeling the macroeconomic effects of the energy-efficiency gains associated with the proposed energy policies, Eldridge et al. (2008) used American Council for an Energy-Efficient Economy's Dynamic Energy Efficiency Policy Evaluation Routine (DEEPER) model. Inputs used by the model include annual program spending, electricity savings resulting from energy-efficiency investments, and the capital and operating, including financing, costs associated with those investments. The DEEPER model is described as a quasi-dynamic input-output model with six key modules:

- Global data (economic time series data, key model coefficients, and parameters needed to generate final model results)

- Macroeconomic model (input-output relationships based on IMPLAN data)

- Investment, expenditures, and energy savings

- Price dynamics

- Final demand

- Results

The macroeconomic modeling procedures used in DEEPER, which includes I-O matrices, are similar

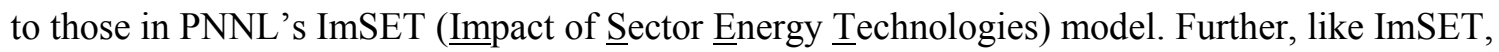
DEEPER considers the impact of investment financing costs. Unlike ImSET, DEEPER also includes modules designed to explore the impact of reduced energy consumption on wholesale electricity prices.

Policies evaluated by Eldridge et al. include implementation of federal and state appliance standards, more stringent residential and commercial building codes, policies designed to encourage investment in combined heat and power systems, and expanded utility demand response programs. The impacts of these policies were estimated to result in 15 percent savings in energy consumption compared to the reference forecast, producing $\$ 861$ million in consumer energy cost savings in 2015 and $\$ 2.6$ billion by 2025 . On average, households in Maryland are forecast to save $\$ 8$ on their monthly electricity bill in 2015 with an additional $\$ 2$ in savings resulting from the impact of declining demand 
on wholesale energy prices. These energy savings are forecast to result in positive net employment effects of 8,067 jobs in 2015 and 12,241 jobs in 2025 . Wages are forecast to increase by a net $\$ 462$ million in 2015 and $\$ 780$ million in 2025.

Note: The above discussion was taken largely from a literature review in Scott et al. (2009).

Prindle WR, AM Shipley, and RN Elliott. 2006. Energy Efficiency's Role in a Carbon Cap-and-Trade System: Modeling Results from the Regional Greenhouse Initiative. Report No. E064, American Council for an Energy-Efficient Economy, Washington, D.C. May 1, 2006.

Key excerpts from the report:

"This report focuses on the Regional Greenhouse Gas Initiative (RGGI), a nine-state effort to develop a regional carbon cap-and-trade system. At the invitation of New York Governor Pataki in 2003, the governors of Maine, New Hampshire, Vermont, Massachusetts, Rhode Island, Connecticut, New Jersey, and Delaware committed to developing a model carbon cap-and-trade rule for the region's power sector by 2005. A state agency working group, a stakeholder group, and other mechanisms were set up to develop the model rule. As a core part of the rule's development, the working group conducted extensive modeling of the regional power sector using ICF Consulting's Integrated Planning Model (IPM) linear programming model plus Regional Economic Models, Inc.'s (REMI) 20/20 Insight ${ }^{\mathrm{TM}}$ regional economic model to assess RGGI's potential impacts. Part of the IPM and REMI modeling effort was dedicated to simulating the impact of accelerated energy efficiency deployment scenarios."

“The RGGI staff working group selected the Regional Economic Models, Inc.'s (REMI) 20/20 Insight ${ }^{\mathrm{TM}}$ model4 to assess the impacts of the RGGI program on the nine-state region. REMI, an input-output model based on matrix algebra like most mainstream economic policy models, has been widely used by state and other government agencies to simulate the economic effects of various policy regimes. Like IPM, REMI creates a reference case for the region, using current conditions and other known factors to generate a business-as-usual regional economic future. REMI, however, uses IPM's outputs to assess the economic impacts of different policy scenarios. Changes in energy prices, power sector inputs and outputs, and related variables are mapped into REMI's input formats."

"For the IPM runs involving energy efficiency investments, working group staff mapped additional data into REMI's input formats. For example, increased investment in sectors stimulated by efficiency investments were mapped into specific REMI sector input vectors. Increased employment in sectors where efficiency investment created new jobs was also mapped into REMI, as were the effects of money saved on energy bills generating added spending in other sectors."

Sedano R and C Murray. 2005. Electric Energy Efficiency and Renewable Energy in New England: An Assessment of Existing Policies and Prospects for the Future. The Regulatory Assistance Project, Montpelier, Vermont. May 2005.

This 2005 study examined the economic impact of energy-efficiency programs and renewable energy investments in New England. More specifically, the study used the IMPLAN I-O model to estimate the direct, indirect, and induced effects of three distinct programs: 1) energy efficiencyoriented programs beginning in 2000 with planned funding levels extended through 2010;2) 
renewable energy deployments since 2000; and, 3) the two previous scenarios with additional investments required to meet existing renewable portfolio standards requirements. Sedano et al. account for the tradeoffs between reduced electricity prices, enhanced business profitability, increased consumer purchasing power, and enhanced spending on efficiency-related goods and services relative to fuel and operating expenses for power plants. Their projected result of the energy-efficiency programs in New England includes a net increase in economic output of $\$ 2$ billion, employment of almost 15,000 job-years (15,000 cumulative years of employment over the study period), and about $\$ 700$ million in cumulative income over the $2000-2010$ time period. Similar analysis in PNNL's ImSET model shows a job increase of 28 thousand job-years and $\$ 1.8$ billion in cumulative income over the 2000-2010 time period.

As noted previously, Sedano et al. (2005) uses the IMPLAN model to estimate the economic impacts of energy scenarios. In so doing, the model traces the flows of income, goods and services, and employment among various sectors of the economy. IMPLAN, as employed in Sedano et al. (2005), is very similar to ImSET in that it considered energy cost savings, increased costs associated with investments in technologies, and a shift away from business activity in the generation of power, all in a static manner. The Sedano et al. (2005) estimate was for a regional economy. Using the same assumptions, ImSET, which is a national model, should show (and does show) a larger impact because it incorporates economic impacts that ordinarily would be part of the "leakage out of regional economy such as New England's" (Sedano et al. 2005). However, it is not entirely clear from available documentation whether there is complete equivalency of assumptions.

Note: The above discussion was taken largely from a literature review in Scott et al. (2009).

Tellus Institute. 1999. The Impacts in Florida of U.S. Climate Change Strategy. Prepared for World Wildlife Fund. November 1999.

Three indicators of the economic impact in Florida of the national policies and measures were developed - net incremental jobs, wages and salaries and Gross State Product for the years 2005 and 2010. These impacts were estimated using IMPLAN (Impact Analysis for Planning), an input-output (I-O) model that represents interactions between different sectors of the economy.

The report contains a clear discussion of the how IMPLAN was used to generate employment impacts. It was not evident, however, from the discussion whether or not there was "free financing" of the efficiency investment.

\section{C.4 Studies Related to American Recovery and Reinvestment Act (ARRA)}

Research Into Action, Evergreen Economics, and Nexant Inc., NMR Group Inc. 2013. Preliminary Energy Savings Impact Evaluation: Better Buildings Neighborhood Program. Prepared for U.S. Department of Energy, Office of Energy Efficiency and Renewable, Washington, D.C. November 2013.

This report presents the results of a preliminary energy savings and economic impact analysis of the Better Buildings Neighborhood Program (BBNP). The BBNP is an energy efficiency program administered by the U.S. Department of Energy's Office of Energy Efficiency and 
Renewable Energy. Much of the initial funding beginning in 2010 was through the American Recovery and Reinvestment Act (ARRA). Beginning in 2010 [through the end of 2012], the program allocated $\$ 508$ million among 41 grantees representing state and local governments, as well as community organizations.

This report was prepared by a number of firms, including Research into Action, Inc., Evergreen Economics, Nexant Inc., and NMR Group, Inc. The primary focus of the report is to estimate the energy savings that was generated over approximately the first year and half the program that was funded by ARRA. The report describes in detail how estimates of energy savings were developed. As a first step, monitoring and verification (M\&V) "activities were conducted to determine gross verified energy savings through a combination of file reviews, telephone surveys, on-site inspections, and engineering analysis of projects." In addition, the evaluation team also conducted a regression analysis of pre- and post-retrofit energy bills to estimate realized energy savings at the project level (for a sample of projects). A third step involved the use of telephone surveys in an effort to understand what fraction of program participants were motivated to undertake an energy retrofit directly in response to the program.

The analytical approach to assessing the economic and employment impacts was the same as that described in Koson et al. (2013). The impact analysis team, led by Matthew Koson of Evergreen Economics, employed IMPLAN as the primary tool to estimate economic and employment impacts.

The report presents quarterly data from 2010:4 through 2012:2 on level of grantee outlays and estimated measure (invoiced costs) for 31 thousand residential retrofits and 1,350 commercial retrofits. Over this period, total grantee outlays were $\$ 246$ million, and estimate measure costs were $\$ 281$ million. The total ("gross") number of jobs over the evaluation period was estimated to be 6,681 (person-years). The report indicates that over this period, the "net" economic impacts were $\$ 650$ million in output, and 4,266 jobs (again, presented as person-years). Net jobs were determined by estimating the total number of jobs in a counterfactual case where the same level of government spending was directed in a manner consistent with its average (i.e., "normal") mix of goods and services. Thus, the report implies that the number of person-years associated with this counterfactual case was $2,415(=6,681-4,266)$.

Similar to Koson et al. (2013), the discussion of the economic impacts does not contain detailed information on exactly how IMPLAN was used. Specifically, it is also not clear the extent to which any impact of the redirected energy cost savings factor into the reported employment impact. The report, however, does permit one to develop an approximate estimate of the overall multiplier associated with the investment aspect of the program. The report indicates that total spending over the evaluation period was $\$ 525.5$ million and that consumer bill savings over that same period was 27.8 million. Under the assumption that 10 jobs (in this context, person-years) are generated per million dollars of bill savings, it is possible to subtract an approximate number of person-years from this effect $(=10 \times 27.8=278)$ and consider all other person-years $(6,681$ $278=6,403$. Dividing this adjusted number by $\$ 525.5$ million suggests a (gross) investment multiplier of 12.2 
Koson M, S Grover, A Josephson, and E Vine. 2013. "Better Building Neighborhood Program: An Economic Impact Analysis of a Whole-Building Retrofit Program." Paper presented at 2013 International Energy Program Evaluation Conference, August 13-15, 2013, Chicago, Illinois.

This paper presented the results of a preliminary impact analysis of the Better Buildings Neighborhood Program (BBNP). The BBNP is an energy efficiency program administered by the U.S. Department of Energy's Office of Energy Efficiency and Renewable Energy. Much of the initial funding beginning in 2010 was through the American Recovery and Reinvestment Act (ARRA). Beginning in 2010 [through the end of 2012], the program allocated \$508 million among 41 grantees representing state and local governments, as well as community organizations.

Matthew Koson, the lead author, was affiliated with Evergreen Economics in Portland, Oregon. His co-authors were from Evergreen Economics, Pinnacle Economics, and Lawrence Berkeley National Laboratory. The impact analysis team employed IMPLAN as the primary tool to estimate economic and employment impacts.

The paper presents quarterly data from 2010:4 through 2012:2 on level of grantee outlays and estimated measure (invoiced costs) for 31 thousand residential retrofits and 1,350 commercial retrofits. Over this period, total grantee outlays were \$246 million, and estimate measure costs were \$281 million. The report indicates that over this period, the "net" economic impacts were $\$ 650$ million in output, and 4,266 jobs (presented as person-years). Total annual energy cost savings by the last quarter of the analysis was $\$ 6.6$ million.

As a conference paper, the authors were constrained to report only high-level findings, and detailed information on exactly how IMPLAN was used is lacking. There is some question as how employment impacts were developed separately for administrative costs of the program (including marketing and outreach) versus the spending associated with the actual retrofits. It is also not clear the extent to which any impact of the redirected energy cost savings factor into the reported employment impact. It expected that a final impact analysis (report) of the ARRA funding of this program would likely present greater detail from which the supporting employment multipliers would be more transparent.

Taylor JB. 2011. "An Empirical Analysis of the Revival of Fiscal Activism in the 2000s." Journal of Economic Literature 49(3):686-702.

From the journal article abstract:

An empirical review of the three fiscal stimulus packages of the 2000s shows that they had little if any direct impact on consumption or government purchases. Households largely saved the transfers and tax rebates. The federal government only increased purchases by a small amount. State and local governments saved their stimulus grants and shifted spending away from purchases to transfers. Counterfactual simulations show that the stimulus-induced decrease in state and local government purchases was larger than the increase in federal purchases. Simulations also show that a larger stimulus package with the same design as the 2009 stimulus would not have increased government purchases or 
consumption by a larger amount. These results raise doubts about the efficacy of such packages adding weight to similar assessments reached more than thirty years ago.

This article considered two impacts from the discretionary fiscal policies that were undertaken in the 2000s to spur the economy in the short run. The policies broadly considered were 1) increasing personal income through (lowering) taxes and increasing transfers, and 2) increased federal expenditures, either as direct purchases of goods and services or increases in grant to states and localities. Perhaps the most relevant from the standpoint of energy efficiency impact analysis is the first, given that energy efficiency leads to essentially higher real income for consumers.

In a very straightforward fashion, Taylor performs a set of quarterly regressions (over the 2000s) that are designed to show the influence of the increased income, resulting from the fiscal policies, on personal consumption. The statistical results do not support the supposition that these increases in income had any measurable effect on consumption over this period. Taylor interprets these results in the following manner:

This is the kind of regression result that one would expect from the Friedman permanent income hypothesis, the Modigliani life cycle hypothesis, or from consumption smoothing in an intertemporal utility maximization model. Experimenting with different regression specifications gives similar results, so effectively the data are speaking for themselves without the constraint of particular parameter values or functional form.

The Taylor results clearly lend support that temporary increases in (aggregate) income have little impact on consumption in the short run. However, it is reasonable to conclude that increased disposable income that results from lower energy bills would be deemed as relatively permanent. As such, these savings would be spent (although a small portion may be saved) on other goods and services. Under the general assumption that the distribution of this marginal spending is similar to the average distribution of spending, the multiplier results generated by the typical input-output modeling approaches can be viewed as reasonable estimates. Even if the marginal and average distributions diverge, there will be a net increase in jobs as long as the average labor intensity of these additional purchases is greater than the labor intensity of those energy sectors where demand has been reduced.

Pollin R, J Heintz, and H Garret-Peltier. 2009. The Economic Benefits of Investing in Clean Energy. Department of Economics and Political Economy Research Institute, University of MassachusettsAmherst, and Center for American Progress, Amherst, Massachusetts. June 2009.

This report was prepared in response the U.S. Congress' consideration of a comprehensive bill to support major federal government action (as a follow-on to ARRA) to spur a green energy economy: the American Clean Energy and Security Act (ACESE). The report used the IMPLAN model (with 2007 data) to analyze the employment impacts of a $\$ 150$ billion program to promote clean energy (including both efficiency and renewable energy supply). The overall conclusion: "Our detailed analysis, based on robust economic-modeling methodologies that are explained in detail in the paper and in Appendix $1 \ldots$ calculates that roughly 2.5 million new jobs will be created overall by spending $\$ 150$ billion on clean-energy investments, while close to 800,000 jobs would be lost if conventional fossil fuel spending were to decline by an equivalent amount." The energy efficiency aspect of ACESE is modeled solely as an increase in building retrofit 
(weatherization) spending as final demand, split evenly between IMPLAN sectors residential repair construction and nonresidential repair construction. At a national level, the model indicated a total of 11.9 jobs per million dollars of retrofit construction versus 3.7 and 4.9 jobs per million dollars of final demand spending in the oil and gas, and coal sectors, respectively. The report purposely compares the trade-off between conventional energy production and green energy (both efficiency and renewable energy) in terms of dollars, rather than developing estimates of equivalent BTUs.

http://www.americanprogress.org/issues/2009/06/pdf/peri_report.pdf

Pollin R. 2009. "Memo to DOE on ARRA program employment impacts", Political Economy Research Center, University of Massachusetts-Amherst, Amherst, Massachusetts. August 12, 2009.

This 5-page memorandum to the Department of Energy lays out the basic input-output methodology for estimating employment impacts from government programs. The memorandum focuses on the rationale and estimation methods for calculating induced employment impacts. The methodology relies upon an econometric function to related household consumption to real gross employee compensation in a dynamic framework. This approach is contrasted against a more basic method that simply uses the consumption function implicit in the input-output accounts. Based on a 2006 version of the IMPLAN model, Pollin indicates that an increase of $\$ 1$ million in employee compensation will result in about 9.2 (induced) jobs.

Council of Economic Advisors. 2009. "Estimates of Job Creation from the American Recovery and Reinvestment Act." Washington, D.C. May 2009.

This report was prepared by the Council of Economic Advisors a few months following the passage of the ARRA in early 2009. Quoting from report's introduction, "This report describes the estimating procedures used so far; specifies procedures to be used by recipients for estimating job creation going forward; discusses reporting requirements for job creation; and describes the procedures the CEA will use to evaluate the job creation and retention benefits of the ARRA going forward." The report basically recommends the use of the overall government spending figures to translate expenditures into jobs. Based on simulations from a macroeconomic model (FRB/US), the report suggests the following estimates of job impacts from three separate type of fiscal stimulus: 1) direct federal spending, $\$ 92,136$ per job-year; 2) tax cuts, $\$ 145,351$ per jobyear; and 3) state fiscal relief, $\$ 116,603$ per job-year).

Romer $\mathbf{C}$ and $\mathbf{J}$ Bernstein. 2009. The Job Impact of the American Recovery and Reinvestment Act. Council of Economic Advisors and Office of Vice President-Elect

Basically, this report presents some of the administration's preliminary estimates of job creation envisioned for the proposed ARRA. In terms of methodology, the report was superseded by the May 2009 report from the CEA - see entry above 


\section{C.5 Miscellaneous and Qualitative Energy Efficiency Policy Reports}

Gayer, Ted and Emily Parker. 2013. "An Evaluation of the Car Allowance Rebate Program." The Brookings Institution, Washington D.C. October 2013.

This report presents a report by two staff at the Brookings Institution who made an analysis of the 2009 "Cash-for-Clunkers" program. The report relied heavily on a 2012 article in the Journal of Environmental Economics and Management by Shanjun Li, Joshua Linn, and Elisheba Spiller. 2012. "Evaluating 'Cash-for-Clunkers': Program Effects on Auto Sales and the Environment." (2012). (Available at: http://econ.eller.arizona.edu/docs/Seminar_Papers/Sp\%2011_Li.pdf.)

Based upon the analysis in the Brooking article, this program was a flawed policy from the jobscreation perspective. Each new job cost approximately \$1.4 million in Federal investment through this program. Given the lack of comparability with conventional state-level energy efficiency programs, this report is not summarized here.

http://www.brookings.edu/blogs/brookings-now/posts/2013/11/cash-for-clunkers-more-costly-lesseffective

Muro M, J Rockwell, and D Saha. 2011. Sizing the Green Economy: A National and Regional Green Jobs Assessment. The Brooking Institution, Metropolitan Policy Program in collaboration with Battelle Technology Partnership Practice, Washington, D.C. July 13, 2011.

This 2011 study clearly defines its bottom up method, which it calls the "Brookings-Battelle method." It presents clear definitions, assumptions, and scope of analysis. For example, the methodology only measures employment in establishments that directly produce goods and services with environmental benefits, or produce uniquely tailored goods and services that add value to products with an environmental benefit. Therefore, any estimates of job creation derived directly from this study are conservative-lower than studies that include "indirect" jobs.

The study concludes that the "clean economy, which employs some 2.7 million workers, encompasses a significant number of jobs in establishments spread across a diverse group of industries." It goes on to say that "Most clean-energy jobs reside in mature segments that cover a wide swath of activities including manufacturing and the provision of public services such as wastewater and mass transit." As implied in this latter statement, the clean economy, as defined by the authors in this study, covers other activities in the economy than those typically associated with energy efficiency.

U.S. Department of Commerce. 2010. Measuring the Green Economy. U.S. Department of Commerce, Economics and Statistics Administration, Washington D.C. April 2010. 
This 2010 report used the data from the 2007 Economic Census to estimate the size of the U.S. green economy. With regard to employment the report estimated the green economy to account for between 1.8 million and 2.4 million jobs, equivalent to $1.5 \%$ of $2.0 \%$ of total private sector employment in 2007. Green sectors of the U.S. economy were classified in terms of five categories: 1) pollution control, 2) renewable/alternative energy, 3) energy conservation, 4) resource conservation, and 5) environmental assessment. Employment related to energy conservation was estimated to account for nearly $50 \%$ of all green jobs. There was no attempt by the report to estimate a multiplier for energy efficiency or other green jobs.

A major limitation of the report stems from reporting for purposes of the census. As stated in the report, "Industry and product codes do not distinguish between green and non-green industries, products, or services. For example, product categories for windows and doors do not distinguish windows and doors that provide better insulation from those that are not insulated and therefore are not energy efficient." As a further example, LEDs appear to be a sub-category of the larger 6digit NAICS sector, Semi-conductor and related Manufacturing. On the other hand, green industries classified as energy conservation in the report include, for example, all insulation material manufacturing, bicycle manufacturing, and bus and mass transit transportation. Thus, while the report suggests what industries or sectors may be affected by energy efficiency programs, the accounting framework in this report provides little guidance in terms of the relative impacts across those industries for the most common of such programs. (Even at that, the report does not include the employment or shipments data at the detailed level that went into the estimated national level impacts.) The report can be accessed at:

http://www.esa.doc.gov/sites/default/files/reports/documents/greeneconomyreport_0.pdf

Bureau of Labor Statistics. Green Jobs Initiative.

The goal of the Department of Labor/Bureau of Labor Statistics (BLS) Green Jobs Initiative was to "develop information on the number of and trend over time in green jobs, the industrial, occupational, and geographic distribution of the jobs, and the wages of the workers in these jobs." Energy efficiency is defined as one of the five green goods and services categories. The initiative instituted three new data collection activities on green jobs: Green Goods and Services survey, Green Goods and Services Occupations data, and Green Technologies and Practices survey. Green goods and services data are available for 2010 and 2011. Funding was cut in 2013, terminating data collection programs. The (still maintained) BLS website (cited) below provides a good discussion of how BLS defined green jobs and intended the measure their number. Information available at http://www.bls.gov/green/)

Goldman C, MC Fuller, E Stuart, JS Peters, M McRae, N Albers, S Lutzenhiser, and M Spahie. 2010. Energy Efficiency Services Sector: Workforce Size and Expectations for Growth. LBNL-3987E, Lawrence Berkeley National Laboratory, Berkeley, California. September 2010.

This report was jointly authored by researchers at the Lawrence Berkeley National Laboratory (Goldman, Fuller, and Stuart), and staff at the consulting firm Research into Action. A principal aim of the study was to measure the size of the current U.S. workforce involved in providing energy efficiency services. The study focused on the workforce related to building energy efficiency, those "personnel "needed to design, implement, manage and evaluate energy efficiency programs and to design, construct, install efficient building systems" 
The study employed an extensive set of interviews ( 300) with "program administrators, education and training providers, regulatory staff and a variety of EESS [energy efficiency services sector] employers, trade associations, and unions; communications with over 50 sector experts; as well as an extensive literature review." Based upon this process, the study authors estimated that in 2008, the energy sector services sector comprised about 114,000 workers (measured as workers working full time in this area). The report acknowledges that many workers "only work part time or spend only a fraction of their full-time job providing energy efficiency services." Overall, the study suggests that nearly 400,000 individuals were engaged full or part-time in EESS activities in 2008.

The study was also able to develop estimates of the number of EESS (full-time) jobs that would be generated per million dollars of efficiency investment. Based on the data for 2008, an average of 6.3 jobs are created per million dollars of investment, but there is a significant range underlying this average. For energy services companies (ESCOs) the survey results suggested about 2.5 jobs per million dollars of investment, while for weatherization and insulation activity 8.9 jobs are generated. These values do not include indirect or induced jobs from such investment.

American Solar Energy Society and Management Information Services, Inc. 2008. Defining, Estimating, and Forecasting the Renewable Energy and Energy Efficiency Industries in the U.S. and Colorado. Boulder, Colorado.

This study, among others, that seeks to estimate the extent of the "green economy" in terms of tangible economic metrics. In the study, metrics are developed for both the U.S. and Colorado. The difficulty in developing such estimates with regard to energy efficiency is implied by the following discussion in the report, "The EE 'industry,' on the other hand [compared to renewable energy], is much more nebulous and difficult to define, specify, and estimate. There are specific elements that are clearly part of the EE industry, such as federal and state EE programs, utility EE spending, the ESCO industry, the recycling industry, etc. However, most EE spending is included in partial segments of large industries, such as vehicles, buildings, lighting, appliances, etc."

Here, as in similar national-level only studies, there is no effort to translate specific energy efficiency programs into employment impacts, as a part of any modeling analysis. Thus, this type of report is of limited use for the analysis in the present study. 


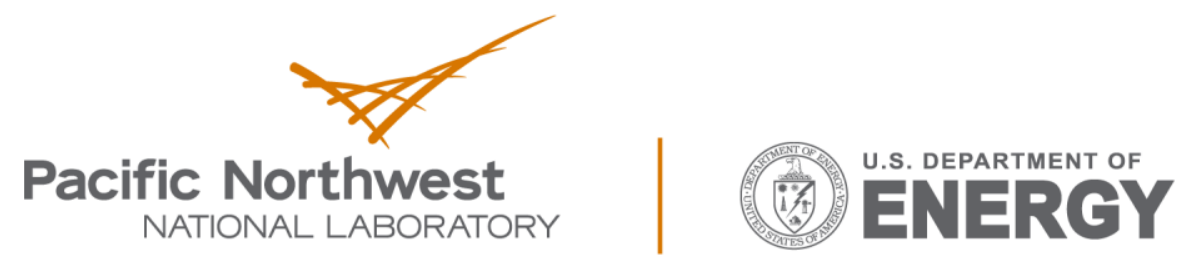

Proudly Operated by Battelle Since 1965

902 Battelle Boulevard

P.O. Box 999

Richland, WA 99352

1-888-375-PNNL (7665)

www.pnnl.gov 